Article

\title{
Polyphony and Poikilia: Theology and Aesthetics in the Exegesis of Tradition in Georgian Chant
}

\author{
Nun Sidonia (Freedman) \\ Sacred Monastery of St Nina, Union Bridge, MD 21791, USA; CantrixCaeca@gmail.com
}

Received: 19 April 2019; Accepted: 16 May 2019; Published: 26 June 2019

check for updates

\begin{abstract}
Georgian polyphonic chant and folk song is beginning to receive scholarly attention outside its homeland, and is a useful case study in several respects. This study focuses on the theological nature of its musical material, examining relevant examples in light of the patristic understanding of hierarchy and prototype and of iconography and liturgy. After brief historical and theological discussions, chant variants and paraliturgical songs from various periods and regions are analysed in depth, using a primarily geometrical approach, describing the iconography and significance of style, musical structure, contrapuntal relationships, melodic figuration, and ornamentation. Aesthetics and compositional processes are discussed, and the theological approach in turn sheds light on questions of historical development. It is demonstrated that Georgian polyphony is a rich repository of theology of the Trinity and the Incarnation, and the article concludes with broad theological reflections on the place of sound as it relates to text, prayer, and tradition over time.
\end{abstract}

Keywords: Georgian chant; Orthodox theology; exegesis of tradition; aesthetics; polyphony; oral tradition; Dionysios the Areopagite

\section{Introduction: Theological and Methodological Frameworks}

The Georgian Orthodox three-part polyphonic chant has begun to receive greater academic attention outside its homeland, and it provides interesting material for historical and musicological study. It is also an excellent case study for questions about the spirituality of Orthodox chant, its place among the sacred arts and in liturgical space, its relationship to prayer, and its concrete expression of theology. This article will discuss such aspects of Georgian chant by exploring examples ${ }^{1}$ within theological and iconographic-architectural frameworks, using historical and musicological analysis, contextual information, and patristic writings as tools for study and interpretation. Some of the same chant items will recur throughout the study as we explore the nature and significance of different details. We begin by establishing the frameworks and briefly describing the sources of the tradition, touching upon the difficult issue of dating the appearance of three-part polyphony in Georgia.

Much of the structural and theological discussion of Georgian chant relates to the concepts of hierarchy and prototype. The term hierarchy first occurs in the various works attributed to St. Dionysios the Areopagite, which some scholars attribute to the hand of the Georgian St. Peter the Iberian and which, in any case, have had an important place in Georgian theology, literature, and liturgy (Lourié 2010, 2016). ${ }^{2}$ The saint defines and describes the phenomenon as follows:

1 I have provided transcriptions for examples, especially those that analyzed in depth, and I have included links to available recordings wherever possible. It was impracticable to provide a transcription for every mentioned chant, and certain aspects may be more concretely and quickly perceived by listening, foregoing the need to first read a score.

2 There are two English translations of the complete corpus. I have used that published by John Parker in two volumes in 1897 and 1899, which is now in the public domain and available online at http://www.tertullian.org/fathers/areopagite_01_intro.htm. 
"Hierarchy is, in my judgment, a sacred order and science and operation, assimilated, as far as attainable, to the likeness of God, and conducted to the illuminations granted to it from God, according to capacity, with a view to the Divine imitation. Now the God-becoming Beauty, as simple, as good, as source of initiation, is altogether free from any dissimilarity, and imparts its own proper light to each according to their fitness, and perfects in most Divine initiation, as becomes the undeviating moulding of those who are being initiated harmoniously to itself. The purpose, then, of Hierarchy is the assimilation and union, as far as attainable, with God, having Him Leader of all religious science and operation, by looking unflinchingly to His most Divine comeliness, and copying, as far as possible, and by perfecting its own followers as Divine images, mirrors most luminous and without flaw, receptive of the primal light and the supremely Divine ray, and devoutly filled with the entrusted radiance, and again, spreading this radiance ungrudgingly to those after it, in accordance with the supremely Divine regulations" (Celestial Hierarchy, 3:1).

Hierarchy; therefore, has to do with deification, ${ }^{3}$ with communication of divinity (Purpura 2017), and in practice, it can be understood as a spiritual pattern that exists at all scales, not unlike a fractal on the physical level (Williams 2010). In his writings, the saint applies hierarchy to the angelic and ecclesiastical orders, but as the definition shows, it includes all beings. He specifies that God is the head of every hierarchy, thereby clarifying that hierarchies do not simply connect to one another in succession; each one exhibits "clinging love toward God" and has its source in Christ and its goal as union with the Trinity (Ecclesiastical Hierarchy, 1:3). Furthermore, hierarchies encompass all deifying activities. In the Ecclesiastical Hierarchy, the Areopagite continues his definition, stating that "every hierarchy, then, is a whole account of the sacred things falling under it, a complete summary of the sacred rites of this or that hierarchy" (Ecclesiastical Hierarchy, 1:3), and though he does not comment on music but only on liturgical texts, chant is a part of such rites, along with architecture, iconography, vestments, vessels, and any relevant object or action. I suggest that there are also further hierarchies that relate to lay piety and folk practices and hymns, such as the Svan examples that we will later explore. The ecclesiastical hierarchy includes a "multitude of divisible symbols", and each hierarchy is "a kind of symbol adapted to our condition" (Ecclesiastical Hierarchy, 1:5), encompassing various needs and contexts. Human beings work to incorporate other created things through proper use and co-operation, as St. Maximus the Confessor describes in one of his texts on love (Berthold 1985, p. 38), and sacred art is a primary outcome. It is; therefore, important to keep in mind that hierarchy has to do with liturgical elements at least as much as with those who carry out the services. While the Celestial Hierarchy primarily describes hierarchical members, their work and relationships, the Ecclesiastical Hierarchy, while giving some explanations of the relevant hierarchs, focuses on liturgical commentary. Some attention has been given to this topic in architecture (Bogdanović 2011), iconography (Ivanovic 2011), and Byzantine art and ceremony in general (Woodfin 2010), but comparatively little practical discussion of the Areopagitic corpus has taken place, perhaps because of the many differing philosophical considerations, interpretations, modes of reception, and attitudes towards it (Ivanovic 2011). However, given the definition of hierarchy, its explanation as "the source of the order of sacred things" by St. John of Scythopolis (Rorem and Lamoreaux 1998, p. 145), and its further interpretation as a particular pattern type, Georgian chant calls for its application. It applies in two primary complementary ways: The tripartite structure of voices, styles, compositional process, and related aspects; and the specific hierarchical relationship among the voices, in which the middle and lowest reflect, follow, and translate the top-voice model melody in many ways. As St. Ekvtime the Confessor (1865-1944) states, "The mode [i.e., with model melody for any given mode] is

I have listed the later translation in the references (Luibheid et al. 1987). For ease of reference, and so that the reader may consult any preferred translation or edition, I have cited the work, chapter, and, where possible, section for all passages in this article.

3 Deification has been discussed in the writings of various Church Fathers, including the Areopagite (Russell 2004). 
the foundation of chanting[;] on the essence of its tune depend the movements of all the voices. Losing the mode is equal to losing the chant" (Sukhiashvili 2014a, p. 421). Yet, in religious folk songs, the middle voice often leads, and different types of compositions can shed light on particular hierarchies or powers within them. Other hierarchies (e.g., sections of a song or the relationship of dance, tune, and text) occur in this repertoire, which we will discuss near the end of this article.

Unlike hierarchy, the term prototype, also rendered archetype, does not generally occur in patristic works along with deliberate definitions, but its meaning is critical in discourses on icons and clear in context. In a treatise by St. John of Damascus, he describes different kinds of images and explains that an "image is not like archetype in every way" (Louth 2007, p. 25). Further on, he quotes St. Basil the Great, stating that the veneration bestowed upon an image passes to its prototype, that is, to the very person who is depicted; it likewise passes from saints and angels to God (Louth 2007, p. 35). Prototype also has a practical meaning, referring to physical icons and their canonical principles, from which other icons are copied and inspired, yet the analogical, theological sense, in which an icon is a "true likeness" by expressing "the sanctity and glory of the prototype", rather than its outward form, is most relevant (Kenna 1985, p. 345). The outward form of an icon can be studied; however, in order to discern aspects that co-operate in the analogy, in the sanctity and glory. In chant, it is somewhat difficult to apply the term in the literal way, since there is no musical equivalent to an icon "not-made-by-hands" (Moody 2016, p. 53), but the study of a specific repertory can bring to light its own means of expression, both musical and theological (Moody 2015). As we will see, within the given tradition, prototype applies in practice to model melodies and evident musical principles. Theologically, it shows how liturgical song comprises incarnate prayer and worship carried out by human beings, no matter the language or musical tradition, and relates to that uttered by those who hierarchically precede them, that is, angels. Prototype also relates to hierarchy, and all copies of prototypes and all hierarchies come from, and lead back to, the Divine archetype according to St. Dionysios (Ecclesiastical Hierarchy, 1:1; Celestial Hierarchy, 2:4). He states that Jesus Christ is the "Source and Essence, and most supremely Divine Power of every Hierarchy", and that in hierarchy, He "folds together our many diversities" (Ecclesiastical Hierarchy, 1:1). We will analyze the unfolding and folding of sound in Georgian chant, revealing prototypical structures, elements, and their significance. Like the complex surfaces of icons and textiles, chant can be characterized by the aesthetic term poikilia (Pentcheva 2010, p. 140), often translated as "variegation", which we will describe in more detail in the discussion of ornamented examples. While the term relates to visual surfaces, it was nevertheless applied to music and poetry, though most scholarly discussions of such examples relate to the Classical period (LeVen 2013).

A third concept that underlies the entire interpretive framework in this study is that of the logoi of things. The logos of something is its reason for existence, God's will for it, what it can communicate from God to human beings, and its "point of contact with the Godhead" (Lossky 1997, p. 98). St. Maximos the Confessor (d. 662), who commented on the Dionysian writings, who was exiled and buried in western Georgia, ${ }^{4}$ and whose writings played an important role in Georgian culture and theology (Mgaloblishvili and Khoperia 2009), is one of the foremost expounders on the logoi in creation. Symbolism and mystagogical interpretations, such as those that we will quote below from various Church Fathers, relate to contemplation of the logoi, and the connection of subsequent musical analyses to theological frameworks and interpretations also depends on this view of reality. Another underlying concept is that of exegesis, which refers to chanters' interpretations of musical content, not unlike varied scriptural commentaries. The term is notably used in Byzantine chant (Lingas 2004; Touliatos 1989), but it can apply to any tradition. The concept is important since it allows for changes in speed, style, and other characteristics, is the basis for ornamented and melismatic repertoire, and lies behind the idea of a stable tradition with many embodiments. Thus, chanters feel that they sing "the same chants", as we will see below, and such does not entail literal congruence in every detail. The belief in

4 First-hand accounts of the exile, death, and miracles occur in epistles written by St. Maximos and his peers (Allen and Neil 2003). 
an unchanged tradition, then, is not a legendary idea, as such does not denote the sense that chanters across time and space sing the very same material in the very same manner. Hierarchy and prototype tie into this point, since choices based on knowledge and experience of principles lead the process, rather than any particular rendering. The topic of incongruity or disagreement about what may be a valid exegesis will be addressed through examples in several sections of this paper, and we will discover that this aspect has an interesting, even positive, place within the Dionysian framework.

A final methodological note is that it is useful to read sonic expressions in some ways as we would tangible ones, such as Georgian inscriptions, whose specific sizes, formats, self-references, and included crosses mark their prayerful function. The art historian Antony Eastmond considers them to be "textual icons, and states that "their overall form carries the same visual power and figural correspondence as icons in the Orthodox world. The blocks of text acted as mnemonic devices to imprint an icon of prayer on the mind of the viewer" (Eastmond 2015, p. 79). They hold "the same theological value as images, serving as representations of truth with access to the divine" (Eastmond 2015 , p. 96). Sung and spoken texts, like their inscribed counterparts, can be similarly described as icons, and our analyses will specify recognizable forms and features that strike the ear as tangible expressions strike the eye and hand. This point has theological implications as well, since matter is as much a key component of making and hearing sound as of the production and reception of material objects. In order to create chant, solid, functional, resonating human bodies-not only brains, voices, mouths, and ears-and air, in which sound waves are formed, are necessary. St. Dionysios writes that, even through the lowest forms of matter, one can be "led to the immaterial archetypes" (Celestial Hierarchy, 2:4). This idea has to do with symbolism as it relates to God and the celestial hierarchy, and it can apply to expressive media and objects themselves and not simply to figures of speech. We will now consider the material sources and history of Georgian chant, including theological information from a medieval Georgian author. His thoughts will begin to fill in the framework just described while also aiding our understanding of historical development.

\section{Embodied Tradition: Historical and Theological Sources and the Development of Georgian Ecclesiastical Polyphony}

Besides later transcriptions and audio recordings, the historical record of Georgian chant is sparse in musical sources. Only six medieval neumed sources survive, all from the tenth century, and all other manuscripts contain only text and modal designations. Notation does not appear again until the eighteenth century (Oniani 2013). The neumatic systems that occur on both sides of the notation gap, through the twentieth century, are ekphonetic. Later neumes are idiomatic to each source (Graham 2008), but all tenth-century manuscripts employ the same notation. Oral transmission continued even after transcription into staff notation began in the nineteenth century, an effort that was led by several Georgian transcribers and master chanters after annexation by Russia and through the Soviet period (Graham 2007). Staff notation is now used, but like other repertories that include written notation, such as Byzantine chant (Khalil 2009), Georgian polyphony continues to have orally-transmitted components (Graham 2008). We will especially look at oral variation in the discussion of paraliturgical repertoire. While Georgian scholars have further analyzed neumatic notation types, Western scholars have not generally sought any connection between late and early Georgian sources, though sometimes between early Georgian and contemporaneous chant from elsewhere (Jeffery 1992). However, comparison of Georgian sources leads to interesting questions and conclusions about polyphony and the nature of oral tradition. Analysis of chant examples with the most variants and widest documentation reveals the structure and development of the tradition and provides rich material for theological explication. It is possible to ascertain certain points about the development of these examples and what they, and thereby Georgian chant in general, may have been like at least as early as the twelfth century, by reading primary sources concerning musical structure and professional activity; examining modal designations, notation, and text in manuscripts and printed sources; and considering audio recordings and the process of oral tradition, exploring the complex ways in which it relates to the extant neumes 
from all periods. The notation gap and different combinations of musical source types-neumes, texts, transcriptions, and audio recordings—at different periods presents a complicated situation, but we also need to look outside the sources in question. Other primary information can then guide interpretation of musical specimens. Subsequent theological interpretations do not depend on questions of history, but we will see that they in turn have historical importance, helping to date three-part polyphony in the Georgian context.

Let us begin with the neumatic sources. Ekphonetic notation types feature two lines of neumes, one below and one above the text. Scholars debate whether or not the tenth-century neumes represent polyphony, but those on the other side of the gap correspond to three-part singing. One recently-discovered twentieth-century example, which has a corresponding recording, appears to outline the middle and bottom voices of a Trisagion variant. ${ }^{5}$ In his recent work, the mathematician and chanter Zaal Tsereteli has compared the structures of heirmoi in tenth-century sources with those of nineteenth-century transcriptions. Previously, he proposed that there was no relation between these sources, but through statistical analysis he found a clear correspondence of phrase and structure (Tsereteli 2012). Georgian chants are based on genre-specific, top-voice model melodies for each of the eight modes, which are harmonized differently in each chant school and, as we shall see in later analyses, by individual chanters, and these are reflected in sources on both sides of the notation gap. We will look at the theology of this model-based, three-voiced form below. The Old Georgian term for harmony, "mortuleba", is polysemantic, and the chanter and musicologist Magda Sukhiashvili considers its appearances in tenth-century sources to refer to polyphonic rendering of chant (Sukhiashvili 2015). Whether harmonization of any kind is as early as these sources or even earlier will be discussed later, and at this point, one may surmise that polyphony, considered in the global context of Christian chant traditions, could have developed in Georgia at least as early as in Western Europe (Shugliashvili 2013).

There are various explanations for the dearth of notated sources between the tenth and eighteenth-centuries, such as the havoc of successive invasions and political upheavals. However, many liturgical books survive, especially in Georgian monastic centers outside the country, such as Mt. Sinai and Jerusalem. It may be that notation declined as polyphony developed, or was perhaps implemented in order to facilitate its beginnings, but it seems that oral tradition took precedence at all stages, as shown by scribal notes and hagiography. For example, in the margin of an eleventh-century menaion, the chanter and translator St. Giorgi the Athonite states that the theotokia are not included in full because "By God's grace we [Georgians] know them by heart", while Greek books give the full text, which would be intoned by a canonarch (Sukhiashvili 2014b, p. 435). This comment is one of many references to memory and orality. Earlier hagiographic accounts, such as that of St. Grigol Khandzteli (759-861), describe their subjects as knowing "the [canons] of all the feasts very well" (Sukhiashvili $2014 b$, p. 435). These descriptions are not literary exaggerations and align with well-documented nineteenth and twentieth-century chanters (Graham 2008). Thus, oral transmission and preservation, and reliance on the same over written sources, was prevalent even for text. We may infer that such was the case regarding musical material as well, and the ekphonetic nature of all notated sources before the transcription movement, and of idiomatic neumes through the twentieth century, indicates this situation across ten centuries. Concerning the lack of notated manuscripts, then, it may be that notation was not widely used, as is the case in other Eastern traditions, such as Ethiopian chant (Shelemay et al. 1993).

Regarding both practical and theological matters in Georgian chant, let us consider a passage from the preface to the translation of the Psalter by the twelfth-century Gelati Monastery theologian Ioane Petritsi. ${ }^{6}$ His oft-quoted reference to three parts in music, names included, has nevertheless been

5 This example is discussed along with several unique oral variants from the Mengrelian singer Polik'arpe Khubulava (d. 2015), who also refers to his father's use of some kind of graphical or neumatic notation (Kalandadze-Makharadze 2014).

6 An English translation of the entire preface has been recently published, with the Old Georgian text on facing pages (Gigineishvili 2014, pp. 194-235). Another translation, also by Gigineishvili, of the first part of the passage on music, 
interpreted by some scholars as referring to parts of a range rather than to voices in polyphony. The passage is part of an exposition of Trinitarian theology, based on mystagogy of the liberal arts, which somewhat echoes certain ideas in Clement of Alexandria's Miscellanies (Book I, Chapter XIII), but is far more specific in its purpose and in the various phenomena that it describes. This musical mystagogy appears after explications of arithmetic and of the three geometric principles of point, line and plane.

"Now, what about music? Is not, actually, our beloved book [the Psalter] altogether a music embellished by the Holy Spirit?! And any music requires three tunes or phthongs from which any wholeness is composed. They are called mzakhr [strained, high pitch], jir [middle], and bam [lower tension, bass], and, verily, all attunements of strings and voices make a pleasant melody through those three, because the beauty of any ornament derives from the irregularity of its adornments. The same is perceived in the number of the transcendentally Holy Trinity, for we say the 'birthlessness' of the Father, the birth of the Son, the [procession] of the transcendent Holy Spirit, and the unity of the Nature with differentiation of the Hypostases. Similarly, in the musical differentiation of mzakr, jir, and bam you will perceive a unity of composition. In fact, through the paradigmatic images, posited in His First Intellect, God has adorned and musically composed the order of the whole creation and has imposed ideas even on the prime matter looking to [introduce] a diversity even in the oneness of matter. Eventually, during wars and battles the best strategists used to arrange their armies in the shape of a triangle, deeming this shape invincible. In fact, wherever the power of seven is the third corresponding image (or: icon) of the first three. Why? Because, the first odd number is three, the second five and the third the renowned seven, which neither gives birth nor is born, for which reason, according to the teaching of the Italians, it was considered as the virgin [number] and was worshiped as such by them" (Gigineishvili 2014, pp. 221-22).

Readers may ask why Petritsi includes geometric and numeric figures since these aspects were already expounded. Analogy links the perhaps seemingly disparate illustrations, and such is especially so regarding the triangle. As the musicologist Nino Pirtskhalava also notes, he associates the three-voice structure with this shape, hence why the linear sense of range is not intended (Pirtskhelava 2014, p. 485). ${ }^{7}$ In addition, the voices are also called "tunes", indicating that they could be sung independently, though the three together form a whole. Elsewhere, Petritsi mentions "simultaneously-sounding pitches", and he employs much polysemantic harmonic language in his works, sometimes using the term in the horizontal or general Greek sense and sometimes in the vertical sense, calling for close, contextual readings. Thus, notwithstanding the practical relation of ideas in this passage, its theological purpose primarily reveals the musical phenomenon to which the author refers. The Trinity underlies all his "theories", as he calls them, and a three-part polyphonic structure serves as sonic iconography, while a range of notes, sounded in horizontal patterns across time, does not. Following Petritsi's order, the top voice is like the Father, bearing the model melody, from which the equally or sometimes more active middle voice, like the incarnate Son, is begotten and the co-operative, grounding bottom voice, like the Holy Spirit, proceeds. The middle voice often has a leading role, especially in paraliturgical song, and St. Dionysios ascribes an important mediating power to the middle member of a hierarchy (Celestial Hierarchy, 9:2). Along with this Trinitarian discussion, Petritsi's geometrical analogies of the triangle and of point-line-surface figural construction are useful for musical analysis and for a theological understanding of sacred art and one's prayerful engagement with it (Freedman 2019).

with several different renderings, one of which I have used below ("procession" instead of "issue"), appears in an earlier publication (Gigineishvili 2007, p. 100).

7 Note that the author, following the earlier edition of Petritsi's works, writes that the Psalter preface is instead an epilogue to the commentary on Proclus' Elements of Theology. There may also be some confusion between Petritsi's separate annotated translation and commentary on Proclus and their related translations into other languages, which may explain the variations that she finds in the quoted Russian and English translations. Petritsi's writings on music call for further research, and as Pirtskhelava's work exemplifies, passages from various works should be examined together. Close contextual readings within each work are also of paramount importance regarding both musical information and Petritsi's own philosophical views (Gigineishvili 2007). 
Petritsi's contemporaries would have shared the precise musical and iconographic experiences that correspond to his contemplations, and texts, icons, church buildings, and, as we are describing, at least general musical models, structure, and sensibilities have been carried forward from his time. If a three-voiced basis for musical knowledge was as commonplace as a triangle, polyphony was likely in practice for some time before Ioane Petritsi's twelfth-century theological exegesis. We will return to this point and see that monophony is not necessarily an older phenomenon or predecessor to polyphony in Georgian contexts and from a global perspective, and it is important to note how the theological purpose of the passage helps to clarify the music that it describes.

Nineteenth and twentieth-century sources, such as transcribers' notes and interviews, give further practical information, describing the oral transmission process and providing points on musical structure and history (Sukhiashvili 2014b). Chanters described a five-year curriculum: students began with "study voices", singing in parallel fifths and octaves in order to sharpen the polyphonic paradigm, and then learned the three chant styles, called "modes" in English, not to be confused with the modes of the oktoechos, which are called "voices" in Georgian. ${ }^{8}$ First came what were considered the oldest and structurally essential chants: the plain mode variants. It is important to note that such entails model melodies and relatively simple contrapuntal style but can differ in harmonization and figuration (Graham 2012), as we will see in our examples. It may also be helpful to consider the three styles as existing on a continuum rather than as three separate entities, and chanters' aesthetic choices affect the quantity, extent, and type of decoration in any rendering in any mode. After becoming proficient in all three voices, students could add and adjust the other parts after learning the top voice of new chants. They then learned the other two styles, the true and ornamented modes. Ornamented versions have striking features respective to Eastern and Western schools, such as a highly-ornamented, active middle voice, passing between chords, in the former and voice-crossing (called "going across the cross") and diversion from model melodies (Graham 2013), with additional vowels, often over long melismas, in the latter. In simple variants, harmonization and bottom voice gestures differ, but as John Graham notes, shared features, such as model phrases, three-part structure, and cadence types point to the singing of developed polyphonic chant throughout Georgia before the 1220 Mongol invasion and subsequent separation (Graham 2016). Regional folk styles share features with the geographically-associated chant schools (Tsitsishvili 2010, pp. 295-97), and especially in the ornamented mode, improvisation is of great importance, especially in the Gelati and Shemokmedi traditions, and depends on chanters' practical, not theoretical — and there are no extant Georgian music theory treatises-understanding of musical structures, principles, and rules. As the master chanter Artemi Erkomaishvili, whose style we will explore, described it, one "hears the end of the [chant] in advance, and if the goal is seen, it is not difficult to achieve it; whichever way you take and how many turns you may take up and down, you are sure to get there ... However, the voices may be twisted, we know where to get, but it is impossible to twist the voices in one and the same manner twice" (Sukhiashvili 2014b, pp. 436-37). John Graham describes how chanters use cadence pitches, textual rhythm, and most interesting for this study, what we will call reflections and translations of model phrases, that is, inversions and the singing of the same melodic patterns in a different range, to guide their improvisations (Graham 2013). Yet, these examples do not demonstrate the height of decoration that historically existed. A further method of ornamentation, of which we have no extant examples, was the addition of up to three more voices to the foundational three-part structure, each part with its particular name and characteristics (Shugliashvili 2013). Several scholars have noted that ornamented variants are akin, not historically or directly, but as a musical phenomenon, to late Byzantine kalophonic chant (Shugliashvili 2010), yet an important difference is that, rather than being entirely new compositions, they still follow the "traces", to use St. Ekvtime's term, of the model

8 The term "mode" will be used in both cases in this paper, as context should make it clear whether Georgian chant style or the oktoechos is under discussion. 
melodies (i.e., their formulae and contour) (Sukhiashvili 2014b, pp. 447-48). This importance of model melodies is indicative of the mechanism of orality over notation in the development of the tradition. It is likely, then, that the co-existent variants and the oral pedagogical process reflect the historical development of Georgian chant, beginning with the plain mode versions or perhaps the study voices. Three-part polyphony is the prototypical, foundational, hierarchical pattern, with the top voice having structural but not chronological importance for chanters. It begets and sends forth the other two voices, not existing before or without them; there is no monophonic stage in the curriculum. The ekphonetic neumes of later sources were used by chanters working with this knowledge and background, and the tenth-century neumes could have been read in a similar cognitive and perceptive context; diachronic graphical comparisons of neume types could shed much light on this situation. I suggest that, while allowing for great variation and development, three-part structure gave triangular strength and stability to oral tradition across the centuries, depending on at least three singers' memories and successful combinations of voices. Even when transcriptions emerged as a preservation measure, their very proponents nevertheless noted the necessity of oral transmission. Scores were understood as means to support and revitalize such learning but not to replace it. It was noted that chants sounded "out of tune" when choirs without the aural background sang from transcriptions (Graham 2007, p. 103). Yet, some kind of shared, somewhat precise, even if not entirely accurate, notation was needed in order to prevent the utter loss of repertoire under oppression and to make it possible for long-term preservation to occur when oral transmission was hampered. After yet further oppression in the Soviet period, the continued synergy of oral tradition and written score has been taking place since at least the late 1980's. Thus, embodied polyphony has been a primary technology of preservation as well as an enduring pattern over time and across sacred and secular music. We will briefly consider similar patterns in other forms of sacred art and discuss the chant-related linguistic and artistic inculturation process of Christianity in Georgia before examining specific musical examples.

\section{Inculturation and Aesthetics in Chant, Architecture, and Iconography: Contextualizing Sacred Polyphony Amidst Language, Space, and Material Culture}

Archaeological traces of Christianity are evident in Samtavro and other parts of eastern Georgia from the second century onwards (Licheli 1998; Mgaloblishvili 1998), and it became the state religion of Eastern Georgia, that is, the kingdom of Iberia, in the first quarter of the fourth century. The religion also became widespread in the kingdom of Egrisi in Western Georgia, which had continuous cultural exchange with the Hellenistic world from the classical (Giorgadze and Inaishvili 2016; Tsetskhladze 1992) through Byzantine periods, ${ }^{9}$ and it is interesting that archaeological remains, churches, attributed apostolic burial sites, hagiographic summaries (Vinogradov 2017), and folk stories of specific apostolic episodes survive together (Makharadze and Ghambashidze 2014). The general Eastern Christian approach of inculturation, as opposed to acculturation, took place in Georgia (Doborjginidze 2014, p. 329), and while elements from surrounding cultures are present, local art, vernacular texts, and specific practices developed (Eastmond 2015; Schrade 2001). While it is sometimes difficult to ascertain whether a given element is Georgian, especially apart from language, since many cultural, literary, and practical elements are shared or follow indirect paths, ${ }^{10}$ specific characteristics of Georgian Christian expression are identifiable. It is understood that music was also an integral, though less easily documentable, part of the same process. Studying the linguistic, artistic, and even topographical inculturation process can help to contextualize, interpret, and understand associated chant material.

The linguistic inculturation process can be divided into two major stages: a "functional", linguistically-legitimizing phase of initial assimilation and translation, ending in the tenth century, and a "qualitative" period of incorporating further knowledge, Byzantine influence, and precise use of

9 Roman and early Byzantine monuments are rich in this region, greatly supplementing brief references in historical literature (Khrushkova 2007).

10 There is a useful recent study of culture in late antiquity (Cameron 2015). 
language, characterized by the translation of many new works and retranslation of others, ending in the twelfth century (Doborjginidze 2014, p. 331). Ioane Petritsi's work belongs to this second stage. The earliest Georgian liturgical books contain the Jerusalem rite, some containing notes about its use and translation by such figures as Ivane Zosime and Giorgi the Athonite, and such chant books are our only extensive hymnographic sources for Jerusalem liturgy in any language (Frøyshov 2008; Jeffery 1992). Two manuscripts of the iadgari (i.e., the Georgian Jerusalem hymnographic collection) are neumed, and Georgian churches kept contact with Jerusalem and followed the Palestinian typikon of the Byzantine rite (Mgaloblishvili 2014). The liturgical scholar Symeon Froyshov describes complementary ways of dividing the phases of liturgical inculturation, such as the multi-stage development of the Georgian recension of the Jerusalem rite through its final Byzantine form (Frøyshov 2008, pp. 264-67). Some texts underwent several shifts, such as the paschal canon, whose final form, reached by the twelfth century, was its fourth extant translation, two of which had been made before the tenth century (Frøyshov 2008, p. 240). Some early Jerusalem hymns nevertheless remain in the Byzantine rite and were not given new translations. While translations were being made, primarily from Greek, original hymnography was also composed, such as hymns by the aforementioned St. Grigol Khandzteli (ninth century); Mikaeli Modrekili's iambic compositions and much other indigenous hymnography (tenth century) (Froyshov 2008, p. 261); St. King Demet're's paraliturgical hymn to the Theotokos, displaying a particular poetic form (twelfth century), sung today according to at least five regional variants, one of which was recently documented (Kalandadze-Makharadze 2014); ${ }^{11}$ and octosyllabic redactions of hagiographical accounts (Pataridze 2013, p. 62). Two important forms of Georgian poetry, known as high and low verse, are octosyllabic, and further study of indigenous liturgical compositions, in comparison with Greek, Latin, Syriac, Ethiopian, and other literature, could lead to a greater understanding and discernment of specific cultural elements. Otherwise, such may not be noticed, or a common feature may be referred to as "Georgian." Froyshov discusses the question of indigenous elements in the Jerusalem rite manuscripts, highlighting original hymnography, pointing out elements that may have come from Syriac sources, and discussing common language concerning the Incarnation, which some scholars had previously attributed to one language or another (Frøyshov 2008, pp. 261-64). Georgian musical features are recognizable today, as are architectural and iconographic ones, some of which also have practical or symbolic roots in Jerusalem.

Jerusalem had an important place in Georgian Christian development in several aspects along with liturgical development. While the old capital, Mtskheta, became a New Jerusalem, with representative sacred sites, especially corresponding to the Holy Sepulchre and Golgotha (Mgaloblishvili 2014), such sites occur elsewhere, for instance, Imereti, and a monastic cell type, a tower containing an upper chapel and a lower cell, reflects the same symbolic geography (Gagoshidze 2015). The same hierotopy, that is, hierarchical pattern of sacred space (Lidov 2010), occurs on increasingly smaller scales, by southern church entrances marked by standing stone crosses, which also copy what was literally at the Jerusalem site according to Egeria's fourth-century account, (Chichinadze 2014) and again inside churches, by altars and uniquely-Georgian pre-altar crosses (Gagoshidze 2014). Forms of the cross in these sites and contexts, often featuring triangular decoration and atop three-stepped pedestals (Figure 1), simultaneously symbolize the life-giving pillar from the tree in Mtskheta, the cross at Golgotha in Jerusalem, the true cross (pre-altar crosses sometimes containing relics of the same), and the cross opening the gate of Paradise (Gagoshidze 2015). Especially in pre-altar crosses, their unique structure, patterns, and decorations bear interesting reflections of musical traditions, including a Trinitarian structure, variations specific to regions or workshops, and aesthetic and geometric parallels. Though there is not space to discuss these features here across media, I have described some examples elsewhere (Freedman 2019), and we will analyze some of the relevant features in chant examples

11 John Graham has provided pages on this chant, similar to that cited below for the paschal troparion. http://www. johngrahamtours.com/shen-khar-venakhi-3/. 
from the underlying structural and theological point of view. Three-part polyphony exists within this material and aesthetic milieu and contains its own Georgian elements, echoes of Jerusalem practice, and through cross-domain mapping, patterns, structures, and decorative trends found in material culture, ${ }^{12}$ a point that may be overlooked if chant texts alone are over-emphasized.

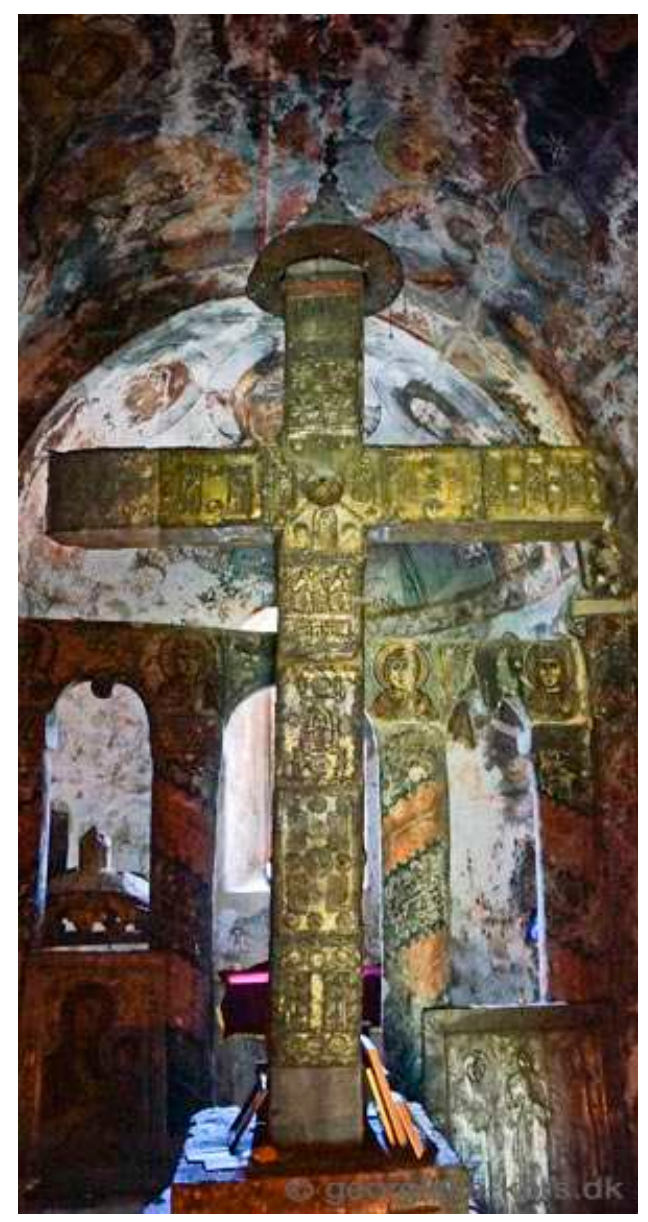

Figure 1. Pre-altar Cross; photograph taken by Norma Mikeladze-Andersen; http://www.georgiskekors.dk.

In order to further explore historical development, let us briefly consider contemporary variants of Jerusalem repertoire along with preceding historical documentation. The troparion of the Cross, though designated mode II in other Byzantine rite sources, follows the mode VI (plagal II) model melody in Georgian variants. Though assigned to mode II in the Jerusalem lectionary, it is plagal in tenth-century iadgari manuscripts. While there is an early Byzantine modal area that encompasses features of modes II, plagal II, and IV (Dubowchik 1996, p. 119), the Georgian system of model melodies for each mode suggests that this change may relate to Georgian musical development or categorization. While modal designations and gestures in monophonic repertoires are somewhat fluid, especially among medial modes or between authentic and plagal counterparts (Moran 2010), some melodies also possibly pre-dating modal codification (Jeffery 1992), the situation in Georgian chant is somewhat different since, with scale and range remaining consistent, each mode has one general melody for

12 Examples of this kind of phenomenon have been recently studied (Harries 1973; Mora 2012), including other parts of the South Caucasus, though from a rather different linguistic and musical tradition (Naroditskaya 2005). Besides the aforementioned work on textiles, pre-altar crosses, and icons, I have previously discussed one Georgian folk Christian example, a Svan labyrinth carving (Freedman 2017). 
troparia and one for heirmoi; other chant types follow similar formulas in the respective mode, and others, such as the Trisagion and cherubic hymn, have their own dedicated melodies. The modal change of St. Andrew of Crete's great canon, from mode VI to mode IV, took place in the eleventh century, coinciding with a new translation by St. Giorgi the Athonite, and it was translated again in the twelfth century by St. Arsen (Managadze 2006, p. 410). Today, its heirmoi have the mode VI model melody, but the "Have mercy on me, O God; have mercy on me" refrain sung between the troparia of each ode follows a mode IV formula. The decision to change the mode as part of the effort towards better translations may likewise stem from Georgian musical sensibilities and available material at any particular period, given the use of pre-existing heirmos translations by St. Giorgi, as the musicologist Khatuna Managadze notes (Managadze 2006, p. 410). By the twelfth century, such may relate to text setting and model melodies, especially since lexical, though not metrical, aspects of translation became quite Hellenophilic in the high Middle Ages (Doborjginidze 2014, p. 337).

This study will not analyze chants whose mode has changed, but it is important to note this phenomenon in conjunction with model melodies in Georgian chant development. Later, we will discuss the mode VI troparion model melody as it occurs in practice, but now let us consider late redactions of two Jerusalem chants.

Though no medieval neumes survive for these, our examples are the paschal troparion ${ }^{13}$ (plagal I in Byzantine rite sources but no designation in the early Georgian lectionaries) and the Trisagion for the departed, also sung at Great Saturday matins and listed there in the lectionaries (not assigned to a mode) (Tarchnischvili 1959, p. 205). Variants from Svaneti (and for the troparion, also Lechkhumi, Samegrelo, and Rach'a) exist, adding to the number of regional, and sometimes family or personal, chant styles for comparison.

Six variants of the paschal troparion, representing different regions and degrees of ornamentation, are shown (Figures $2-5) \cdot{ }^{14}$

The phrase division is the same in all despite the perhaps textually odd separation before, and beginning the next phrase with, the verb. The syllabic setting, often precise textual rhythm, is synchronous, except for expanded, decorated West Georgian endings. Plain mode variants have long notes at places that afford such expansion and decoration. The top voice model structure, which has an $\mathrm{ABa}^{\prime} \mathrm{b}^{\prime}$ form, is evident, remaining even when voice crossing occurs, passing between the top two voices. Varied harmonization and ornaments; however, often render different structures. The middle voice is also of interest, particularly in Western plain mode versions. Contour and direction are similar, despite the characteristic solo call gesture in the Svan setting. The middle voice has a leading function in Svan song, and this way of building polyphony exists in counterpoint to the top voice-based structure described above; yet, even in that context, the middle voice stands out, for instance by receiving the greatest ornamentation in chants from Kartli-K'akheti. The voice with striking or foundational features, then, may differ and such does not coincide with chronological precedence. Each voice is fundamental in particular ways. Interestingly, in Svan folk song, when monophonic variants occur, they are derived from polyphonic ones (Khardziani 2010), and it seems that this process of shedding voices has taken place on a larger scale in Meskhian (Samsonadze 2012) and Pshav-Khevsurian ${ }^{15}$ ritual song.

13 Note that the spelling of this hymn's title line, which this author renders as "Krist'e Aghsdga", differs in the scores used throughout this paper, due to different transliteration systems and older and newer forms of the verb in the respective sources.

14 Transcriptions of these and many other variants, along with recordings, videos, and commentary, have generously been made available online by John Graham at http://www.johngrahamtours.com/kriste-aghdga.

15 I have not come across a specific reference to voice shedding in this Eastern highland repertoire, and some scholars consider it to be an old, monophonic layer of Georgian music. However, Zurab K'ik'nadze and Kevin Tuite have shown that Pshav-Khevsurian ritual and religion, rather than being archaic, pre-Christian practice, are late developments derived from medieval Georgian Christian feudal culture (Tuite 1996). Religious terminology, e.g., "khat'I" ("Icon") and "jvari" ("cross"), come from Christian liturgy, and one may surmise that the ritual diaphonic and monophonic repertoire, along with some of its textual elements, may have derived from three-part polyphonic chant. A short or seemingly simpler structure "does not imply antiquity", as Frøyshov's study of hymnographic development demonstrates (Frøyshov 2008, pp. 264-67), and it is 


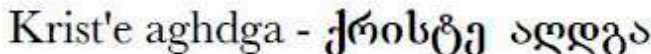
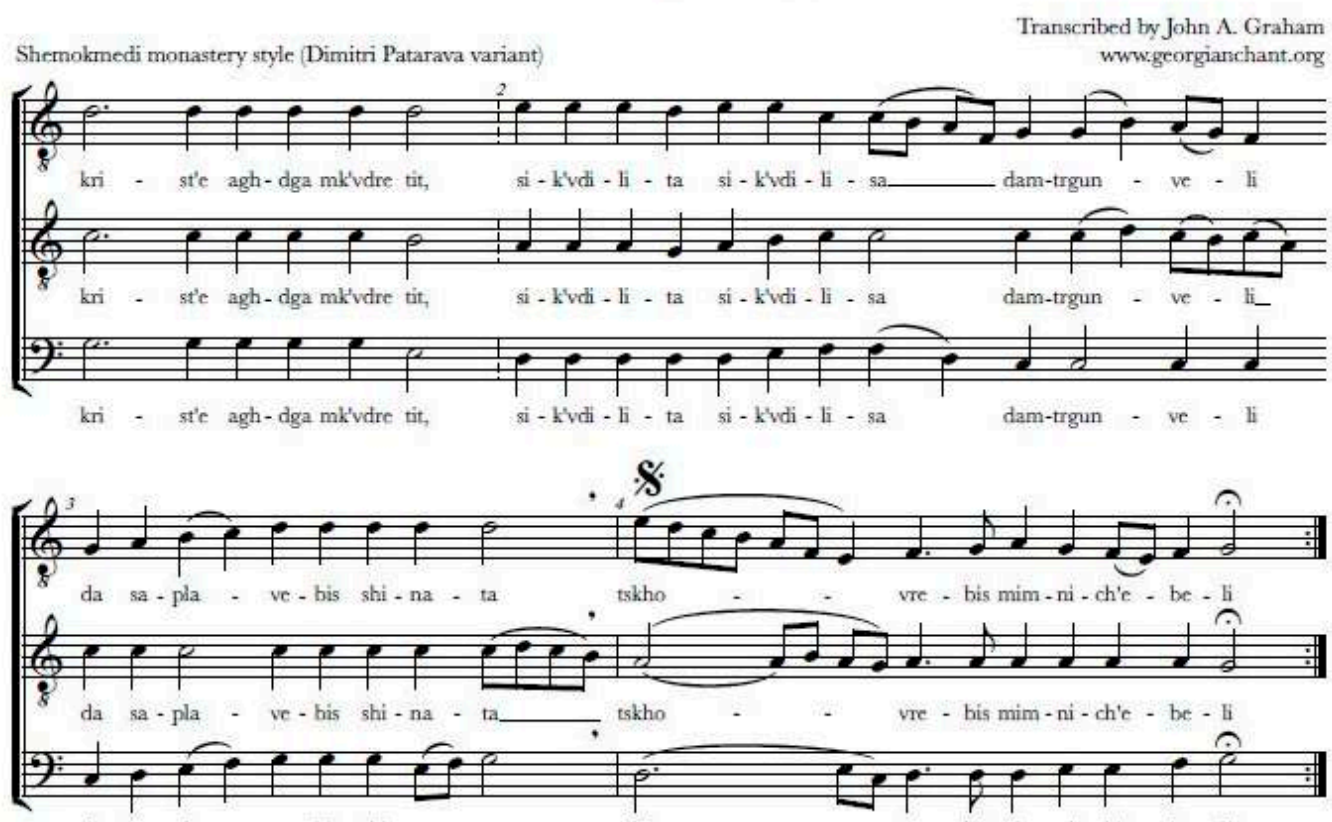

da sa-pla - ve - bis shi-na - ta ta tskho vre - bis mim-ni-ch'e - be - li

๑ 3rd ending (same tempo)
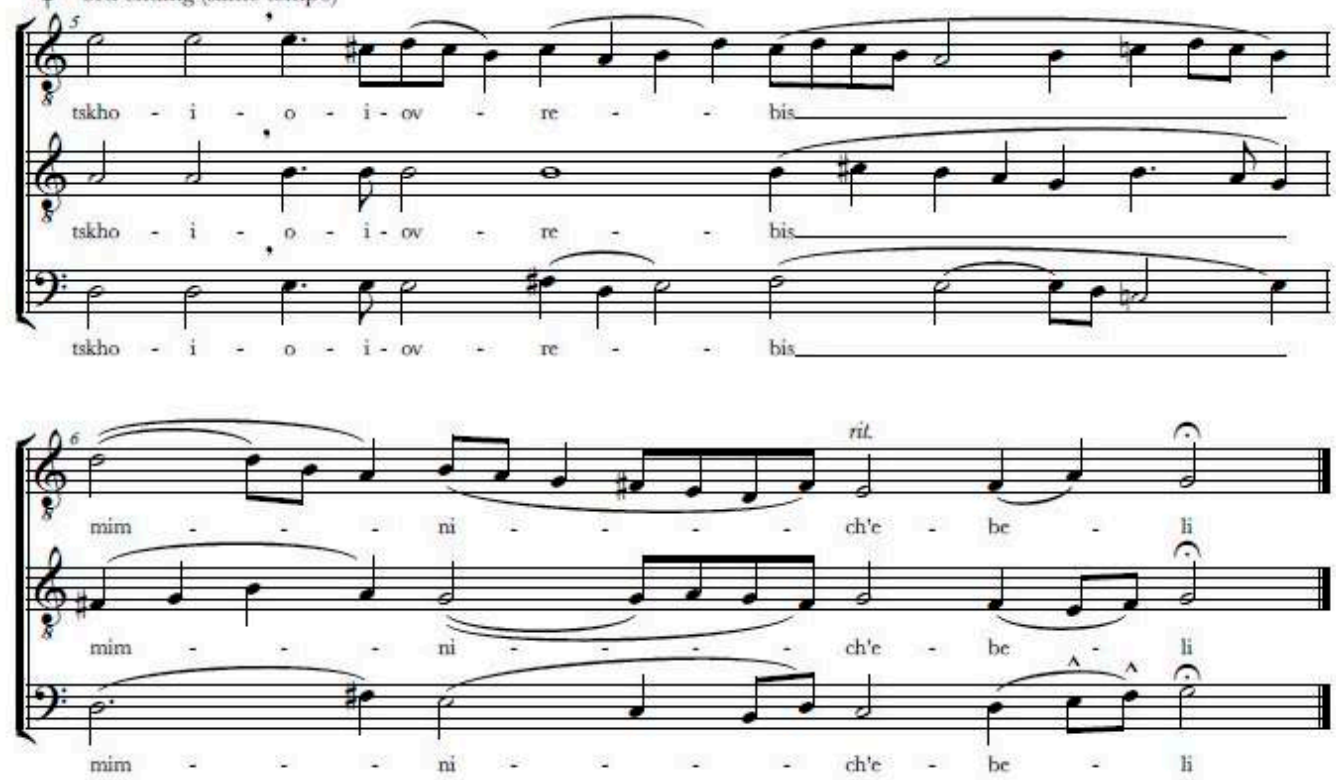

Figure 2. Paschal Troparion; Svetitskhoveli School.

noteworthy that most Svan ritual repertoire retains a three-part structure, pointing to differences in context, development, and/or age. We will discuss the development of this repertoire below. 


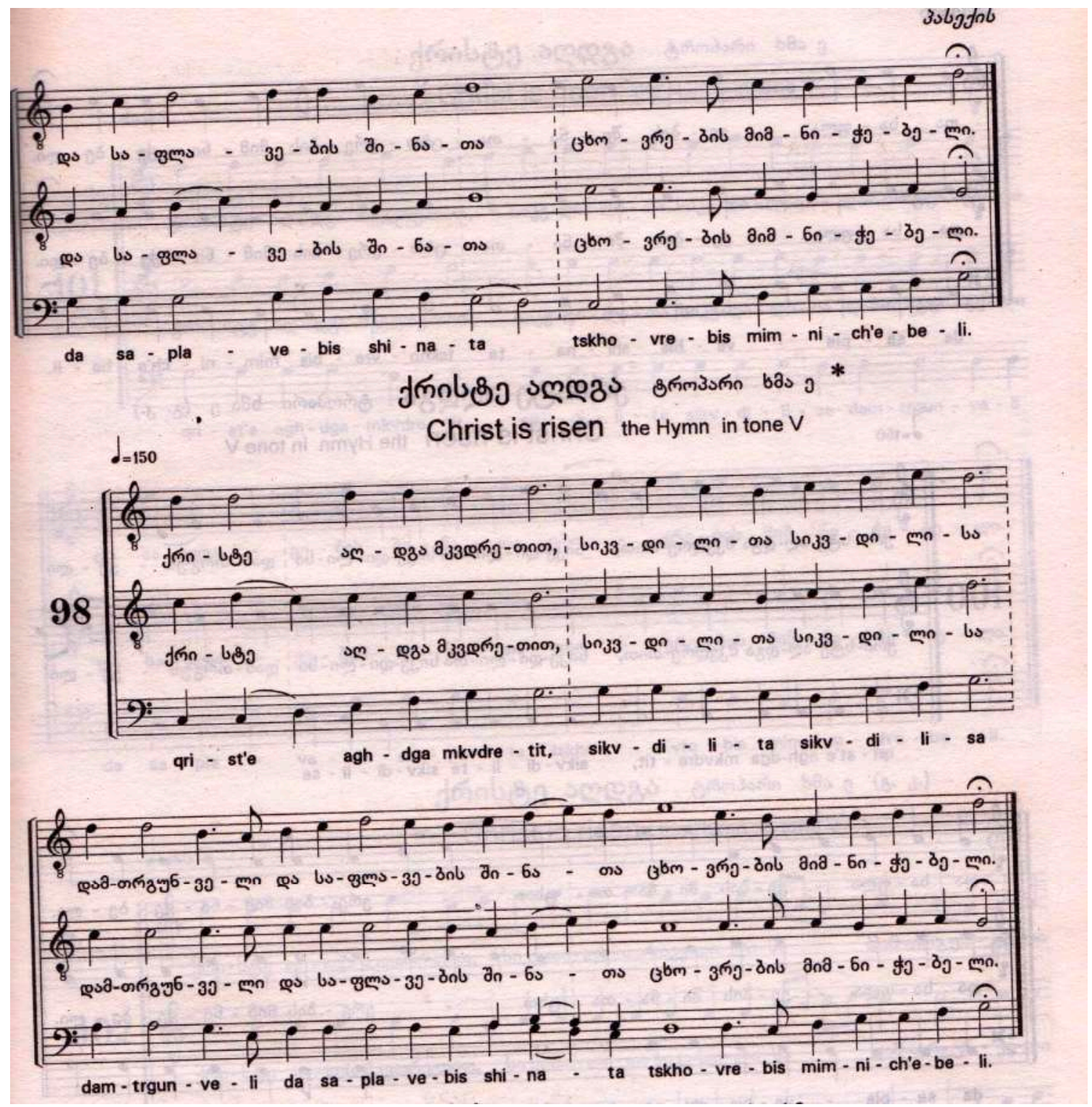

Figure 3. Paschal troparion; Gelati School.

To aid further interpretations from this brief analysis, let us examine the Svan troparion and Trisagion variants (Figures 6 and 7) in their local context.

These are two of only four ecclesiastical texts with Svan variants, accompanied by occurrences of Svanified "Kyrie eleison" in folk hymns and one setting of a triple "Lord, Have Mercy" for the departed (Figure 8).

Along with these chants, ritual round dances, folk hymns (some associated with specific medieval church buildings or villages), funeral songs, and prayers are sung to the present day; we will discuss some examples later. All exhibit three-part polyphony, and even extemporaneous spoken prayer is simultaneously uttered by three men (field notes, 25 July 2011; 28 August 2016; 24 July 2017). Some singers consider this paraliturgical repertoire to have pre-Christian origins, though they also deem it a part of their Christian faith and worship (field notes, 22 July 2011). Local veneration of Christ, the Theotokos, the Archangels, and various saints has its associated songs, high medieval churches, adorned icons, rituals, and manuscripts (field notes; Schrade 2001). The recently studied Kurashi Gospel contains the earliest known Svan specimens (this endangered Kartvelian language is primarily oral) in marginal notes, which include prayers written by fourteenth-eighteenth-century 
hands (Gippert 2013). Several, such as a fifteenth-century prayer, reflect the character of folk hymns in their ornamentation with vocables, primarily to extend vocatives, including those in the Trisagion and Kyrie Eleison (Gippert 2013, p. 100). A vocative "O Christ" occurs at the beginning of prayers for blessing (Gippert 2013, pp. 95-97) and even at the start of a note that does not seem to have sacred content (Gippert 2013, p. 98), and this same calling upon the Lord is a common opening element in inscriptions on icons (Chichinadze 2008) and Svan folk songs. It is surprising to find these written witnesses to what is considered an oral folk tradition with no traceable past. Let us now explore the ornamented Svan repertoire in light of the three Georgian chant styles.

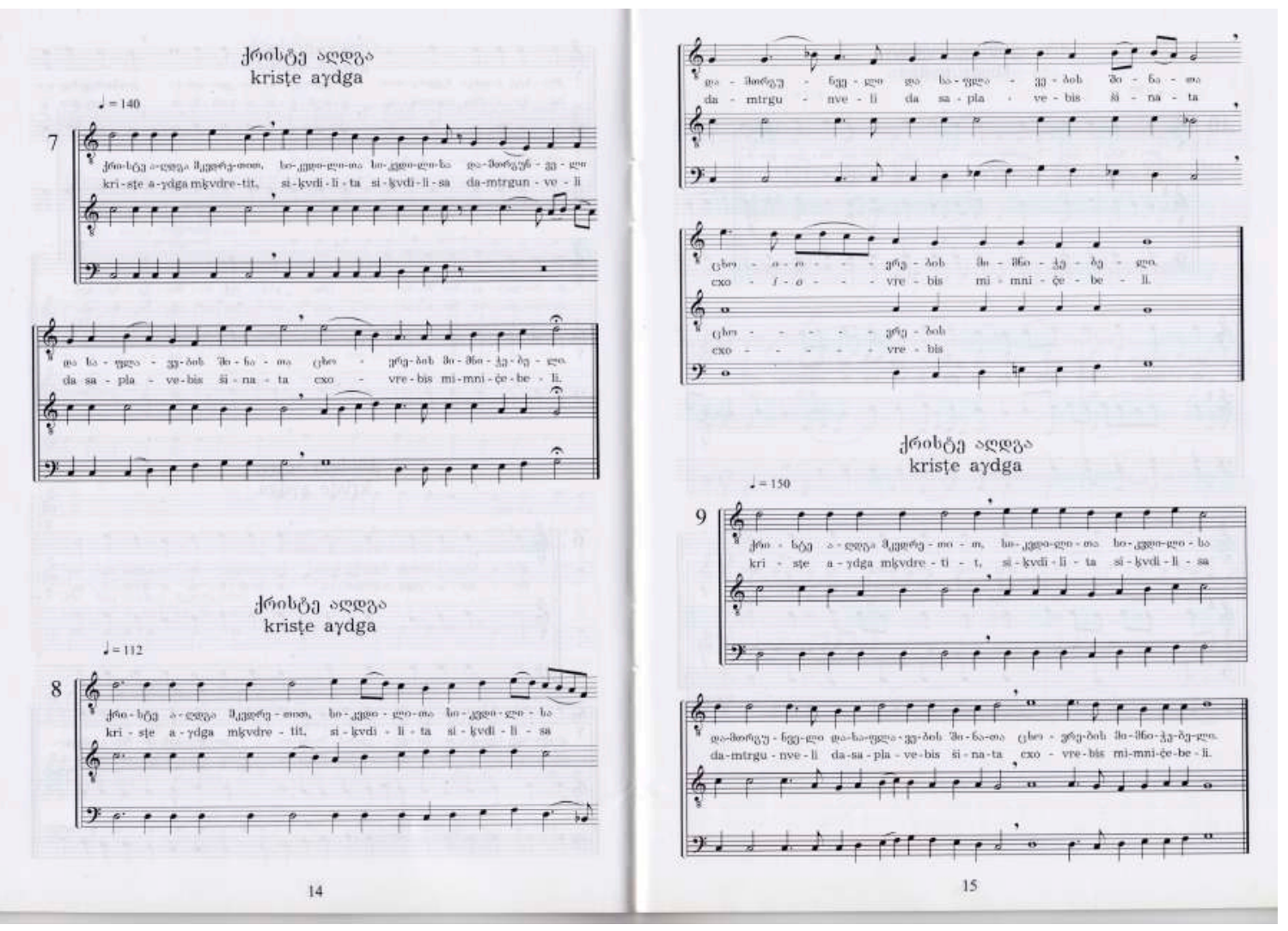

Figure 4. Paschal troparion; Shemokmedi School.

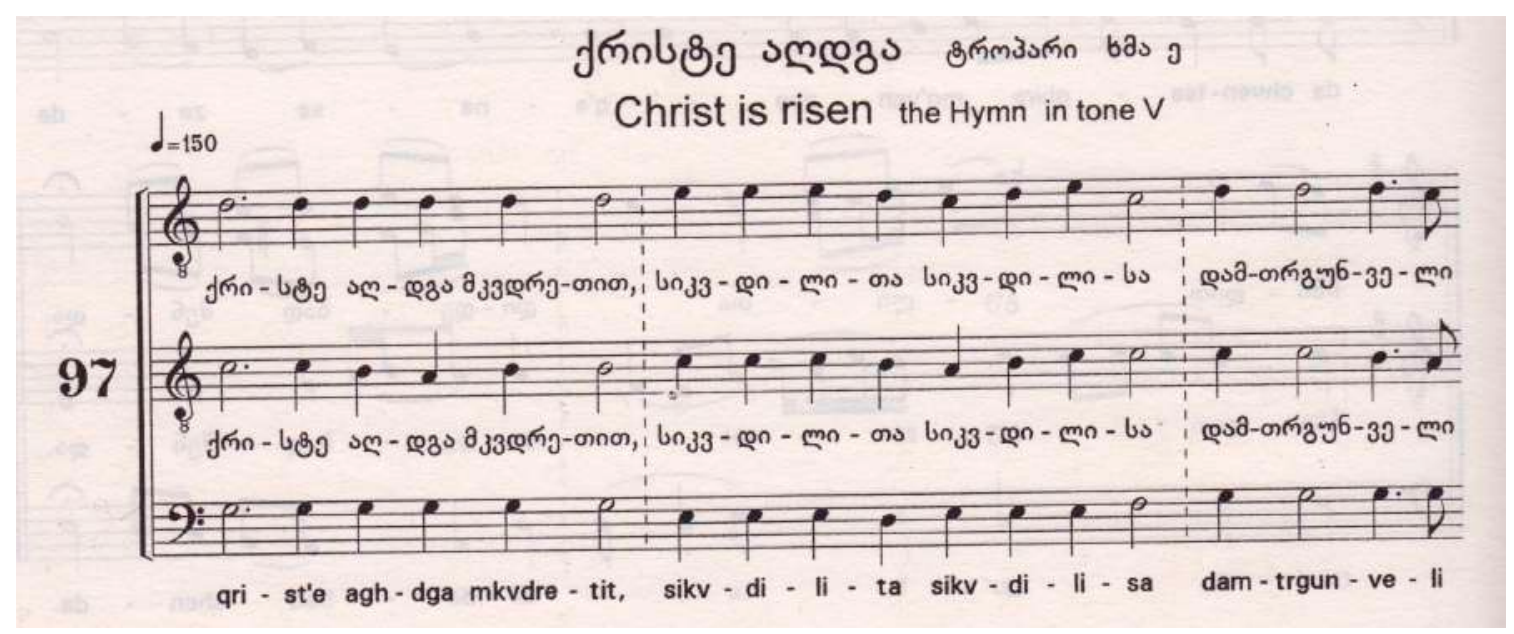

Figure 5. Paschal Troparion; Svan variant. 


\section{Ts'mindao Ghmerto 1}
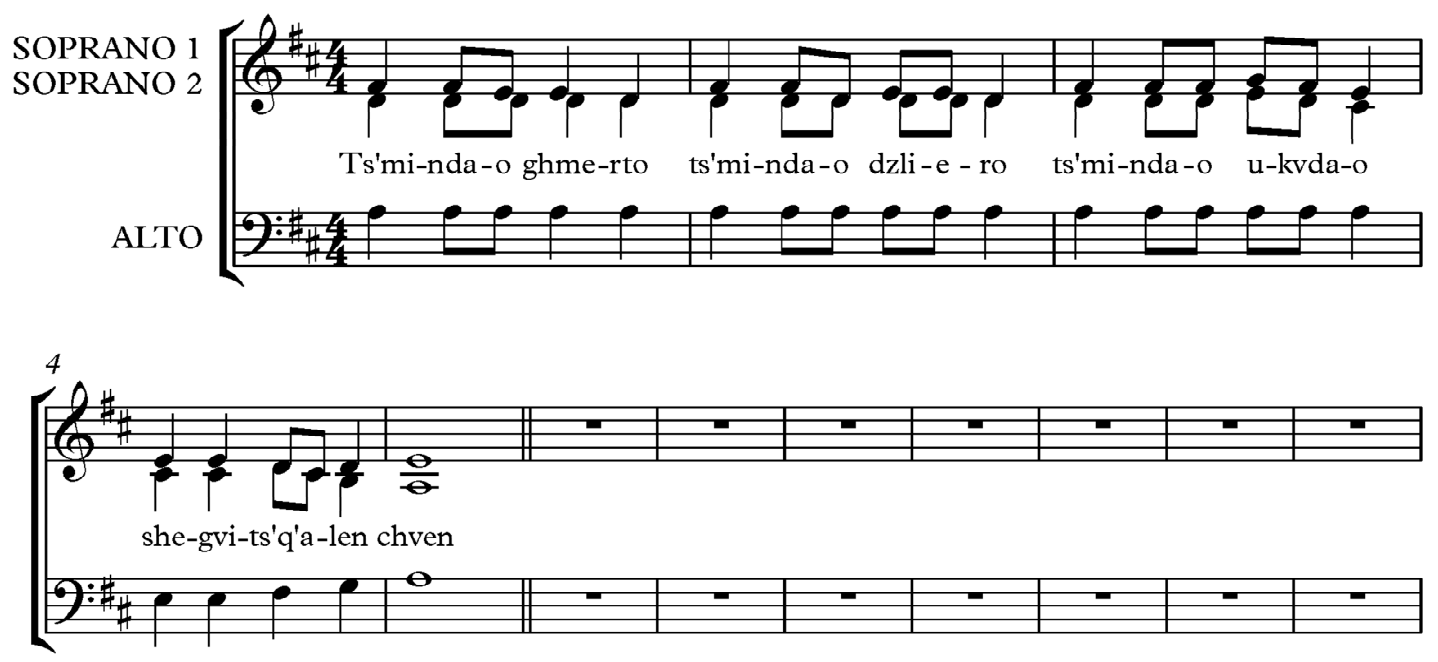

Figure 6. Funeral Trisagion; ornamented mode; Upper Svan variant.

Krist'e Aghsdga is likely the latest Svan chant, from the eighteenth or nineteenth century as John Graham suggests, ${ }^{16}$ since it is plain mode, existing without decorated variants, and I suggest that it developed from other Western variants which, like manuscripts, made their way into this mountainous region. Its harmonic progression shares features with the plain mode Trisagion and, besides the latter's unison cadence, the "Lord, Have Mercy;" however, even the latter has been sung as a fifth (field notes, 24 July 2017). The Trisagion is likely somewhat older, since it has multiple versions, including that for the departed, which bears ornamental features. Svan chants have not been previously categorized according to the three styles, but the principles of decoration are clear. Some, such as rhythmic expansion and ornamented key pitches, occur in all Georgian chant schools. Others, such as the addition of vowels, are similar to what we find in Shemokmedi and Martvili chants (Kalandadze-Makharadze 2014; Shugliashvili et al. 2014). The parallel use of particular vocables and the concentric repetition of smaller cyclical figures inside larger ones are Western Kartvelian features, which we will continue to analyze. One decorated Trisagion ${ }^{17}$ has different tunes and more repetition, but vocable patterns, placement thereof, and phrase structure are the same, which is why one could consider it another variant of the same chant, not simply because it shares the same ecclesiastical text. Vocables and lexoids comprise a sustainable and stable aspect of Svan song; singers consider them to be the essence, text, and tune allowing for variation and improvisation (Mzhavanadze and Chamgeliani 2016, p. 50). I add call gestures, pattern, vocable placement, repetition, types of beginnings and endings, harmonic and melodic figures, stock texts, certain structures, such as the labyrinth, and a particular type of three-part counterpoint to the prototype of the icon of Svan religious song (Freedman 2017). All these elements become clear when exploring what may be the oldest repertoire, paraliturgical hymns to Christ and St. George and a group of round dances and hymns that share certain lines of text, the same tune, and/or the same dance, as discussed in the relevant section of this article. Concerning the funeral Trisagion, the division of phrases, cadential patterns, and structure of the ornamented variants are similar to those in Gelati and Svetitskhoveli counterparts, showing how some features, not entirely

16 Personal communication, May 2016.

17 http://www.alazani.ge/base/basiani/Basiani_-_TSMINDAO_GMERTO.mp3. 
text-dependent since other variants differ (cf. the Trisagion structure types described below), are common across regions. In the small group of Svan Trisagia, precise sequences of pitches or melodies are not fundamental, but they are preserved in, created by, and varied through the counterpoint of the aforementioned prototypical aspects. The co-existing repertoire of ecclesiastical chant from other schools also follows musical principles, and many are the same, such as the employment of model phrases, space between voices, labyrinth structure, trends in modulation, and some harmonic gestures. Thus, not only are Jerusalem chants translated into the Georgian language but also into recognizable local music that has its own prototypes, which can only be understood through many copies.

\section{Ts'mindao Ghmerto 2}
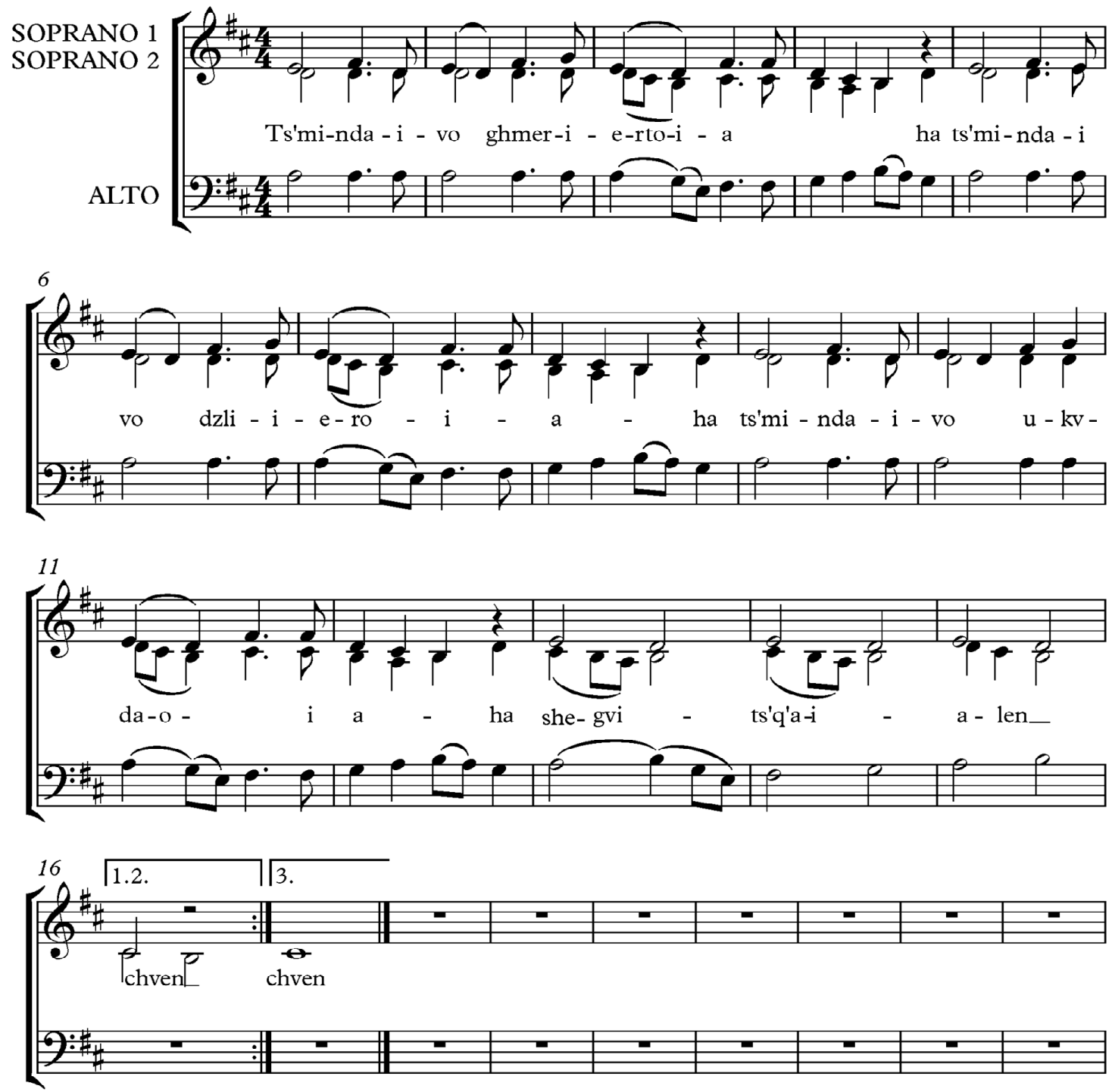

Figure 7. Trisagion; plain mode; Upper Svan variant, Lakhushdi Village. 


\section{Upalo}
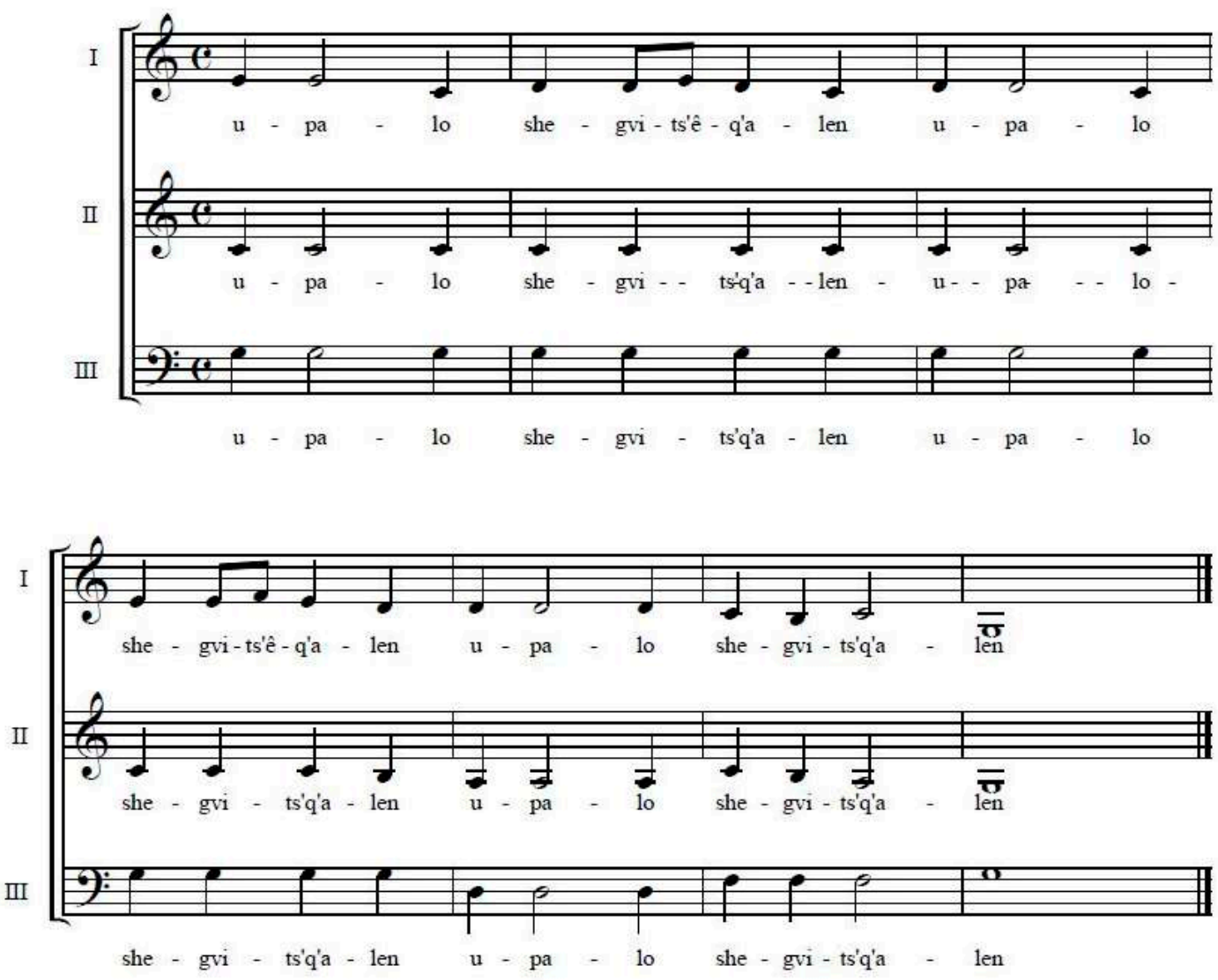

Figure 8. Triple Lord, Have Mercy; plain mode; Upper Svan variant, Lakhushdi Village.

We conclude this section with a few historical notes. If some form of Svan polyphony dates to pre-Christian times, and given its triangular stability, Georgian chant may have taken on polyphony as part of the inculturation process in each region at an early stage. As mentioned above, this process can be measured by textual sources and other art forms, such as architecture, which the art historian Erga Shneurson considers to be an artistic form of Georgian self-identity against the background of the surrounding Byzantine and Persian cultures (Shneurson 2012). The first, functional stage of linguistic inculturation established Georgian as the liturgical language; the Jerusalem lectionaries date from this period, as do some texts still in use. The second, qualitative stage included the creation of new terminology, that is, the "education" of the Georgian language in order to translate Greek semantics, in conjunction with the translation of new material and the revision or replacement of previous translations, in order to produce, as translators wrote, "icons" of the Greek texts (Doboriginidze 2014, p. 338). This stage is when we find the first neumes, the changing of some modal assignments, the references to harmony in chant manuscripts, and the works of Ioane Petritsi; thus, musical inculturation perhaps also underwent a second stage in the central Middle Ages. Being ekphonetic, the early neumes tell the chanter "where to get", and Tsereteli's work shows that the slope and destination correspond with variants from nine centuries later. When a translation was complete, specialized professionals put it to music; some propose that, by the twelfth century, this process entailed setting to model melodies and subsequent harmonization (Managadze 2006, p. 410). Some posit that Georgian polyphony dates to the division of the Kartvelian tribes in antiquity, though the passage from Xenophon sometimes 
employed to make this point is too vague to lend support (Graham 2015). Yet, the ethnomusicologist Joseph Jordania states that choral singing was the first human music and provides countless examples that demonstrate the worldwide presence of folk polyphony (Jordania 2011). It is not out of the question that Georgian music to which Christians arrived was polyphonic. The music that they brought with them was most likely monophonic, though intriguing musical language that seems to describe instrumental polyphony occurs in patristic sources, such as St. Ephraim the Syrian's Hymns on Virginity (e.g., Hymn 30:1; translated in McVey 1989, p. 394). Though direct documentation of such is only as early as the nineteenth century, Georgian music entails polyphonic thinking; singers often find it difficult to sing isolated voice parts and will improvise additional voices to arias or unison Western and Byzantine music (Jordania 2006, p. 9; field notes, June, August 2014). Chant development includes much creativity, and translations that fit Byzantine meter when appropriate exist alongside those that do not. As shown by hagiography, canons, and rituals, Georgians may have sung paraliturgical songs and baptized folk traditions at an early stage, and/or these may have developed alongside, or out of, ecclesiastical chant and liturgy (Freedman 2017; Ghambashidze 2006). Regarding imported Greek monophony, they may have translated at least Kyrie Eleison into new musical idioms by the ninth century, and the aforementioned life of St. Grigol Khandzteli lists this as the only Greek text in use at the time (Lang 1995, p. 147). Folk settings occur in Western regions, including the aforementioned written and sung ${ }^{18}$ Svan examples. ${ }^{19}$ As with many human phenomena, it is impossible to firmly date the beginnings of polyphony; one can only roughly date occurrences as they are discovered and may yet find illuminating pilgrim's accounts and scribal notes. The earliest known Christian Georgian inscriptions, which include recognizable forms of what is now commonly called the "Jesus prayer", were found in Nazareth (ca. 330-427) (Tchekhanovets 2011, pp. 458-60), and Georgian polyphony, religious or otherwise, may have been sung by pilgrims in Palestine even as early as the mid-fourth century. Once textual translations were stable, ecclesiastical music could flourish, but vocable-rich song, which does not depend on written texts, could have existed earlier. Some Jerusalem texts occur in the Byzantine rite; the paschal troparion is one; the Trisagion is another, and its music has its own model melodies. These chants exist in a multitude of polyphonic variants with interesting similarities. As is the case now, it may have been in eighth-century Jerusalem, ninth-century Tao-Klarjeti, tenth-century Svaneti, eleventh-century Mt. Athos or Sinai, or twelfth-century Imereti, for any number of texts; that is, they may have been sung by Georgians in many ways, yet always in three plaited parts along the same path, which, as we saw, cannot be done in "one and the same manner twice." Plain mode variants may have been solidified by the twelfth century, at the end of the second inculturation stage. What some consider the most well-preserved Kartvelian folk music, Svan ritual song, shares, or has developed, features along the same lines, giving us two interrelated repertoires that embody similar principles. We will view this repertoire in a complementary way below and see that musical developmental patterns may differ, and that ornamenting with vocables may be a foundational, rather than a decorative, feature. Chants in notated and textual second-stage sources are still being sung in one variant or another, each performance constituting a new construction by those who know how to build towards the same goal. If we could have chanters from across the centuries sing for each other as Bishop Aleksander Okropiridze did from across the country in the nineteenth century, we might receive the same puzzled response, given by a Gurian choir director after listening to Eastern variants: "Why did you bother to bring us here? You have the same chants that I know" (Graham 2007, p. 102).

18 http://www.alazani.ge/base/Riho/Riho_-_Kviria.mp3.

19 This text also occurs in Mengrelian paraliturgical songs (Makharadze and Ghambashidze 2014). The authors consider the changing of Kyrie Eleison into similar-sounding vocables to be a late phenomenon, in order to hide the sense of the words during the Soviet period, but given the Svan manuscript example and general Western decorative principles, I suggest that such is not the primary factor. This article also provides an interesting hagiographical story, passed down orally and related to the named festival, about first-century apostolic activity of St. Andrew and of Christianization in Western Georgia. Interestingly, like the story of St. Nino in Kartli, it includes the cutting down of an important tree, albeit in a very different context and for different, somewhat negative reasons. 
Thus, the Georgian offspring of Jerusalem chant has multiple forms of three-part exegesis within a threefold system of styles according to regional chant schools; overlapping variations within each style and region; and a polyphonic sound since at least the high Middle Ages, interpreted by chanters according to the liturgical text, knowledge of established musical principles, and work with each other and their forbears. Early and high medieval Georgian art depicts Jerusalem through symbolic shapes and the forms of contemporary Georgian churches, which display local features like the darbazi house structure, rather than through Byzantine or Hagiopolite models (Gagoshidze 2014). We have seen the same phenomenon in sound, where chants from Jerusalem are expressed not only in the Georgian language but also according to Georgian musical forms and ornaments. The spiritual and tangible significance of Jerusalem, along with its practices and texts, are continued not through exact replication of physical form, word, and melody, but through meaningful and effective intermedial translation and iconography. Let us now further examine prototypes in Georgian chant through more in-depth examples, leaving aside questions of history and fully taking up theological discussion.

\section{Musical Prototypes: Model Melodies, Foundational Characteristics, and the Case of the Trisagion}

We have briefly touched on Svan Trisagia and some of their prototypical elements, and this section will look at variants of this hymn throughout Georgia and from different periods. However, we will first address the prototype phenomenon in general through field recordings and practical descriptions.

The role of model melodies as prototypes for Georgian musicians can be well understood in practice. The aforementioned mode VI troparion melody is widely known and documented, and field recordings reveal an interesting cognitive aspect. Several hymns that use this melody were recorded from the same Gurian singers in the early twentieth century. In one example, the paschal processional hymn, ${ }^{20}$ the first two lines of the hymn are sung, followed by the substitution of text with the second half of a Palm Sunday troparion in the same mode. In another example, the troparion "O Heavenly King", ${ }^{21}$ several lines of text are skipped, which leads to fewer repetitions of melodic formulae. It is likely, then, that the models and their formulaic phrases take precedence in memory and are available for the application of texts, whether read, recalled, interchanged, mixed, lengthened, or truncated. The Georgian musicologist Magda Sukhiashvili notes that the application of text to model melodies is not a static scheme but is based on experience and understanding of principles, of the "science of hymnography", as it is called. She describes this kind of compositional process as explained by chanters and through comparative analyses of several troparia. St Polievktos Karbelashvili, who, along with his brothers, preserved many east Georgian chants in the 1880's, called the joining of text to melodic formulae "threading", and the model melodies remain against the historical background of changing styles and aesthetics (Sukhiashvili 2014a, pp. 422-23). Even in the most decorated variants, they act as axes around which decorations move to and fro (Sukhiashvili 2014a, p. 423). Thus, the model melodies act as prototypes or foundational surfaces for text, but unlike monophonic chant traditions, they do so joined with various principles of style and harmonization, as we have already begun to explore. We will now return to the Trisagion. After discussing patristic theology of this hymn, we will examine the musical characteristics along with the text, continuing to identify various elements as prototypical in particular ways and giving rise to various characteristics in specific variants. We will; thus, further explore theology through analysis.

The Trisagion occurs in two primary forms: The direct quotation from the Book of Isaiah (Is. 6:3), sung during the anaphora, which begins with "Holy, holy, holy" and is combined with the praise from the account of Palm Sunday (Matt. 21:9); and an expanded and supplicatory proclamation, "Holy God, holy Mighty, holy Immortal, have mercy on us", which occurs at the end of the great doxology, during the synaxis of the Liturgy, during funerals and memorials, and at the beginning, middle, and

20 http://www.alazani.ge/base/Guria/Guria_-_Agdgomasa_Shensa.mp3.

21 http://www.alazani.ge/base/Guria/Guria_-_Meupeo_Zetsatao.mp3. 
end of services in the daily office (Simmons 1984, p. 42). A third form occurs as the ending phrases in groups of troparia to the Trinity and the troparion for the weekday midnight office, also used for the first three days of Holy Week. Later in this article, we will explore this third form in a single Georgian paraliturgical setting, since the full troparia simply follow the given model melodies. Let us first consider the second form, keeping in mind that all are described as angelic prototypes. The second form is an interesting case for this study since tradition holds that it is not only sung but directly taught to human beings by angels (St John of Damascus, Exact Exposition of the Orthodox Faith, Book II, 10). The Trisagion also holds symbolic and powerful significance, as demonstrated in liturgical commentaries. Referring to the anaphoral form, which is sung by members of the highest angelic hierarchy, St. Dionysios writes the following:

"This, then, according to my science, is the first rank of the Heavenly Beings which encircle and stand immediately around God; and without symbol, and without interruption, dances round His eternal knowledge in the most exalted ever-moving stability as in Angels; viewing purely many and blessed contemplations, and illuminated with simple and immediate splendors, and filled with Divine nourishment-many indeed by the first-given profusion, but one by the unvariegated and unifying oneness of the supremely Divine banquet, deemed worthy indeed of much participation and co-operation with God, by their assimilation to Him, as far as attainable, of their excellent habits and energies, and knowing many Divine things pre-eminently, and participating in supremely Divine science and knowledge, as is lawful. Wherefore the Word of God has transmitted its hymns to those on earth, in which are Divinely shewn the excellency of its most exalted illumination. For some of its members, to speak after sensible perception, proclaim as a "voice of many waters", "Blessed is the glory of the Lord from His place" and others cry aloud that frequent and most august hymn of God, "Holy, Holy, Holy, Lord of Sabaoth, the whole earth is full of His glory." These most excellent hymnologies of the supercelestial Minds we have already unfolded to the best of our ability in the "Treatise concerning the Divine Hymns", and have spoken sufficiently concerning them in that Treatise, from which, by way of remembrance, it is enough to produce so much as is necessary to the present occasion, namely, "That the first Order, having been illuminated, from this the supremely Divine goodness, as permissible, in theological science, as a Hierarchy reflecting that Goodness transmitted to those next after it", teaching briefly this, "That it is just and right that the august Godhead-Itself both above praise, and all-praiseworthy-should be known and extolled by the God-receptive minds, as is attainable; for they as images of God are, as the Oracles say, the Divine places of the supremely Divine repose; and further, that It is Monad and Unit tri-subsistent, sending forth His most kindly forethought to all things being, from the super-heavenly Minds to the lowest of the earth; as super-original Origin and Cause of every essence, and grasping all things super-essentially in a resistless embrace" (Celestial Hierarchy, 7:4).

Note that the saint describes and gives reasons for the transmission of angelic hymnody to the human hierarchies. He specifies that the source is "unvariegated" and that the angels worship "without symbol", but a result of the transmission to, and assimilation by, human worshippers is variety and variegation. Yet, the human chanting of any form leads to unity and even to equality with the angels, including participation in the circular movement around God, as St Maximos the Confessor describes in two passages from his Mystagogy:

"The triple exclamation of holiness which all the faithful people proclaim in the divine hymn represents the union and the equality of honor to be manifested in the future with the incorporeal and intelligent powers. In this state human nature, in harmony with the powers on high through the identity of an inflexible eternal movement around God, will be taught to sing and to proclaim holy with a triple holiness the single Godhead in three Persons. By the Trisagion there comes about the union with the holy angels and elevation to the same honor, 
as well as the ceaseless and harmonious persistency in the sanctifying glorification of God". (Berthold 1985, p. 201)

"The unceasing and sanctifying doxology by the holy angels in the Trisagion signifies, in general, the equality in the way of life and conduct and the harmony in the divine praising which will take place in the age to come by both heavenly and earthly powers, when the human body now rendered immortal by the resurrection will no longer weigh down the soul by corruption and will not itself be weighed down but will take on, by the change into incorruption, potency, and aptitude to receive God's coming. In particular it signifies, for the faithful, the theological rivalry with the angels in faith; for the active ones, it symbolizes the splendor of life equal to the angels, so far as this is possible for men, and the persistence in the theological hymnology; for those who have knowledge, endless thoughts, hymns, and movements concerning the Godhead which are equal to the angels, so far as humanly possible". (Berthold 1985, p. 209)

Thus, the hymn is prototypical, iconic, transformative, and eschatological. However, one may inquire regarding its universal nature since, in any given language and musical tradition, it exists in a different sonic form or, as in Georgian, many musical variants, as well as the several aforementioned textual forms. These many forms are, as suggested above, a result of hierarchical patterns and processes and can be described in Dionysian terms as "variegated sacred veils" (Celestial Hierarchy, 1:2) that reveal what they cover. They may symbolically reflect the aforesaid "many and blessed contemplations" of the angelic orders.

Let us now consider the second of the textual forms in its musical settings. The semantics, syntax, and, where linguistically appropriate, grammar of the text are generally shared across languages. Therefore, the text can be said to be a prototype with many sonic icons even where speech is concerned. It can be labelled with the structure $\mathrm{AbAbAbC}$, A marking the repeated vocative "Ts'mindao", $\mathrm{b}$ the other vocative, and $C$ the imperative phrase; $A A A B$ is the overall structure without divided vocative phrases. Yet, this text relates to given musical examples in a variety of ways. For liturgical examples, we will describe only the first iteration, though the hymn is sung four times at an ordinary Liturgy; some variants contain different settings for the third of these repetitions. The aforementioned ornamented Svan setting for the departed has the parallel musical structure AbAbAbC, as do Gelati and East Georgian funeral variants. Some liturgical settings, also in both Eastern and Western examples, join the final vocative to the imperative, rendering the structure AbAbAC (Figures 9 and 10). ${ }^{22}$

Yet other settings treat the text as a sort of ascending tricolon, again across Georgia, giving rise to such forms as $\mathrm{Aa}^{\prime} \mathrm{B}$ (Figure 11) and $\mathrm{ABC} .^{23}$

The repetition can inspire yet further permutations, and the popular setting by the current patriarch, Ilia II, has the form AbbC (Figure 12).

A lower Svan variant repeats vocatives, rendering the textual structure ABACADEACDE and the musical form $A a B B^{\prime}$, whose rhythm is like that of the above plain mode Upper Svan variant (field notes, November 2015). Like the above paschal troparion, these structures are further developed through harmonization, which, for instance, can turn a into $\mathrm{a}^{\prime}$ and $\mathrm{a}^{\prime \prime}$. Principles of musical form, such as medial and final gestures, have a similar role (e.g., $B$ and $B^{\prime}$ in the Lower Svan Trisagion), and the same affect harmony, the middle ceasing its parallel motion and reflecting the top voice's ascent, moving down a step in order to form the cadential fifth. Changes in ornamentation have similar effects in varying the repetitions, as in variants of the Svan funeral Trisagion, whose figures we will discuss below. Thus, as we previously saw with Svan vocables, principles and elements of musical composition direct the making of a chant alongside the text, and in rendering any given copy of a

22 Another Gelati variant can be heard at http://www.alazani.ge/base/AnchiskhatiG/Anchiskhati_-_Tsmindao_Gmerto.mp3.

23 An Eastern variant with this structure can be hard at http://www.alazani.ge/base/AnchiskhatiK/Anchiskhati_-_Tsmindao_ Gmerto.mp3. 
prototype, harmonic, contrapuntal, and decorative aspects work in synergy. The text, its sounds, and its structure act somewhat like the basic warp in a balanced textile, and the musical features act like multifarious ground and pattern or supplementary wefts. Pattern warps may also be added, such as additional vowels and vocables.

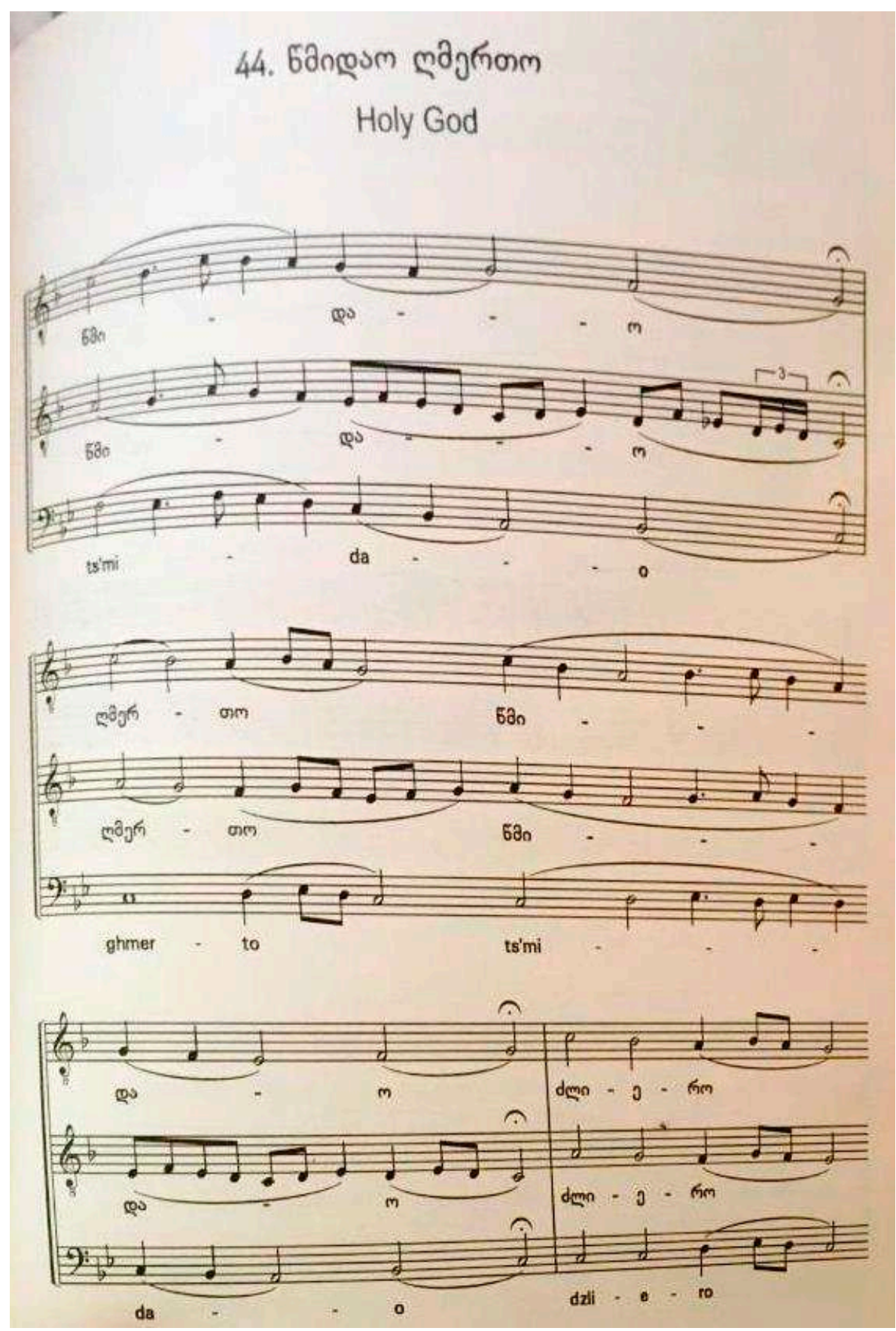

Figure 9. Trisagion; Svetitskhoveli School (Shugliashvili and Tsereteli 2012). 


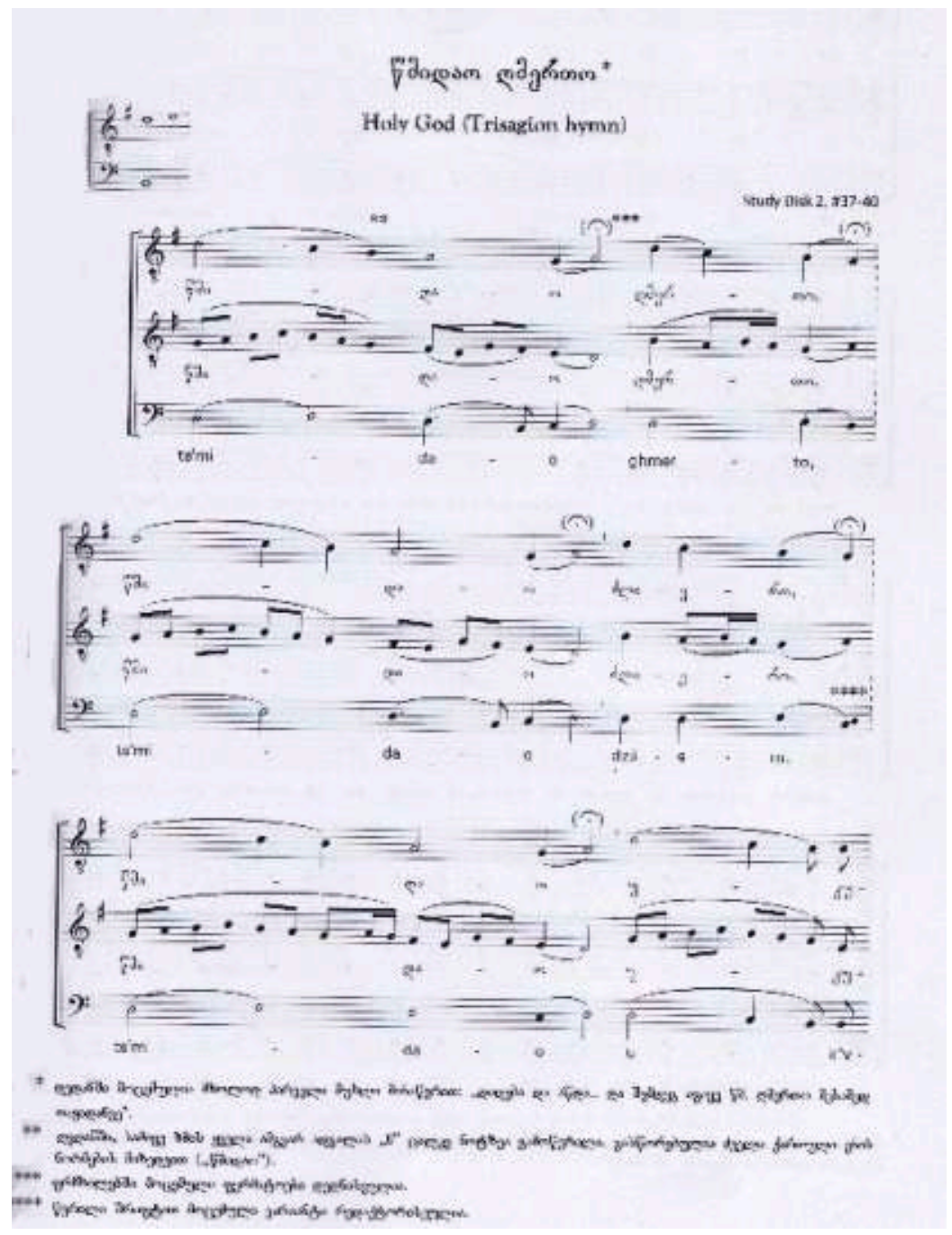

Figure 10. Trisagion; Gelati School (Chkhikvishvilli and Razmadze 2010).

Returning to the topic of the angelic prototype of the Trisagion, while we discussed a theological, hierarchical basis for variants above, one may ask how it practically relates to the many forms sung by human beings. No language or tradition claims to have the original melody or to be concerned with recognizing it. In part, this state of things has to do with the nature of the relationship between icons and prototypes, in which many copies exist, employing various media and techniques, displaying different styles and details, and containing inscriptions in different languages. While questions about literal copying may be difficult to address, we can relate Trisagion variants to their prototype not in the way that an icon relates to its iconographic prototype but to its participation in its theological one, that is, to the depicted person. One may ask, then, where this puts human chanting in relation to that of angels. We have discussed the hierarchical transmission process and begun to analyze some of its results. We can conclude that the outcome is not simple repetition but the creation of hymns, using skills, language, and musical materials accordingly and in co-operation, within the spiritual hierarchical framework. Indeed, an angelic sound may not even be reproducible but only somehow translatable through a multitude of utterances, and angels may have taught translations, providing sonic parallels to the forms in which they appear, which humans can perceive but which are not indicative of their nature (St John of Damascus, Exact Exposition of the Orthodox Faith, Book II, 3). In his aforementioned Celestial Hierarchy, St. Dionysios discusses how and why angels and God are described using symbols, often quite incongruous (2:5), and the great variety of liturgical sounds and 
utterances can be understood as having a similar function. Furthermore, in his Divine Names, he writes that, through "supremely divine hymns", that is, chant, "we are molded to the sacred songs of praise", that is, angelic hymnody (1:3). Chant in the earthly hierarchy, insofar as it is inspired by that of the heavenly, becomes like unto it in a fitting way, which is not in every way bound up with its discernable characteristics. Chant, then, has an apophatic side, in which it is understood to point to incomprehensible sound and experience. Nevertheless, the saint states that we, unlike angels, need symbols, and humans help to create the same, though they are ordained by God and given as "sacred veils of the loving-kindness towards man" (Divine Names, 1:4). It is fruitful; therefore, to fold and unfold sonic symbols, studying all aspects of sacred song.

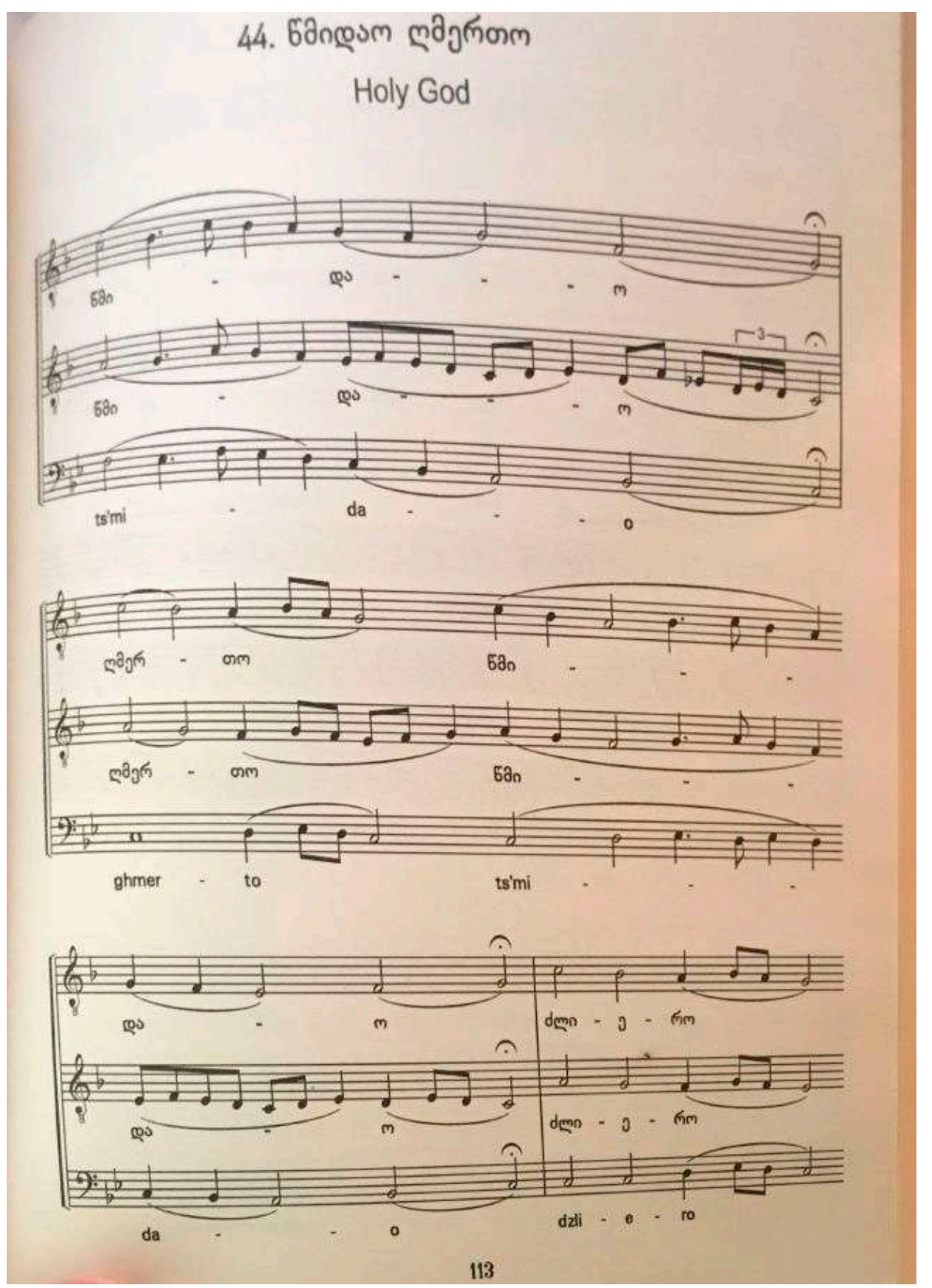

Figure 11. Cont. 


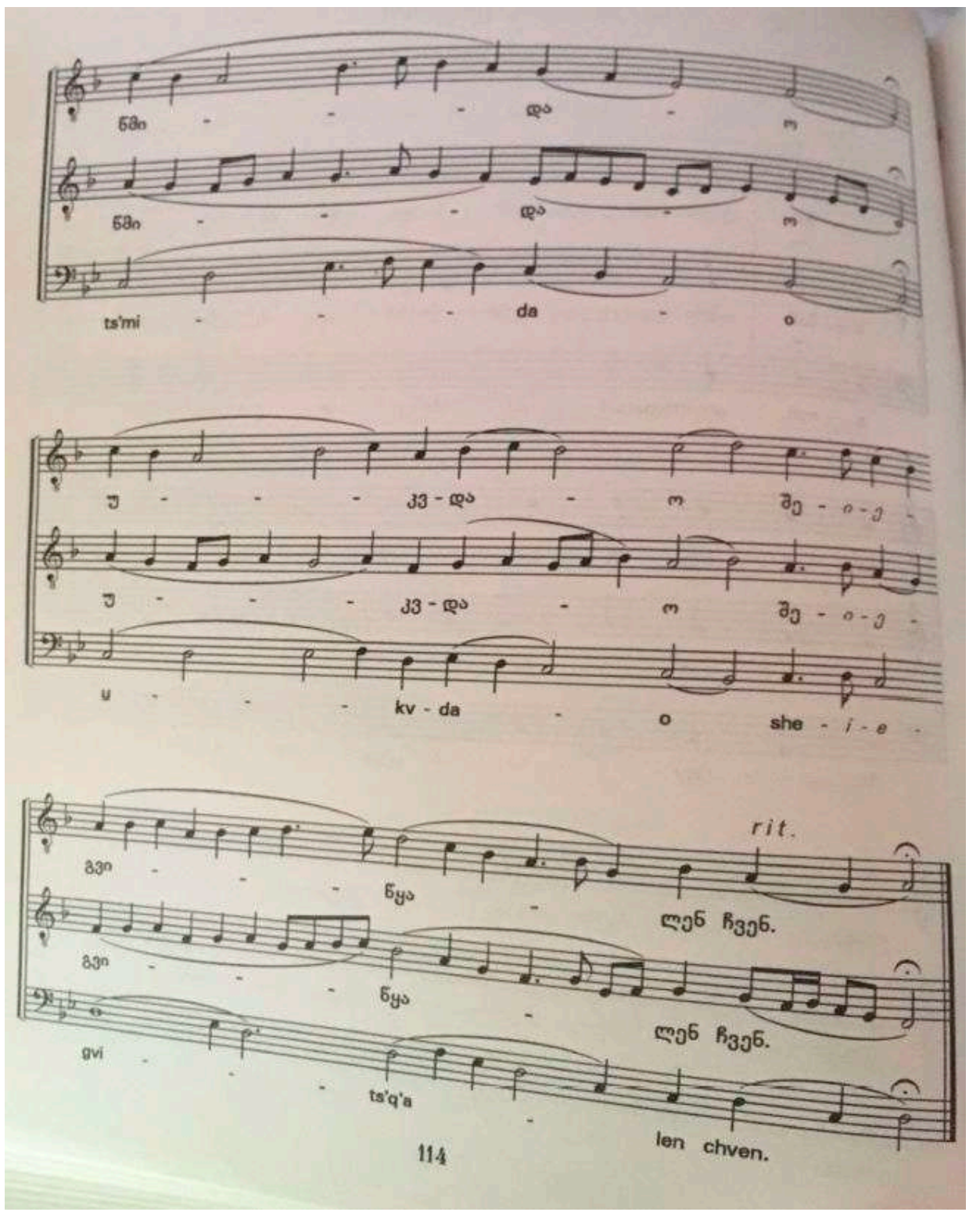

Figure 11. Trisagion; Gelati School (Chkhikvishvilli and Razmadze 2010).

Other patristic works provide further insights on the idea that human and angelic worship are not by all means dissimilar, and St. Dionysios himself specifies that lower hierarchies participate in the characteristics of higher ones but to a fitting degree (Celestial Hierarchy, 4:3), and that every individual participates in God. Near the end of his Celestial Hierarchy, he provides this note: "I might add this not inappropriately, that each heavenly and human mind has within itself its own special first, and middle, and last ranks, and powers, manifested severally in due degree, for the aforesaid particular mystical meanings of the Hierarchical illuminations, according to which, each one participates, so far as is lawful and attainable to him, in the most spotless purification, the most copious light, the pre-eminent perfection" (10:3). 


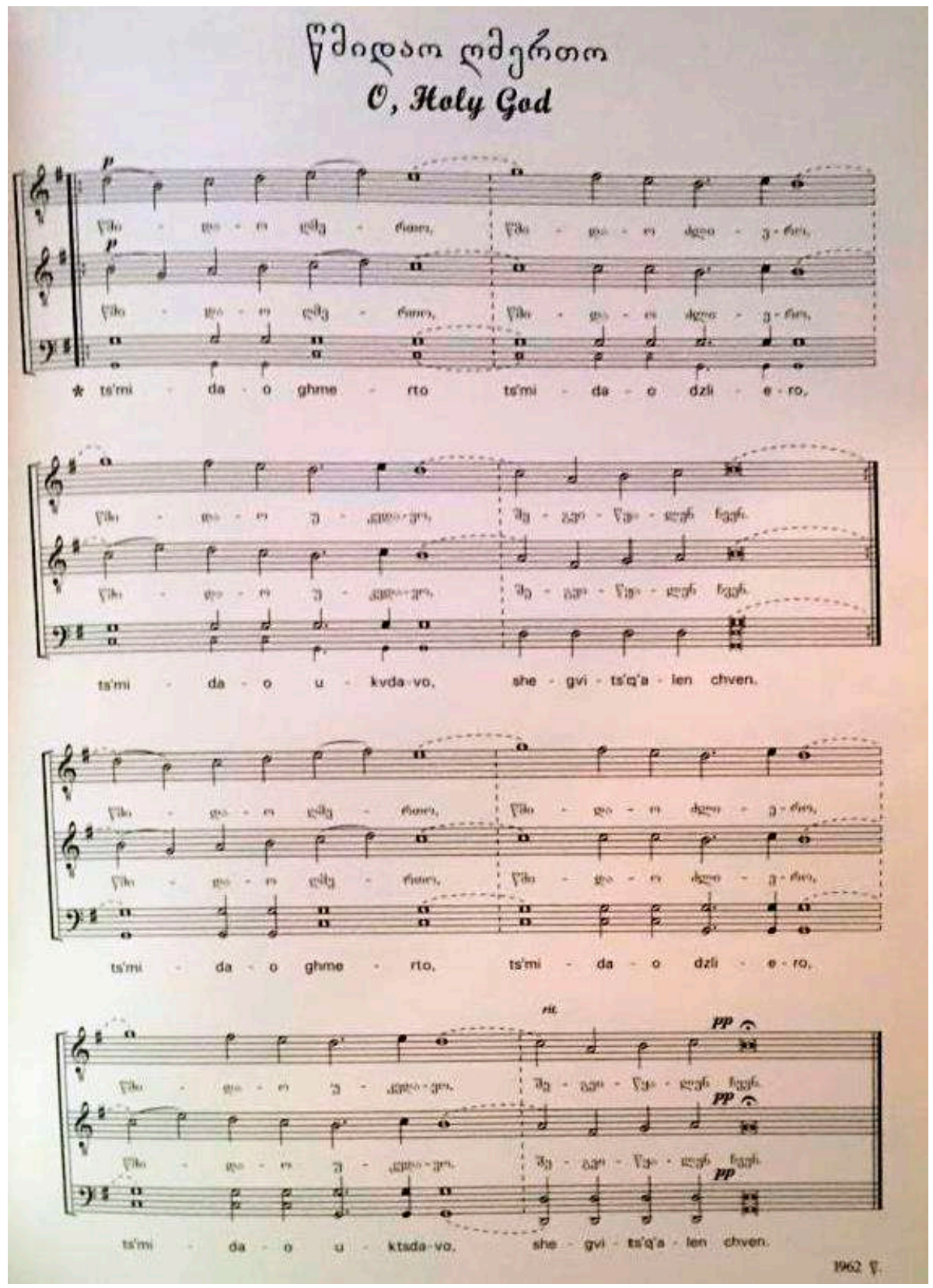

Figure 12. Trisagion; composed by Patriarch Ilia II (Jangulashvili 2013).

Regarding hierarchical participation, St Symeon of Thessalonike (1381-1429) applies the names and qualities of the highest angelic hierarchy-cherubim, seraphim, and thrones-to human beings who bear their characteristics, especially as they pray (Simmons 1984, pp. 9-13); it is understood that such are passed on to, and copied by, the human ecclesiastical hierarchy, monastics, and laypeople. Yet, strikingly, shared angelic and human co-operation also has a reciprocal aspect, and while St. Dionysios describes angels teaching men (Celestial Hierarchy, 4:4), St John Chrysostom states that angels also learn from humans (Homilies on the Gospel of John, II), grace working in synergy with all created beings (Loudovikos 2010, p. 15), with the Holy Spirit directing and inspiring everyone (Hildebrand 1980, p. 64). The forms of the Trisagion help to show this co-operation in practice.

The entire anaphora displays co-operation across all hierarchies, heavenly and earthly, angelic and human, priestly and lay, and the angelic-human relationship clearly occurs in the Trisagion. The first two phrases are the seraphic Trisagion as described by the Prophet Isaiah, while the refrain-like 
"Hosanna in the highest" and third phrase were the children's worship of Christ at His entrance into Jerusalem. Children, to whom the Kingdom belongs, like angels, have an important role in leading worship and, as highlighted in Georgian hagiographic examples, confessing the faith (Lang 1995, pp. 40-43). The second form of the Trisagion hymn, though confirmed in its correct form by angels as mentioned above, was miraculously heard by a child, and it also contains distinctly human praise, as St. Symeon of Thessalonike again describes. He explains that the hymn was composed by the Church Fathers, giving the origin of each word or phrase, including the three "Holy's" from the seraphim, and points out that all other phrases come from the Scriptures, primarily from the Prophet David in the Psalms, and were sung in the Spirit (Simmons 1984, pp. 41-42). He describes how an angel confirmed the form of the hymn to a child when Peter the Fuller attempted to add an element that was deemed to be heretical (Simmons 1984, p. 42), mentioning the importance of children as much as of prophets and demonstrating that angels not only provide hymnography but are understood to confirm the prototypical value of inspired human utterances. Human contributions can; therefore, be easily identified. Even angelic praises, when uttered by human beings, will, like the shouts of the children in first-century Jerusalem, come from particular voices in a particular language and in a particular style and form. Along this line, St Symeon also interprets instances when the Trisagion is sung "with melody" as symbolizing the Gospel being preached and filling the whole world (Simmons 1984, p. 38). Thus, as in preaching, a word or prototype leads to ever-increasing and varying expressions, covering the entire linguistic and associated sonic and cultural scope. Besides angelic and human co-operation in the Spirit, the Incarnation, Resurrection, and process of deification have implications for the nature of chant, which we will further reflect upon in the conclusion of this study. St. Dionysios explains that chant teaches us, constitutes worship, and, like all other aspects of hierarchy, helps to make the work of Christ effective, in the following passage from the Divine Names:

"You will find all the sacred Hymnology, so to speak, of the Theologians arranging the Names of God with a view to make known and praise the beneficent progressions of the Godhead. Hence, we see in almost every theological treatise the Godhead religiously celebrated, both as Monad and unity, on account of the simplicity and oneness of Its supernatural indivisibility from which, as an unifying power, we are unified, and when our divided diversities have been folded together, in a manner supermundane, we are collected into a godlike unit and divinely-imitated union; but, also as Triad, on account of the tri-personal manifestation of the superessential productiveness, from which all paternity in heaven and on earth is, and is named; also, as cause of things existing, since all things were brought into being on account of Its creative goodness, both wise and good, because all things, whilst preserving the properties of their own nature unimpaired, are filled with every inspired harmony and holy comeliness, but pre-eminently, as loving towards man, because It truly and wholly shared, in one of Its Persons (subsistences), in things belonging to us, recalling to Itself and replacing the human extremity, out of which, in a manner unutterable, the simplex Jesus was composed, and the Everlasting took a temporal duration, and He, Who is superessentially exalted above every rank throughout all nature, became within our nature, whilst retaining the unchangeable and unconfused steadfastness of His own properties. And whatever other divinely-wrought illuminations, conformable to the Oracles, the secret tradition of our inspired leaders bequeathed to us for our enlightenment, in these also we have been initiated; now indeed, according to our capacity, through the sacred veils of the loving-kindness towards man, made known in the Oracles and hierarchical traditions, which envelop things intellectual in things sensible, and things superessential in things that are; and place forms and shapes around the formless and shapeless, and multiply and fashion the supernatural and formless simplicity in the variedness of the divided symbols; but, then, when we have become incorruptible and immortal, and have reached the Christlike and most blessed repose, according to the Divine saying, we shall be "ever with the Lord", fulfilled, through all-pure contemplations, with the visible manifestation of God covering us with glory, in most brilliant 
splendors, as the disciples in the most Divine Transfiguration, and participating in His gift of spiritual light, with unimpassioned and immaterial mind; and, even in the union beyond conception, through the agnostic and most blessed efforts after rays of surpassing brilliancy, in a more Divine imitation of the supercelestial minds. For we shall be equal to the angels, as the truth of the Oracles affirms, and sons of God, being sons of the resurrection. But now, to the best of our ability, we use symbols appropriate to things Divine, and from these again we elevate ourselves, according to our degree, to the simple and unified truth of the spiritual visions; and after our every conception of things godlike, laying aside our mental energies, we cast ourselves, to the best of our ability, towards the superessential ray, in which all the terms of every kind of knowledge pre-existed in a manner beyond expression, which it is neither possible to conceive nor express, nor entirely in any way to contemplate, on account of Its being pre-eminently above all things, and super-unknown, and Its having previously contained within Itself, superessentially, the whole perfections of all kinds of essential knowledge and power, and Its being firmly fixed by Its absolute power, above all, even the supercelestial minds. For, if all kinds of knowledge are of things existing, and are limited to things existing, that, beyond all essence, is also elevated above all knowledge" (Divine Names, 1:4).

In this remarkable section, we see that the Incarnation makes all hymnography and symbols grounded and efficacious in the first place and not simply that such things exist in order to make the truth known. Additionally, symbols, including chant, elevate worshipper, making them "equal to angels", as St Maximos also stated. However, the divine is beyond all symbols, yet the same act as steps towards union with Him. The saint points out that we use symbols now but that we will have a completely changed, positive experience of God after the Resurrection. Until then, chant has a particular role in preparing for and pointing to the Kingdom, in which it will become something incomprehensible as those who sing and listen "become incorruptible." We will now continue to explore the sonic characteristics of Georgian variants and their theological symbolism, looking at some of the "shapes and forms" and "things sensible", which make up chant at least as much as lexical content.

\section{Interweaving and Varied Expressions of Hierarchy: Multiple Aesthetics in Harmonization, Counterpoint, and Ornamentation across Region, Time, and Mode}

Let us now explore the hierarchical relationship of the three voices in Georgian chant examples. The lower voices assimilate the model melody in a wide variety of ways, in part according to chanters' aesthetic choices regarding harmony and its related contrapuntal rhythm and types of movement. In place of common descriptions of contrapuntal motion (e.g., oblique and contrary) our analyses will employ geometrical terms. ${ }^{24}$ We begin with two contemporaneous plain mode forms of the prototypical hymn, whose first phrases were added by the Archangel Gabriel, 25 "It Is Truly Meet", as transcribed by the chanters Ss. Razhden Khundadze and Ekvtime the Confessor *** (Figures 13 and 14).

In the first variant, the second voice primarily employs simple translation of the model pattern, giving rise to parallel thirds. Reflection occurs in the bottom voice, especially at cadences, and its movement in the opposite direction leads to intersection with the other voices to form a unison. The hymn is based on the iteration of two formulae, the first of which ends on a unison and the second, on

24 We will use terms that are used to describe the relationship of shapes to one another, including iteration, translation, and reflection, in analyses of contrapuntal movement and relationships. Additionaly, note that chords can be mapped within a non-Euclidian structure called an orbifold (Tymoczko 2006), signifying that Georgian polyphony is a folded, hierarchical entity not in a merely metaphorical sense. Melody, harmony, and counterpoint can all be analyzed and understood in geometrical terms, which are especially useful for repertoires where Schenkerian analysis is not relevant (Tymoczko 2010).

25 While published synaxaria contain the story for the relevant feast day (11/24 June), it can also be found on the website of the associated cell, which still houses a monastic community: http://www.keliaxionestin.com/eng/?page_id=760. 
a triad. The final formula; however, which includes intersection and voice-crossing in the upper two voices and more active top-voice rhythm, renders the unison a step lower.

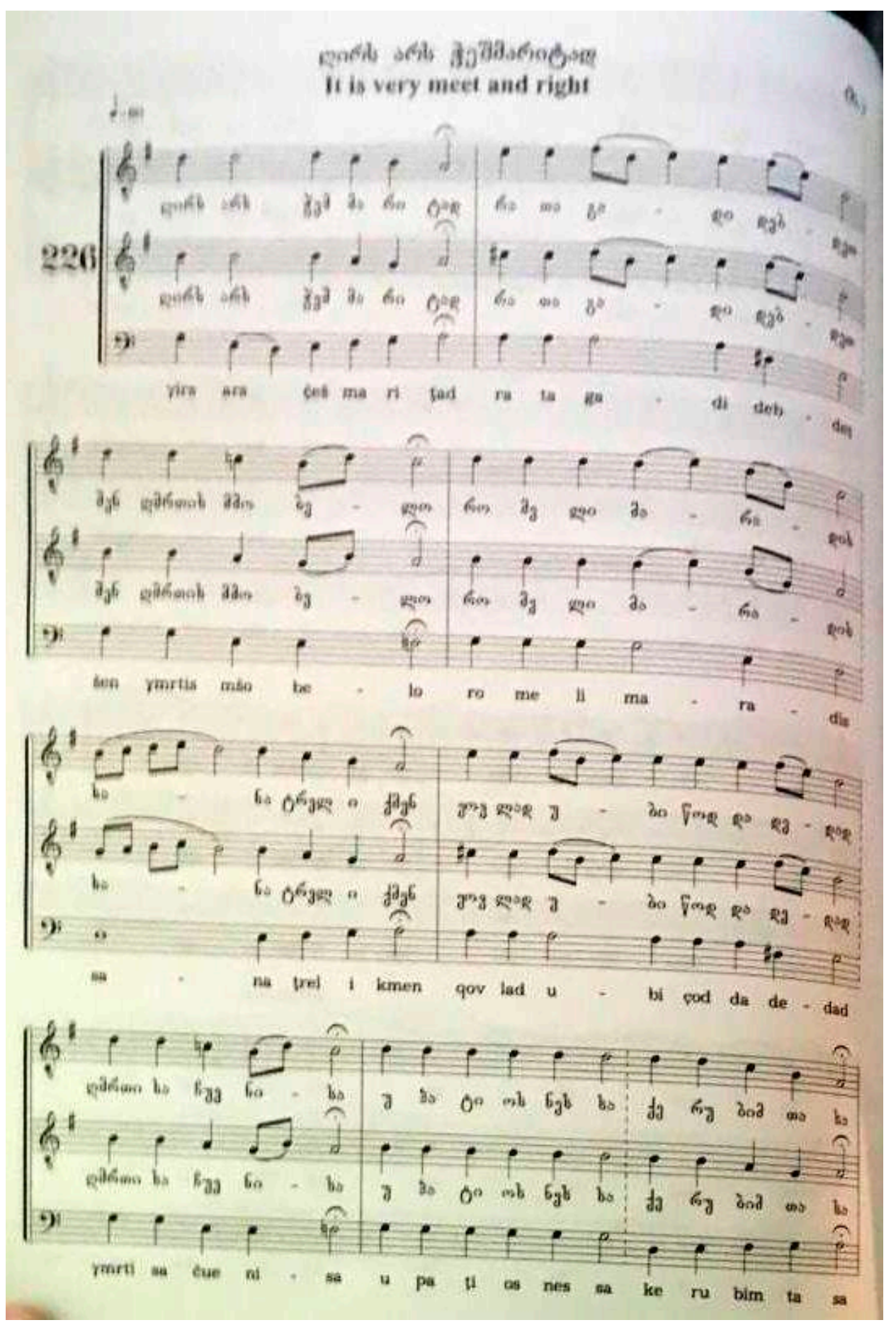

Figure 13. Cont. 


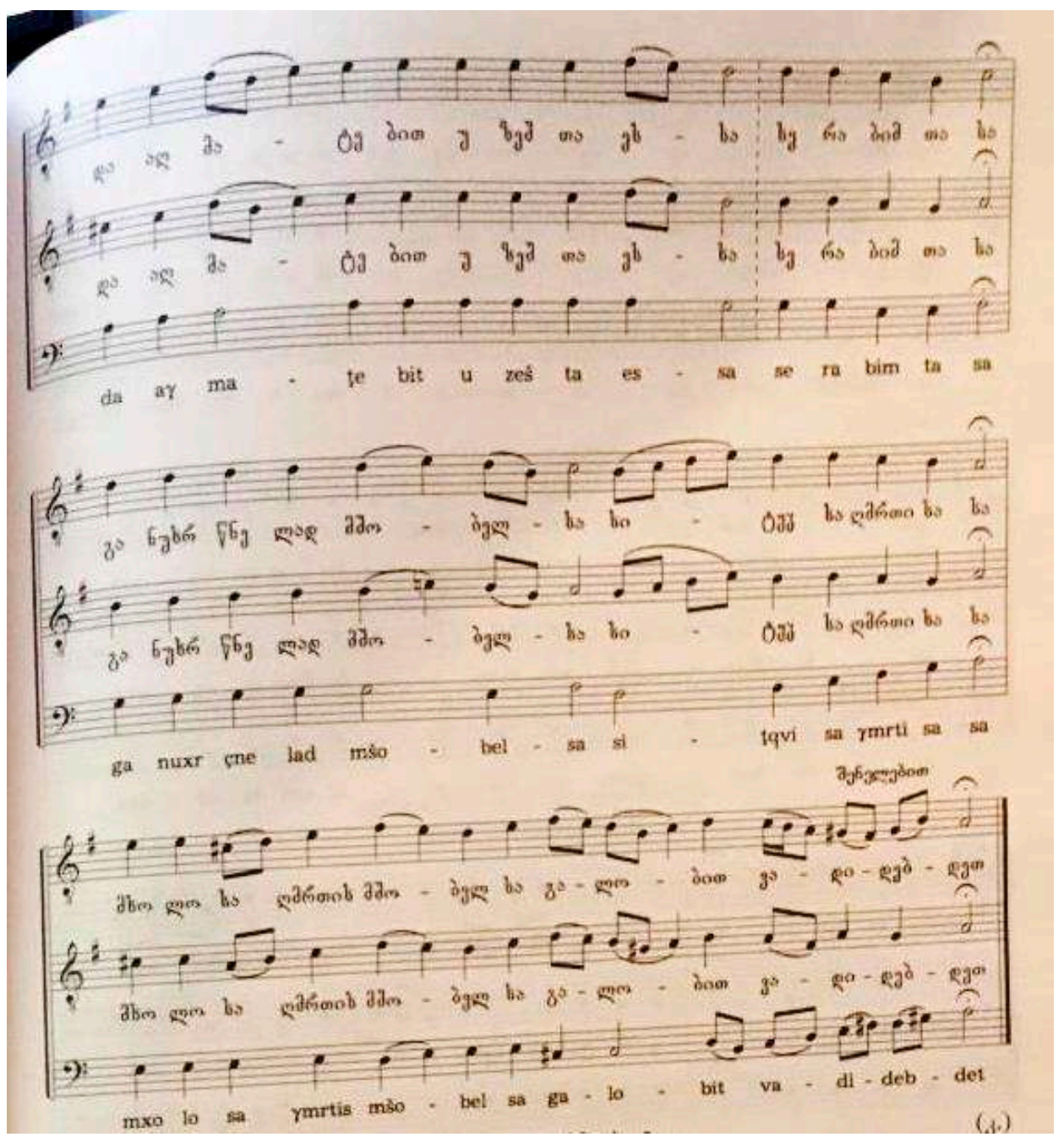

Figure 13. It Is Truly Meet; Gelati School (Erkvanidze 2004).

St. Ekvtime had strikingly different preferences, and the two saints even documented their disagreements in notes to each other in manuscript margins (Graham 2012); one is reminded of Dionysian incongruity. Translation of the model melody does not occur to the same degree and not only in the second voice. Second-voice parallel thirds only occur notably in the initial phrase. Rather, translation often occurs among the two lower voices, which remain on the same pitches while the top voice moves around its central pitch. For short durations, the bottom voice does translate the model, such as the beginnings of the second-formula phrases, creating parallel octaves. At other times, all three voices sing a static pitch in translation as they declaim text. Reflection occurs between the top two voices, such as at "romeli maradis", and while rhythm is often parallel, the top and bottom voices have mixed and active interaction, leading to the internal unisons. At the ends of phrases, the third voice has a characteristic rising, scalar, rhythmic figure, which successively translates and reflects the model's final three pitches. However, the second of these pitches does not occur in all variants and may be understood as ornamental. Therefore, the top voice has a permutation, in turn translating and reflecting the more active rhythm and the final three pitches of the characteristic bottom-voice cadential gesture while passing between the model melody notes. Thus, the top voice can embrace the characteristics of others, and, as we saw previously, translation of a supporting gesture, rather than of the model, can occur in the lower voices. We also saw that either voice may translate or reflect material from the model phrase, and intersection and union is the goal. 


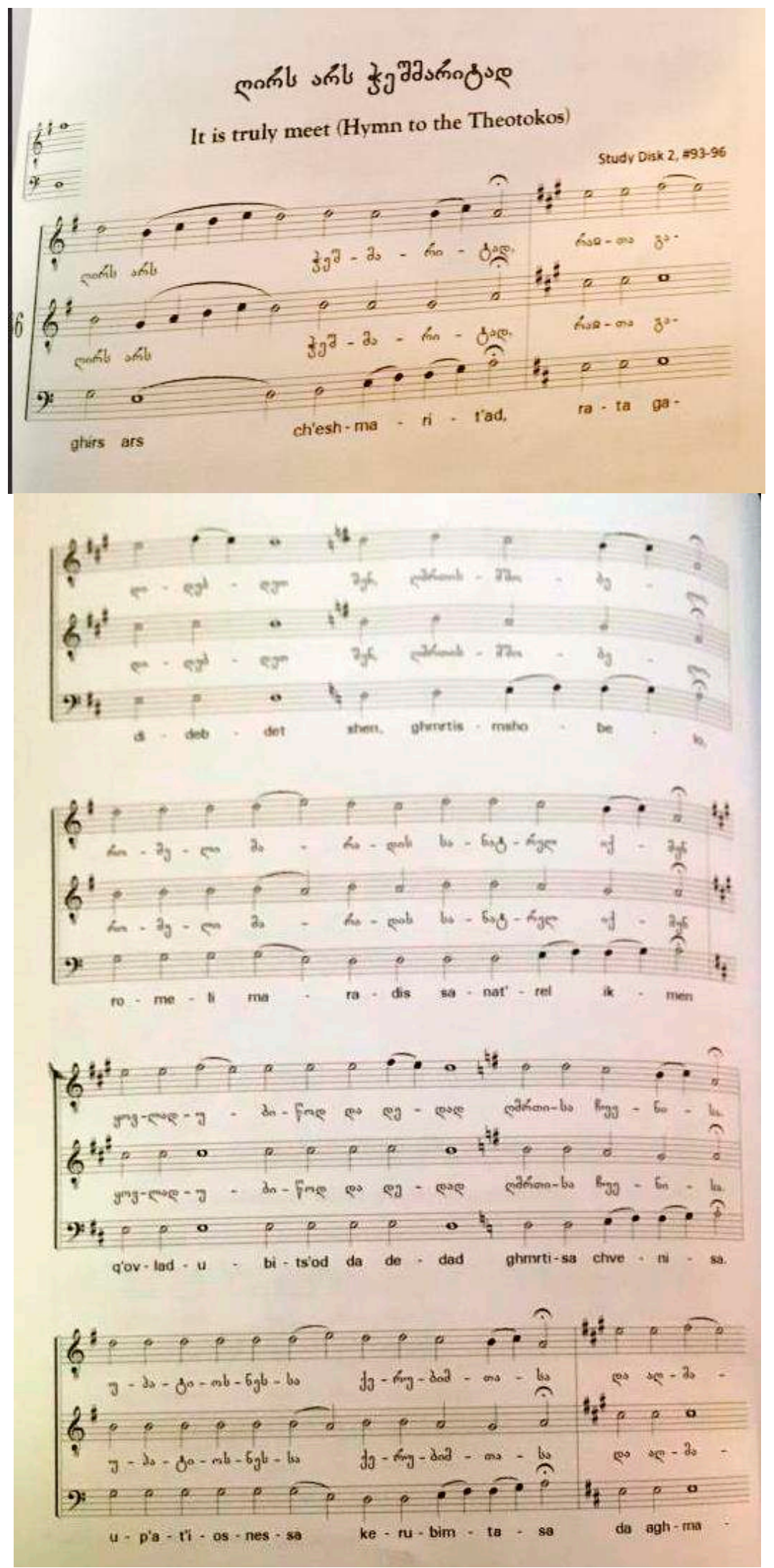

Figure 14. Cont. 


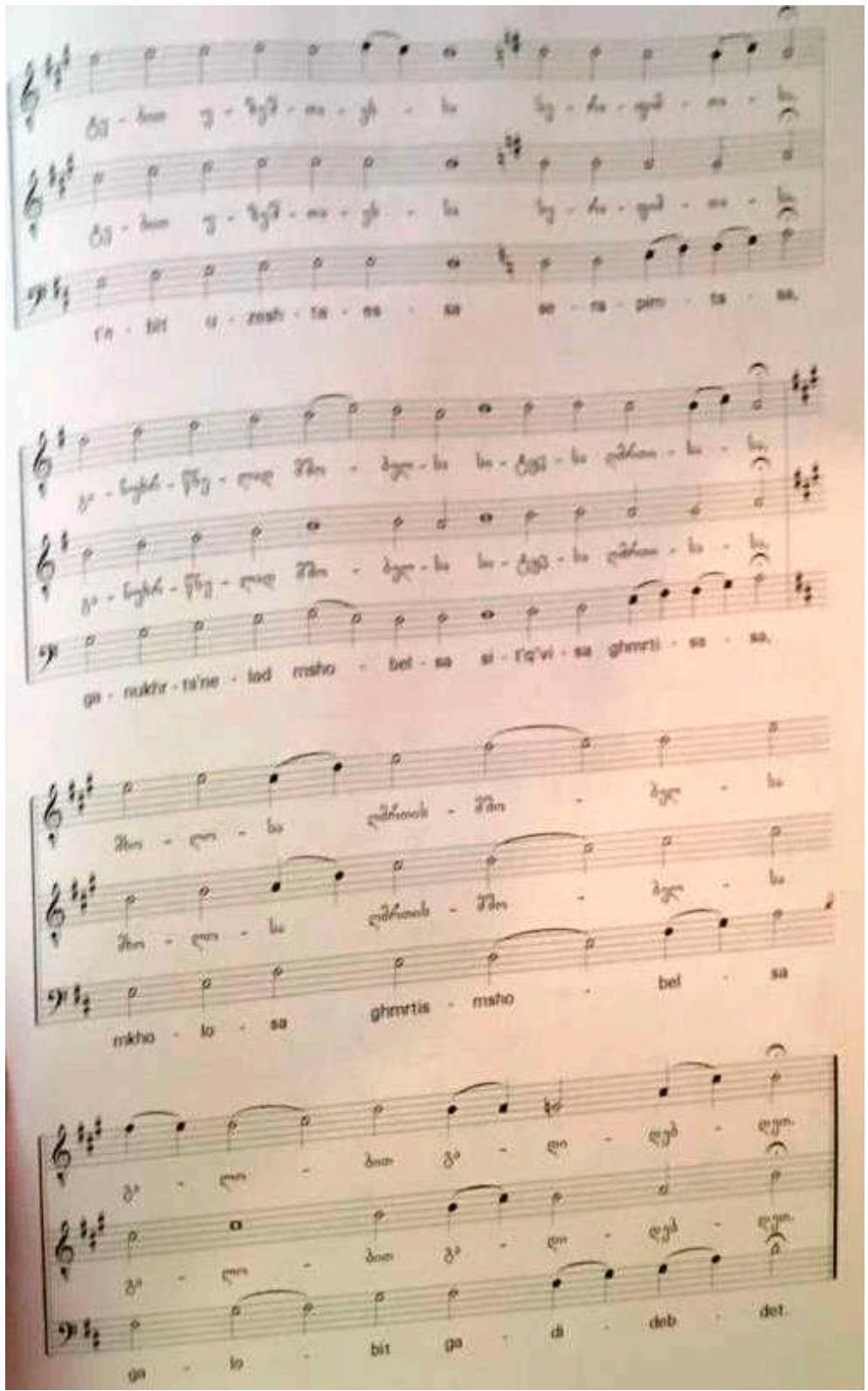

Figure 14. It Is Truly Meet; Gelati School (Chkhikvishvilli and Razmadze 2010).

Harmonic and contrapuntal preferences work in synergy and affect each other, for instance, the like or dislike of parallel thirds or use of particular bottom-voice gestures and octave interaction with the top voice. Given the hierarchical function of the model melody and the prototypical principles of chant, the model need not even remain in the top voice as hinted at by the final phrase voice crossing. In Western Georgian chants in the ornamented mode, as we will see in the next section, a great deal of crossing occurs, with little parallel translation, and the model melody sometimes passes between voices or acts as a reference in the minds of chanters, who create and interweave on its foundation. We will view this and other aspects of the Georgian chant hierarchy as we explore ornamented examples, but we will also see it in a somewhat later Western Georgian variant. ${ }^{26}$ 
This Shemokmedi school variant (Figure 15) was recorded by the Gurian chanter Artemi Erkomaishvili in 1965, and we will explore his ornamented style in more detail later in the following section. However, at this point, we include this example in order to highlight some particular harmonic aesthetics in later Shemokmedi variants. One outstanding feature is stacked parallel fifths (i.e., successive 1-5-9 chords), such as at the beginning of the second phrase. While some consider this type of harmony to be archaic, it occurs primarily in these later variants. While it may reflect the aforementioned "study voices", there is nothing that is by nature archaic about any given type of harmony, despite the trajectory that documented polyphony took in medieval Western Europe, and the affinity of the complex polyphony with Gurian folk songs does not indicate age, either, ${ }^{27}$ since it is difficult to date examples; Jordania's research indicates that new and old styles of polyphony co-exist in Eastern Europe, most Georgian music falling under the "old" characteristics (Jordania 2011, p. 24). What these features do demonstrate is the improvisatory element of the style, its parameters, and chanters' familiarity with the materials and techniques at their disposal. Thus, parallel 1-5-9 chords, voice crossing, and ornamentation work inside the same basic structure seen in the plain mode renderings, with its beginning, ending, and alternating medial phrases, and with the unison cadences of the St. Ekvtime variant. For example, the model melody passes between the top two voices when the middle voice crosses and takes it up at the beginning of alternating phrases. Thus, the alternation of melodic formulae is further diversified by voice crossing, not only in expected cadential gestures or ornamentation in the middle of a phrase, but at the outset. Voice crossing is guided by certain other features, such as the unison four-note figure at the lower unison cadences, as opposed to only sharing the final pitch. Crossing also makes room for certain kinds of ornamentation, such as the top voice's figures on the word "galobit" ("with a hymn") in the last phrase. Therefore, there is a kind of counterpoint of harmonic, melodic, and ornamental elements. Before we fully discuss Western ornamentation, let us look at an earlier Eastern variant of this same chant (Figure 16), ${ }^{28}$ transcribed by the Karbelashvili brothers in the late nineteenth century.

Besides different contrapuntal interweaving than Western plain mode variants, this example displays even expansion throughout, making room for ornaments, some of which also have a functional role. The model melody and overall homorhythmic structure match the plain mode Western counterparts. Note that there is no voice crossing, which is a primary feature of Western ornamented chants. The ornaments are of five main types: The singing of consonants, that is, liquescence in Latin terminology; ascending ornaments in the middle voice; another middle-voice passing gesture, the successive decoration of pitches with adjacent upper and lower neighbors, usually moving towards a cadence (e.g., the last syllable of "gadidebdet"); a transitional descending figure in the lowest voice; and a second transitional motif, which ascends in the second voice, which arrives on the held model melody's note, and descends in the third voice, creating a reflection. The middle voice has other types of ornamental movement as well, some of which reflect each other (cf. the last syllable of "gadidebdet" and that of "deda"). In the two cadential figures, the model melody does not participate in their formation but provides them with a surface. They coincide with the two alternating cadence types in the Western variants and are slightly expanded interpretations of phrase endings that indicate continuation, which are often fifths as opposed to a final unison. Thus, there is a greater variety of ways to form internal cadences through decoration and movement, new ways of delineating structure rather than only enlarging and adorning it. Though this variant adheres to Eastern chant characteristics, it is noteworthy that the rising figures in the more active middle voice are similar to those in Western variants, and reflexive gestures across voices occur across schools, though with different functions as our examples show. In this variant, they are cadential transitions, while in Western chants, they often take place at the beginnings of phrases and lead to unison intersections among, or climax distances

27 Graham, personal communication, 30 August 2016.

28 http://www.alazani.ge/base/AnchiskhatiK/Anchiskhati_-_Girs_Ars.mp3. 
between, voices. We will note instances of these features in the following section. Therefore, decorative and contrapuntal elements are employed and embodied in various ways, and prototypical principles lead to a wide diversity in practical application. Prototypes can be understood as beyond tangible, as so dense that they can be unfolded in an innumerable multitude of ways. Unfolding can also occur on a larger scale, revealing newer and more extensive types of ornamentation and interaction in the ornamented mode.

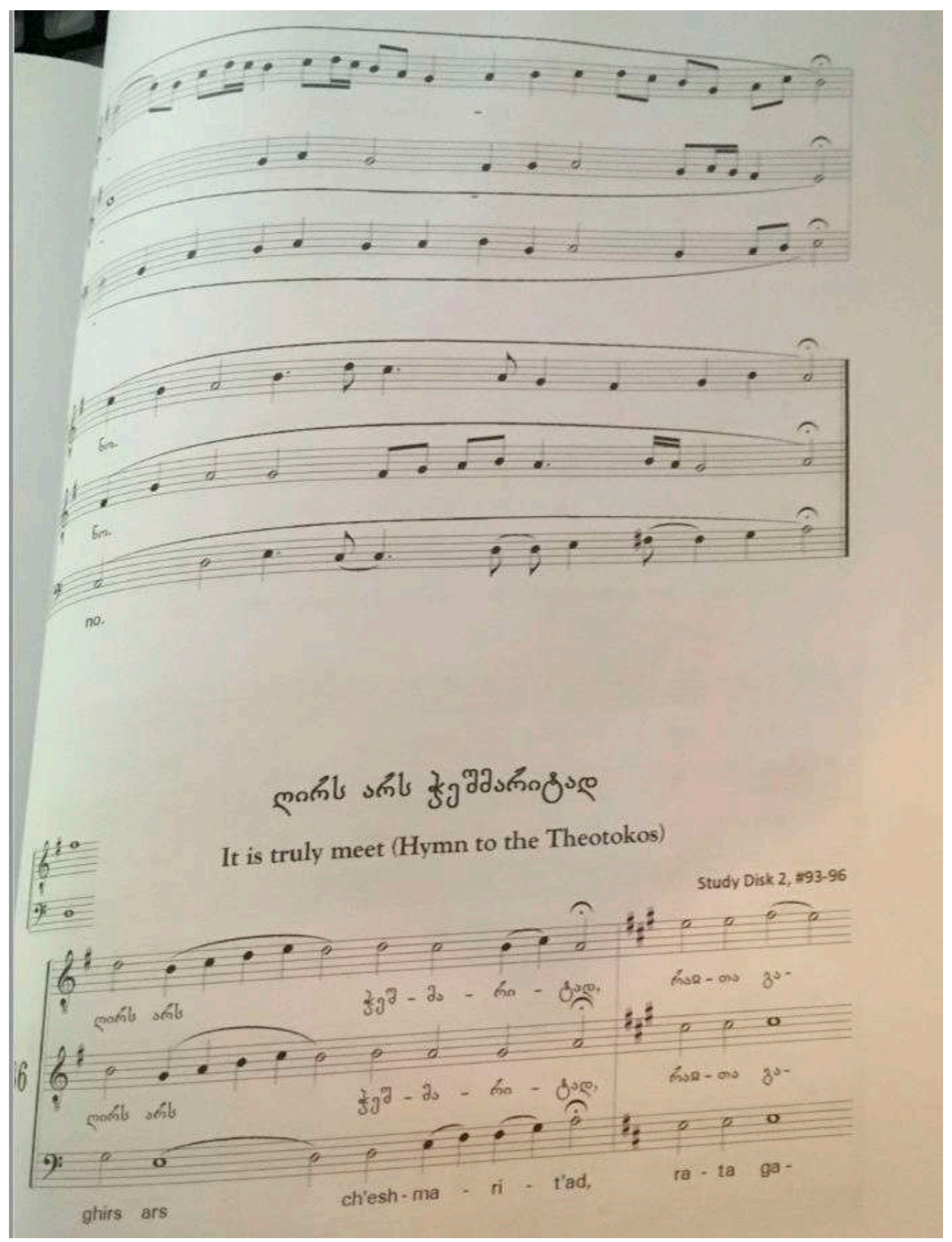

Figure 15. Cont. 

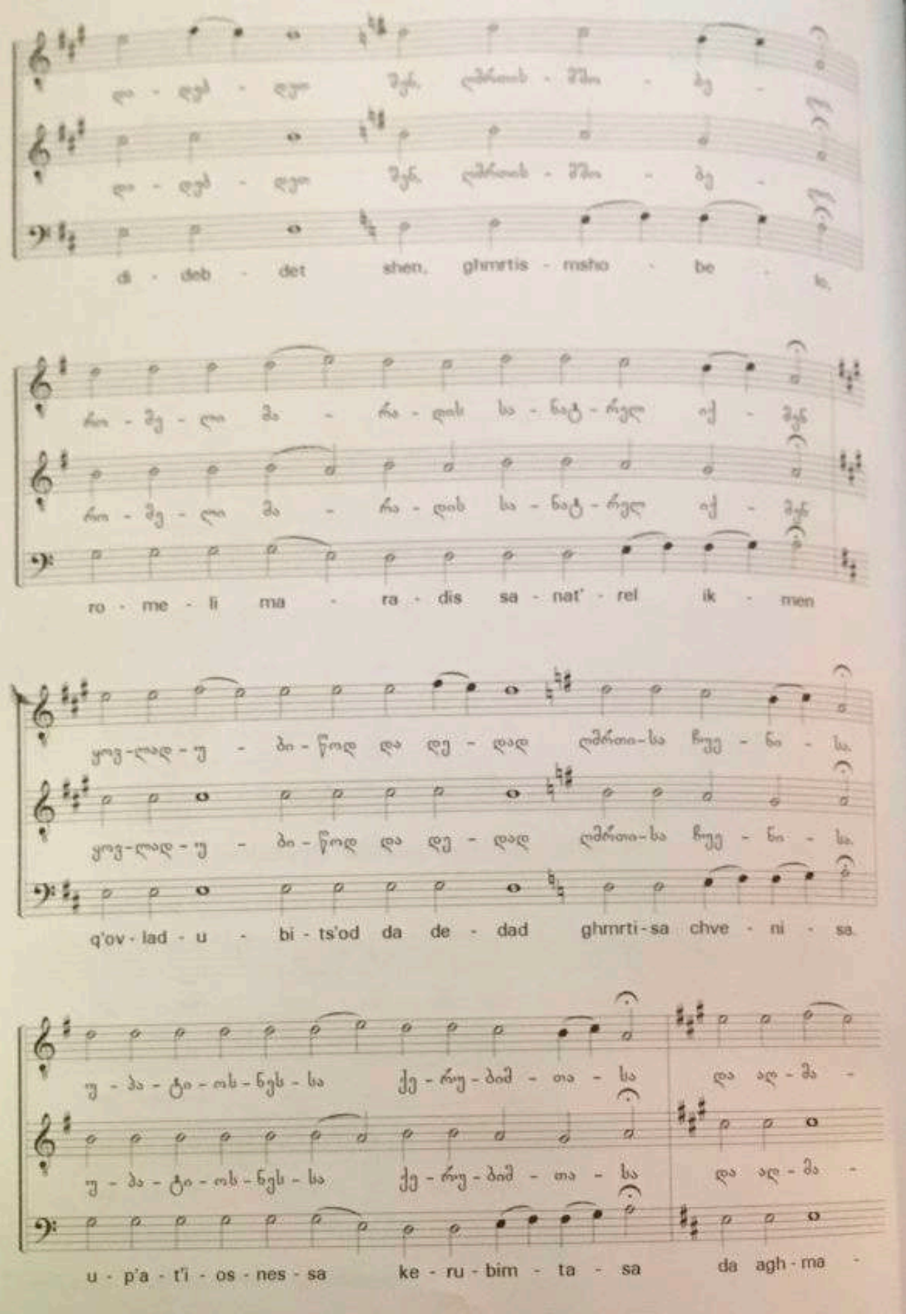

Figure 15. Cont. 


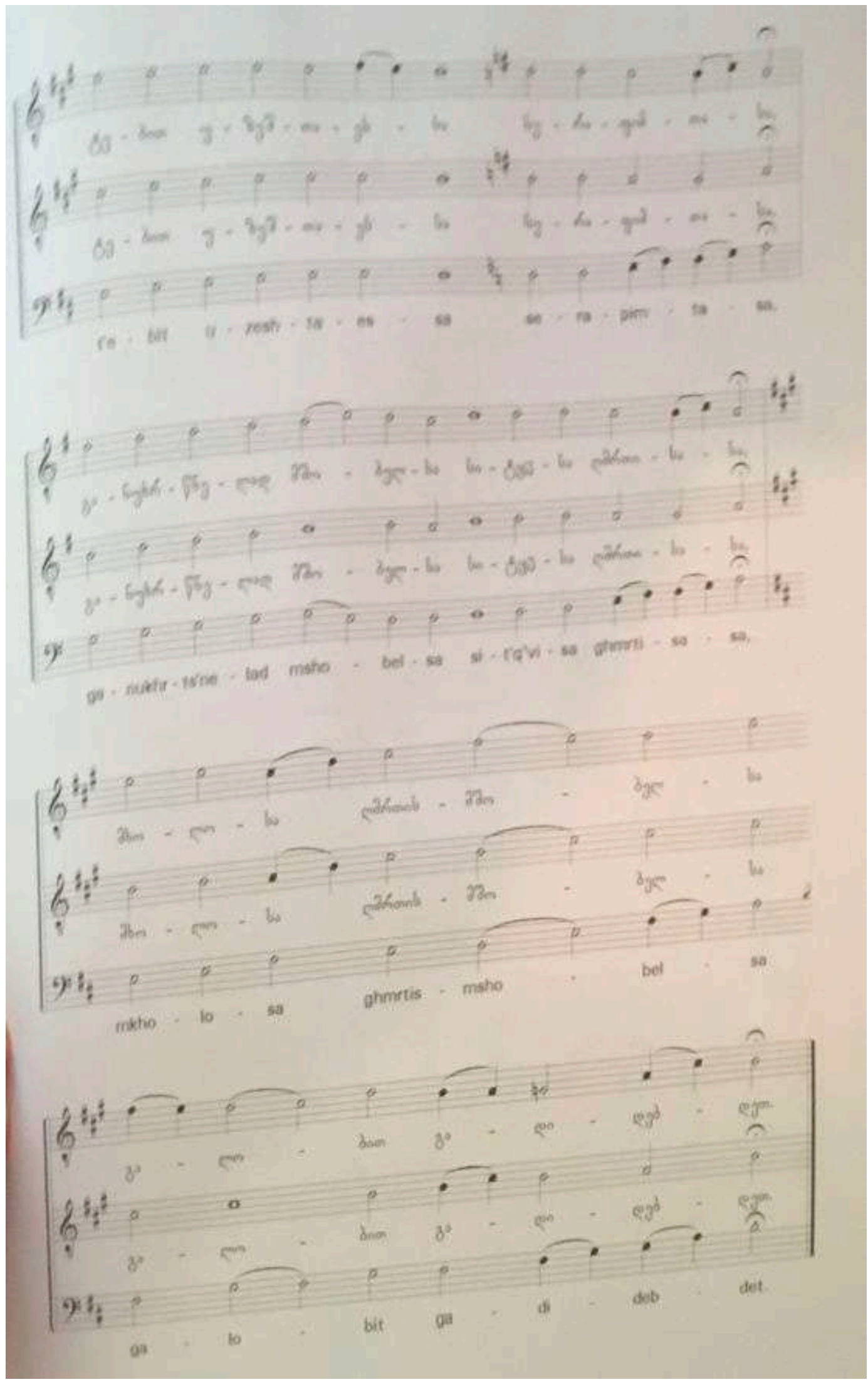

Figure 15. It Is Truly Meet; Shemokmedi School (Shugliashvili et al. 2014). 


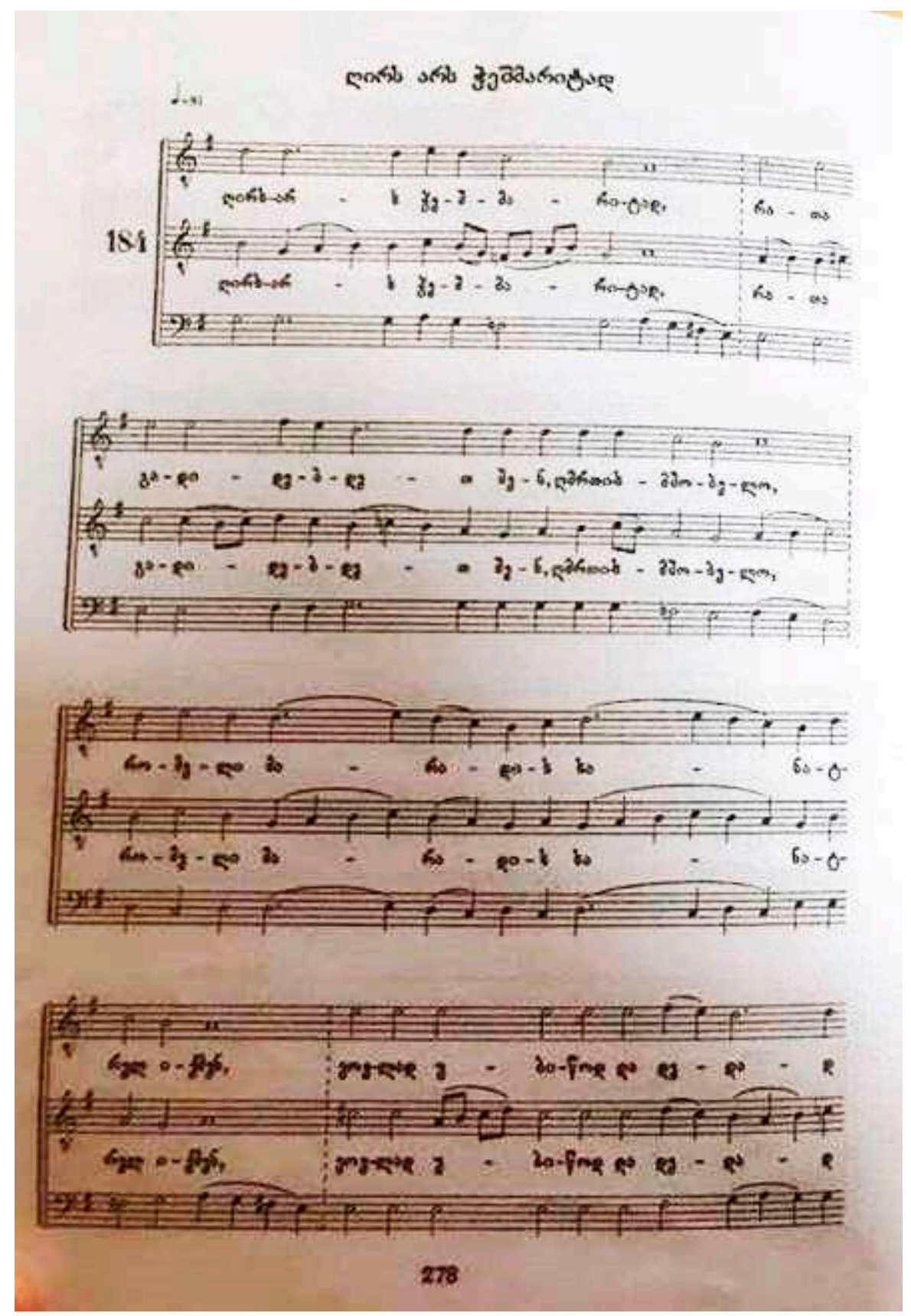

Figure 16. Cont. 

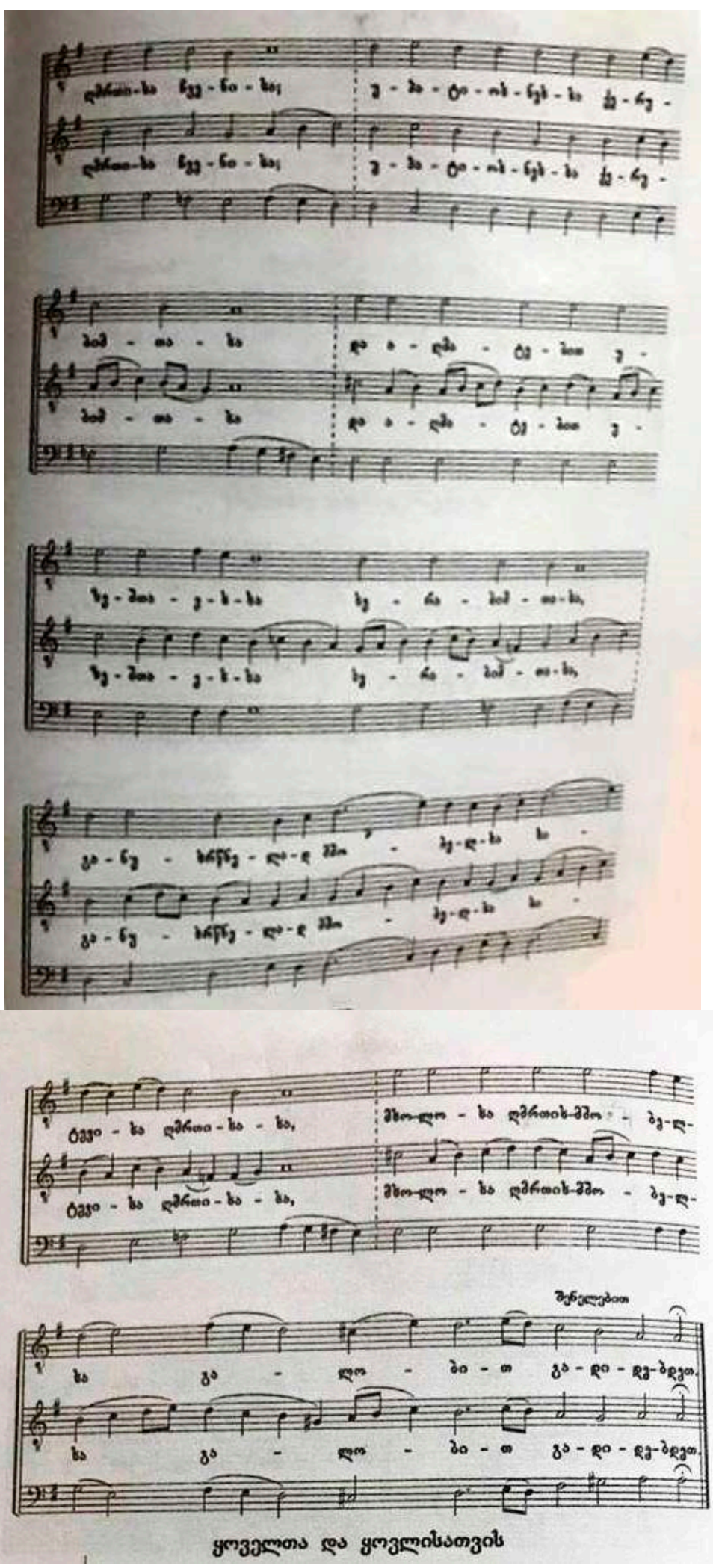

Figure 16. It Is Truly Meet; Svetitskhoveli School. 


\section{Unfolding and Adorning: Expansion and Ornamentation in Chant Variants and New Compositions}

Like the three voices, the three styles of Georgian chant form a hierarchy. The plain mode is the first power, from which the two successively more complex and diverse modes are unfolded and adorned. Additionally, as discussed regarding prototypes, in the hierarchy that contains text, model melody, and three-part rendering, text also plays a role in directing expansion through reiteration of pitches and formulae. We will focus on types of expansion that do not depend on chant texts, though some include the addition of vowels, syllables, and sometimes entire word repetition. Subtle expansion and decoration occur even in plain mode chants, and such is hierarchically necessary. The plain and true modes furnish variants that elegantly display motifs and types of ornamentation in contrast to the surrounding recitational style, as textures in higher relief. We will now examine anaphoral chants with higher degrees of expansion and complexity of decoration.

The chants of the anaphora share a significant amount of musical material and not only in the setting of repeated texts, such as the confession of the Trinity. Let us unfold a recurring passage in a setting transcribed by St. Ekvtime the Confessor. It forms the expanded and decorated endings of four chants, one preceding the Creed and three responses in the anaphoral dialogue. All begin with the simple recitation of most of the text. One of these responses includes a Trisagion (Figure 17), and unlike the form sung earlier in the Liturgy, Georgian anaphoral variants do not generally employ a wide variety of structures. Instead, they declaim the text simply, usually with one or two medial cadences, until the expanded final ending, which is usually on the seemingly unimportant postpositional "shina." Thus, the musical structure itself is significant aside from the text, having a cadential, aesthetic, and symbolic role. In anaphoral chants, it generally occurs on the final two syllables of the respective texts and can be analyzed in two sections. The first contains several smaller units, the first one outlining the final cadential pattern in the top voice, and then moving around a key note a step above the final note. The next segment continues to focus around this same note and can be divided into two primary phrases. The first of these can be further divided into two six-beat units and the third, into three eight-beat units and the final unison note. The first phrase can also be understood as a twice-iterated, four-note figure, preceded by the first recitational pitch and concluded with a descending gesture. The model melody "sings around", to use the Georgian term Sukhiashvili 2014a, p. 422), the key note in the first two phrases and does the same with the final in the third. This first key note is also the second of the two recitational pitches in the preceding phrases, leads into the first major cadence, which is a fifth but nevertheless has the final note in the top voice, and acts as a sort of impetus for cyclical repetition of concentric, looped elements, hence "singing around." It functions like the renewed turning of a spindle in its rotations, and internal cadential fifths act in a similar way but give a greater sense of rest. The elongated rhythm and new central note in the last phrase both signal the end of the chant, and in practice, a ritardando amplifies and accompanies these features. The first major cadence in the chant, at "uplisata" and repeated at the beginning of the expanded passage, acts like a seedling and anticipates the final ending, the model melody moving around and approaching the same final note with the same two pitches but in reflected order, over more syllables, and in a more compact rhythm. The decorative passage expands, adorns, and fulfills the cadential form. 


\section{farcos sink, faros sml}

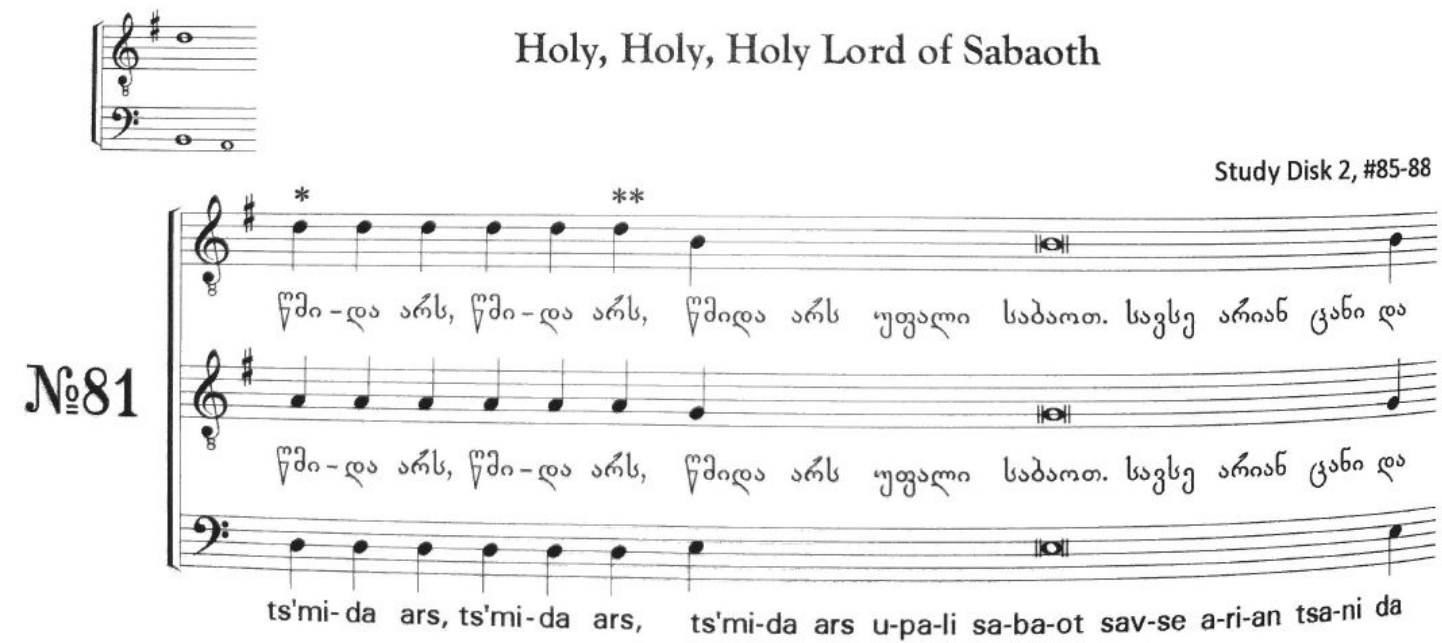

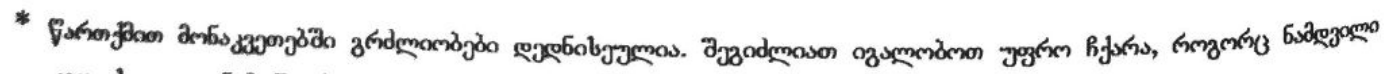

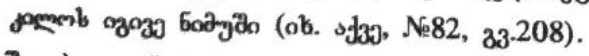

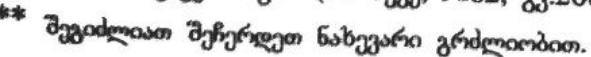

Figure 17. Holy, Holy, Holy; Gelati School (Chkhikvishvilli and Razmadze 2010).

Counterpoint and harmony add further elements as the other voices form their own patterns in order to assimilate the elliptical movement of the model melody. For example, at the end of the first section, while the top voice remains on its key note, the middle voice anticipates another important pitch, the note below the final, which is sometimes a resting point. It highlights this note with a typical "singing around" gesture before descending to the cadential note. The top voice nevertheless also moves to this resting pitch once the middle has finished decorating it, forming a unison intersection, and it continues the faster rhythm of the decoration on its descent, translating it across time. This voice may be perceived as participating in and extending the ornament, and simultaneously, the middle voice decoration may also be inspired by the upcoming active descent in the model melody, thus anticipating it with such an ornament. After this phrase, at the repeated four-note motif in the top voice, the middle voice translates the general melodic direction with a two-note, descending gesture, forming a zig-zag in contrast to the top voice loop. The top voice joins this figure's resting pitch again as it descends two adjacent pitches beyond the key note after its second motif, similar to its movement in the preceding phrase, but with expanded, less rapid rhythm, in part since it is not following an accelerated ornament in the middle voice. For the first iteration of the same motif, the bottom voice reflects the middle by ascending a step, but then, reflecting both upper voices and at a greater distance, it moves down a third, coming to rest, and providing a foundation for the middle and top voices to reach their shared cadential pitch in succession. The shifting harmonization of the same top-voice motif gives a sense of return, yet combined with change, somewhat like a spiral. In the next phrase, all voices begin by translating the ascent of a step, and then a characteristic type of climax occurs, in which the top voice moves up to the usual higher reciting pitch while the bottom primarily reflects it, descending to its lowest note in the entire chant before making its cadential rising figure. At this same point, the middle voice sings a three-note ascending figure, translating the top voice, followed by the descending reflection of that same figure in order to arrive at the usual cadential note, shared with the third voice a fifth below the first. The final phrase displays interaction like that in the above second 
variant of "It is Truly Meet", but it is more rhythmically drawn out. The top two voices reflect each other in order to meet at, and then move away from, the final note before then meeting again, crossing, and reaching the final unison and intersection of all three voices. The top voice sings around the final, and after descending to its lowest note it approaches the unison. It first sounding the earlier resting pitch a step below, followed by the recitational note a step above, ultimately reaching the final itself. This figure, made up of approaching gestures from both directions, is common at final cadences, as is the voice crossing that simultaneously occurs. The middle voice holds the final note while the melody moves around it, thus leading to voice crossing when the top voice descends. It then meets the top voice on the resting pitch, remaining there as the top crosses back over to its usual place above. It then reflects the top voice gesture, moving up a step to the ending unison. During this entire final phrase, the bottom voice has a typical ascending gesture in order to reach the final, and it marks out and holds what becomes the top voice's lowest note during the voice crossing. As we saw in the variant of "It Is Truly Meet", it translates the top voice rhythm for the last three notes. It also participates in the middle voice, sharing its last two pitches, leading and pointing to the shared unison in all three voices. Thus, the phrase tapers to the end with a reflection, as the model melody descends and the other voices ascend together, in order to meet at the goal.

This expanded ending exists in variants that are unfolded to an even greater degree. Artemi Erkomaishvili recorded all three voices of the same three anaphoral responses, and he gives them a shared ending (Figure 18), albeit far more extensive than the previous example.

We are now firmly in the third style, the ornamented, as opposed to the true mode or decorated endings in the plain mode. It will be sufficient to discuss salient features rather than labelling and describing all phrases of this passage in order, though such an analysis was useful for the previous case. The passage occurs on the last syllable and is signaled by cadential octaves, a transition that is characteristic in decorated Western chants and even some zari variants. The top voice contains scalar passages in both directions, sometimes in translation of each other, which end at important cadential pitches, and these allow for many harmonic and contrapuntal permutations with the other voices. Voice crossing is a primary feature, with the top two voices often reflecting each other as they move towards their respective notes at cadential fifths. The bottom voice often has usual ascending cadential gestures, but the same at one point translates the upward scalar movement of the top voice, as opposed to reflecting its general direction as in the previous example. The progression of each voice's melodic line and the related harmonic movement that guides them (i.e., where the chant is going), as Erkomaishvili described above, defines the space within which all voices move independently. The top two voices exchange progressive motifs, such as the scalar ascent to the fifth, leading the movement in turn. They cross regularly and for significant durations, and they move or remain at complementary points, such as the beginning of the second phrase. With such equal activity and the switching of range in the upper voices, if one does not know the prototype, it is not immediately evident which voice is the first in the hierarchy. The nature of the bottom voice may stand out somewhat, but there is no clear leader. The top voice is generally the same in all three chants with this passage, but one must know its wandering line among the others in order to highlight it. Since the upper two voices are traditionally sung by soloists, individual timbre makes shifts more apparent but also facilitates the tracking of each voice. 

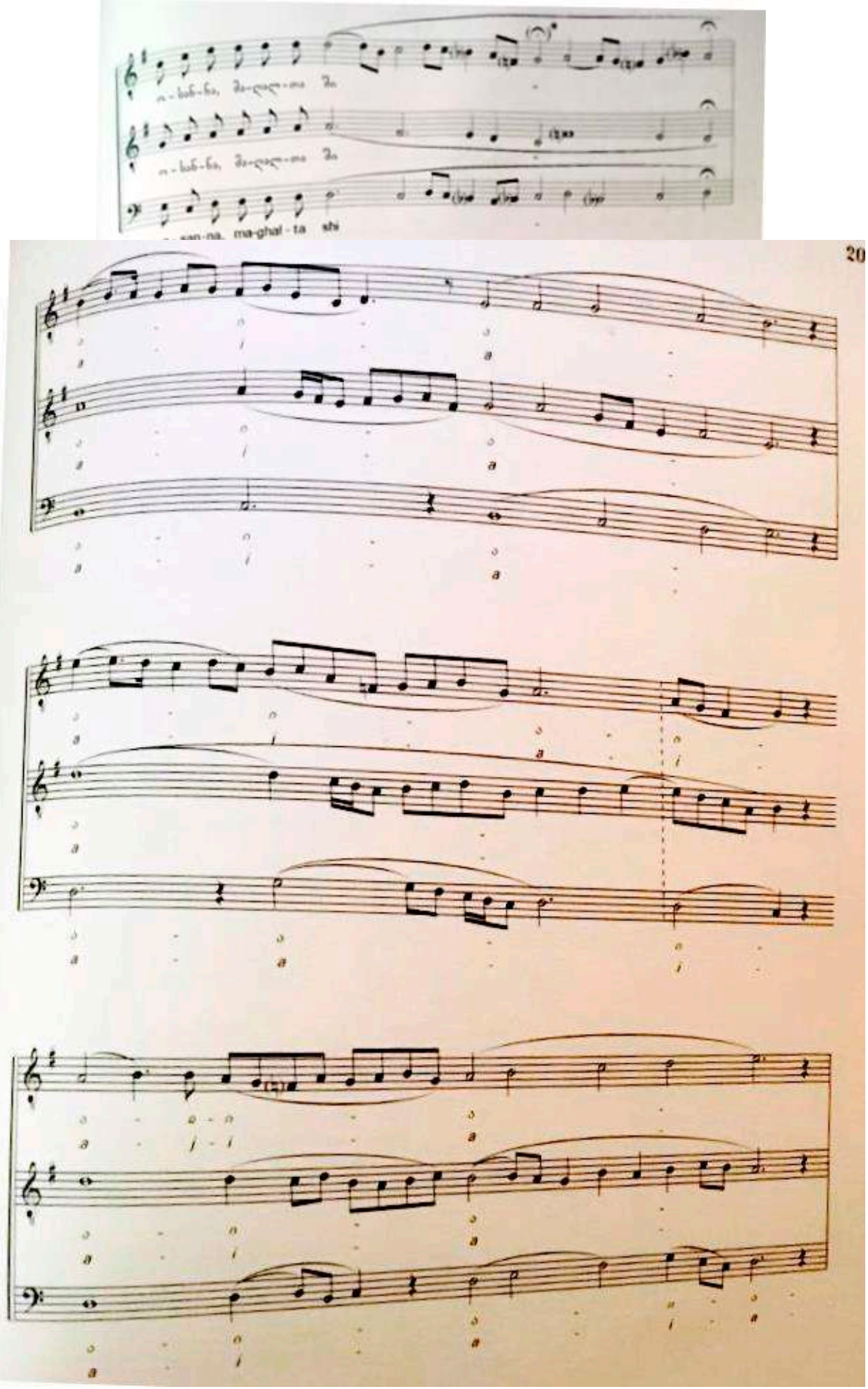

Figure 18. Cont. 


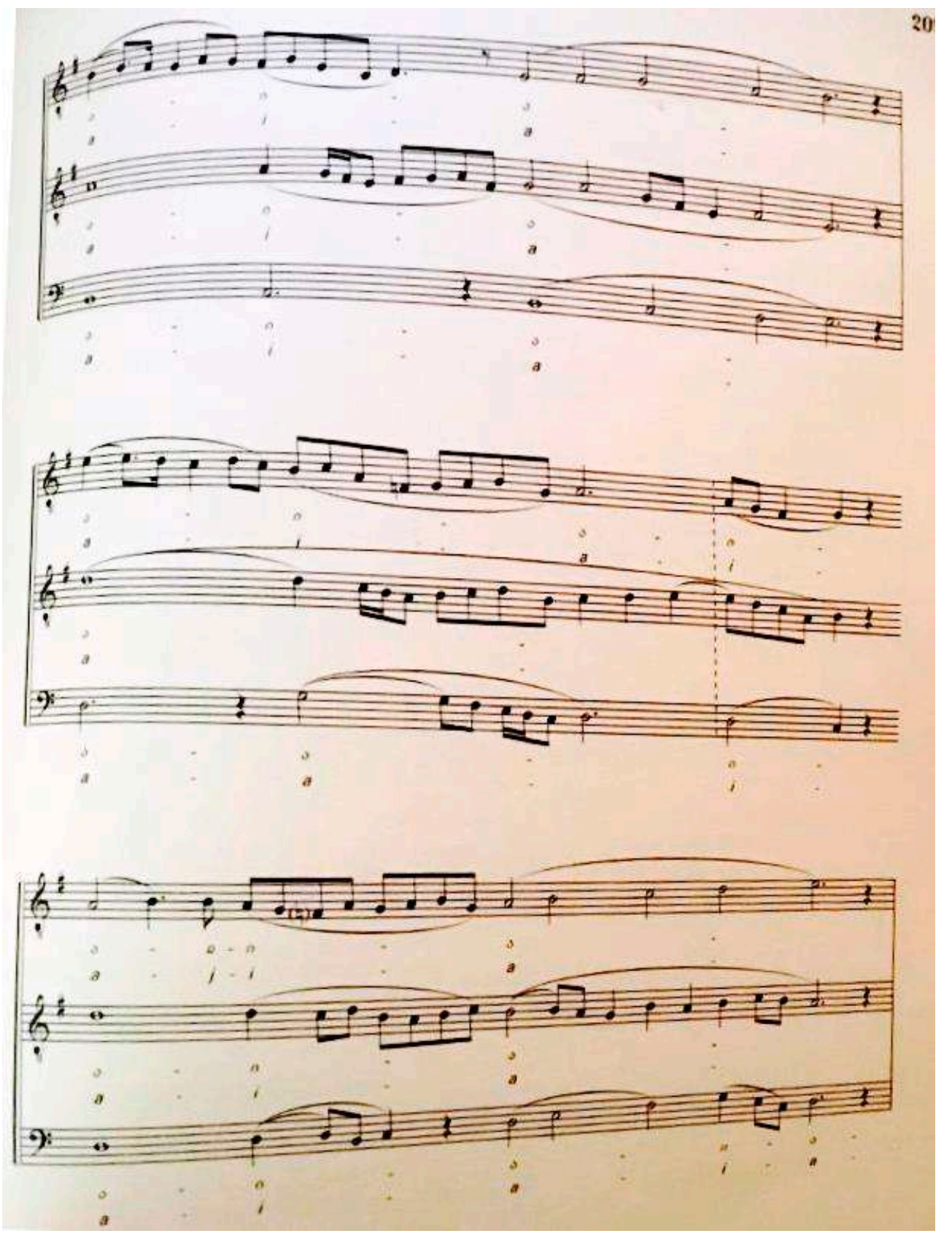

Figure 18. Holy, Holy, Holy; Shemokmedi School (Shugliashvili et al. 2014).

In addition to rhythmic and melodic activity, this passage exhibits a key characteristic of Georgian melisma found in both chant and paraliturgical song, especially the Western Georgian zari and zruni genres and Svan hymns: the expansion or creation of text with a series of vowels. These have their own sort of syntax and occur in particular patterns (e.g., a-i-vo, one that also occurs in Svan Trisagion vocables). Vowels usually change on strong beats, but sometimes one voice, especially the bottom, changes slightly later than the others as in one instance from this passage. The change of vowel adds yet another type of movement to the changing pitch and rhythm, rendering three aspects of sonic progression. The voices generally shift vowels together, and like words, vowels delineate spaces in which the more dense rhythmic activity, harmonic progressions, and melodic lines occur.

With so much activity and shifting voices, the overall sound of decorated chant has a sort of sparkle and iridescence, a strong sense of poikilia. This unfolded chant bears a wide, complexly-composed 
and adorned surface. While experience of poikilia is said to be dazzling, it is not the sheer number of different elements and frequency of change that brings it about. Rather, poikilia is tied to pattern and hierarchy. Ordered change, balance, and coherence of details, like properly woven threads, are primary causes of the perception of variegation, as demonstrated by our sonic example. The interwoven voices, combining their complementary patterns of movement, create a sacred veil, to use the Dionysian term. Since sound exists in space, with all singers, listeners, and environment participating, this veil, while adorning the anaphoral text and analogizing the textile veil over the Eucharistic gifts, enfolds and brings worshippers and their surroundings into the present liturgical moment.

We can further explore the nature of unfolding through new chants and Svan religious repertoire, which we examined above regarding the history of Georgian polyphony. The current patriarch, Ilia II, has composed a number of chants and paraliturgical songs in various styles, such as settings of poems, prayers, and short excerpts of service texts. His version of "It Is Truly Meet" follows the structural principles of phrase arrangement, with two primary phrases, but it has a new melody rather than using the usual top-voice model, which, like the harmonization, is Western European style (Field notes, February 2011). We referred to his Trisagion earlier, which is similar in style. This style of harmony occurs in urban folk songs and other twentieth-century chants, though not always in the major scale and with room for variation. We will now briefly examine a stand-alone setting of the aforementioned troparion ending, "Holy, holy, holy art Thou, O God; through the Theotokos, have mercy on us." ${ }^{29}$ The Bebnisi and Samtavro convent choirs sing this chant without ornamentation (field notes, August 2016, July 2017), but other choirs vary the performance. The rendition by the Georgian parish choir in Dublin, for instance, contains East Georgian folk ornaments (Field notes, February 2011). These were improvised by the singers, who applied them to all occurrences of the descending figure at open cadences (each repetition of "khar" and the second syllable of "Ghmerto"), as roughly transcribed in the example of the first phrase in the top voice (Figure 19).
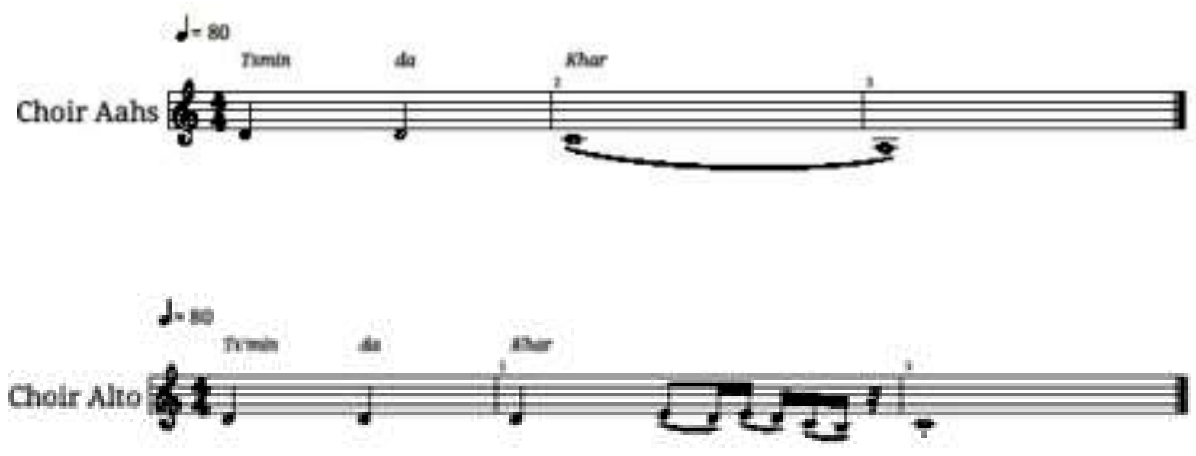

Figure 19. Holy Art Thou; plain and ornamented phrase variants.

The harmonization also differs, with the bottom voice descending a fifth at the cadence that marks the midpoint, at the second syllable of "Ghmerto" ("God"). We can see that adorning and unfolding can happen quickly, especially within a context of established means of doing so, and this chant may follow a trajectory over the years such that highly-expanded, decorated renderings will be created, stemming from the prototype and its contemporaneous adorned variations. This composition, then, fits squarely within its cultural and musical milieu, so much so that it is going through the same historical process, like a tree in the proper environment and conditions.

29 Another unornamented variation can be heard at https://www.youtube.com/watch? $\mathrm{v}=\mathrm{WWdxuvNgHPM}$. The recording quality is poor, but the second repetition is clear enough. 


\section{Unfolding, Folding, and Molding: Hierarchy and Development in Svan Chant Variants and Paraliturgical Polyphony}

Let us now look at the fruit of devotion and compositional processes in a particular context, Svan religious and ritual songs, which cannot be given a precise date. However, we previously saw that something of the sort has existed since at least the fifteenth century. Let us again take up the Svan funeral Trisagion. We noted above that it seems to be a decorated form of the ordinary Trisagion in some respects, but its structure varies in the last two phrases, matching funeral settings from elsewhere. Yet, it can be said to have been created from the same prototype, and; therefore, some kind of relationship is apparent, especially in the A phrases. The same kind of seed will give rise to similar trees and fruit. This funerary form exhibits two primary types of expansion: the addition of vocables, with musical material to support them, and motifs related to "singing around", which make up much of that musical content. One set of vocables illuminates each iteration of "ts'mindao" ("holy"), and another set does the same for each of the second vocatives: "ghmerto" ("God"), "dzliero" ("strong"), and "uk'vdavo ("immortal"). In these vocative phrases, the two vocable types and their settings give parallel, respective highlighting to "ts'mindao" and to the other divine names.

The last phrase, the imperative, only includes an addition of the vowel " $\mathrm{i}$ ", as is common in decorated chants from all regions. This vowel often has a passing function and decorative nature, as in "Ghme-i-erto" in the first phrase. It seems that Georgian melisma is averse to extending a single vowel for very long, save "a" and " $\mathrm{i}$ ", which also fills in other vowels. In the penultimate word "shegvits'q'alen" ("have mercy"), the "i" does more than fill in and adds another syllable, giving parallel second and fourth syllables.

The new fourth syllable expands the rhythm, allowing three iterations of particular complementary figures over an even, six-syllable, twelve-beat space. The top voice has a descending, two-note figure, which it repeats in a zig-zag-like manner. The middle voice complements this figure with a four-note, "singing around" loop, which centers around the two-note figure translated down a third. Recall the complementary figures in the first expanded anaphoral passage. In practice, the top two voices sometimes interchange these figures across the iterations, still centered around their respective two notes, but rarely singing in parallel thirds, that is, not sharing one of the two figures during the same iteration. Thus, we have a sort of "crossing", not of range but of shape. In relation to the first figure, the bottom voice has a reflexive two-note, rising figure. The first and third of these are on the same pitches, but the middle repetition translates it down a fourth, reaching the lowest, yet climactic, pitch, a type of gesture that we also saw in the anaphora. The lowest pitch is reached by ornamental passing notes at the end of the first figure, but in practice, the figures can also be sung in a straight fashion, which also renders the climax pitch a step higher since it is not approached from below. The variations mentioned "in practice" are characteristic of oral tradition, but they also demonstrate the variety of ways in which prototypes are realized. While occurring across variants and voices, they can also occur across a particular voice's rendering of iterations, a feature that gives rise to the trading of figures. At the same time, it also allows a given voice to translate or reflect its own gestures; this characteristic is noteworthy since we have generally discussed such relationships only between voices. The top voice engages in this activity the most, while the others remain on supporting pitches. Reflection often occurs across repetitions of the syllables "tsmin-da-i", also changing the approach to "vo" to a descent and to postponing the intersection on the middle voice's pitch until the end of that same syllable; the initial figure also intersects at the syllable "i." Similar reflection occurs between the first two syllables of the other vocatives, treating the elongated " $\mathrm{i}$ " in "dzliero" as a separate sung syllable and the liquescent " $\mathrm{v}$ " in the same way. This latter case is a simple reflection, transposing the order of the same two notes, thereby changing the distance but not the direction of approach to the following pitch. In these cases, the intervals between voices change, but the overall progression remains. One can assimilate a model melody in various ways not simply in other voices but in the same voice, using similar principles of harmony and movement. 
These variations can be understood as decorative, along with those that sometimes take place on the descending figure that accompanies the "o-i-a-ha" vocative endings that lead to the intersection of voices. This scalar passage is sometimes sung with a repetition of the second pitch, rendering two descending quavers instead of a crotchet on the lower degree. This ornament is in parallel rhythm and thirds with the second voice, thereby translating it. Some singers have marked preferences for not ornamenting this passage in the top voice, or the ascent that follows it, which some singers fill in with a quaver on the second (Field notes, August 2016; July 2017). Alternatively, the middle voice can sing a crotchet for its third note, allowing the top voice to vary its figure while preserving the counterpoint without parallel thirds, and singers must be keenly aware of the other voices in order to attune their choices as much as their intervals. Such aesthetic choices are reminiscent of St. Ekvtime's aforementioned contrapuntal preferences. Even a seemingly small ornament over a short duration, then, can noticeably affect the harmonic and contrapuntal character. The previous cases from the beginnings of phrases did not have this effect since the lower voices remain on the same pitches throughout. There is, then, a kind of counterpoint in how structure, ornament, and harmony work together, forming another hierarchy.

Yet another hierarchy found in Svan polyphony, to which we referred in the introduction, is that of text, song, and dance. These three aspects are intertwined, and songs may share the same dance steps, texts, musical material, or a combination. A particular dance, referred to as "Lamurgwäliash", occurs in songs, some of which share the same tune but which have a variety of texts: prayers, historical narratives, and legends (Field Notes, 25 July 2017). The prayers share text, which also occurs in round-dances with different music and steps (e.g., "Didebata", 30 "Lazhghvash"31 (also performed without dance but with instrumental accompaniment), ${ }^{32}$ and "Lagusheda" 33 ), and in the hymn "Lile", 34 which also exists as a round-dance over the "Lagusheda" tune, requiring only slight textual variation. ${ }^{35}$ All these examples are paraliturgical supplications and glorifications to God and the Archangels, connecting Earthly and heavenly hierarchies. Another song, "Gaul-Gavkhe", 36 shares dance and tune with "Lagusheda" but has a historical text, also a common Svan genre, about a battle that took place in the early nineteenth century. Yet another example, "Bail Betkil", is a legend about the goddess Dali ${ }^{37}$ and only shares the dance element, having its own text and music. This situation is interesting for the exploration of how hierarchy works, how prototypes are copied and layered, how cultural material is appropriated, and what makes repertoire sacred. Text, vocables, and context help to determine the purpose of the stock tune and dance steps.

Studying hymns and funeral songs widens the scope, since they share extensive material. In the hymn “Ts'khav Krist'eshi" (Figure 20), ${ }^{38}$ key passages and cadences are marked.

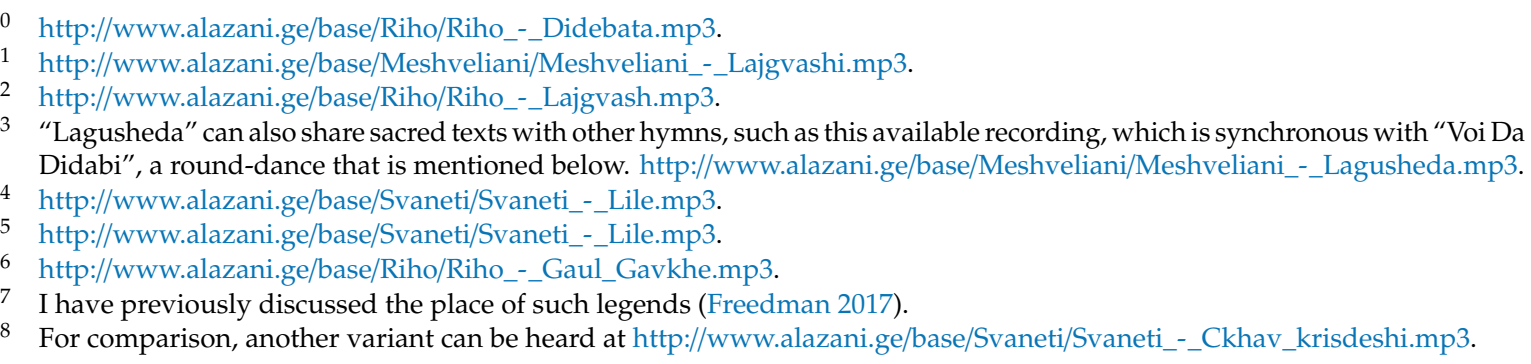




\section{Ts'khav Krist'eshi}
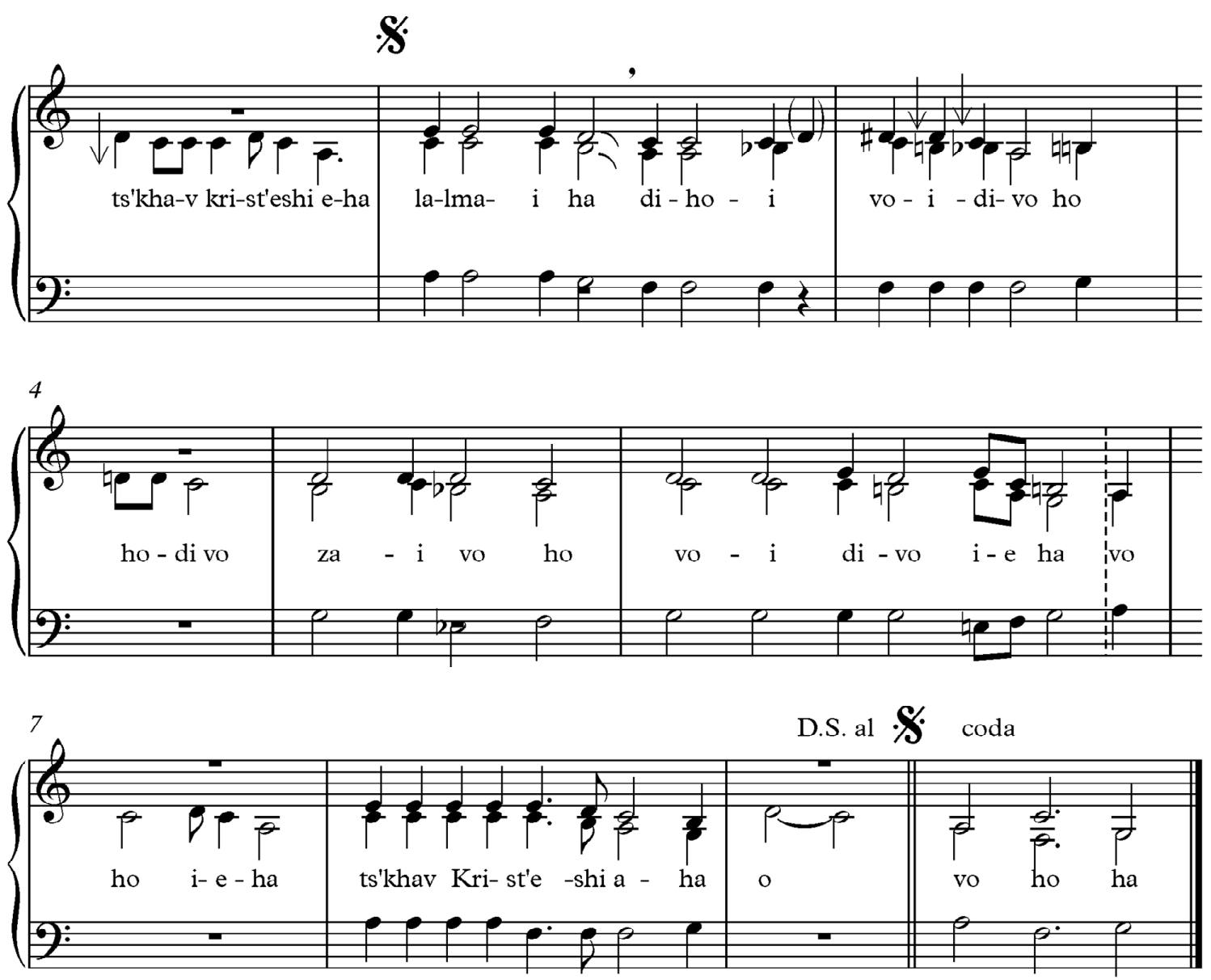

Figure 20. Ts'khav Krist'eshi; Svan hymn to Christ, Lakhushdi variant.

These occur in other hymns and ritual songs, including a hymn to St. George (Figure 22), ${ }^{39}$ a variant of "Ga", 40 another hymn to Christ "O Krisdeshi", variants of the wedding blessing "Sadami", ${ }^{41}$ and zari variants. ${ }^{42}$ Jgragish and Ts'khav Krisdeshi share a beginning, with difference only of the vocative name in the text; the two hymns to Christ, $\mathrm{Ga}$, and zari variants share internal phrases as well as cadence types. In particular, the more extensive, common internal phrases and cadences function like the expanded sections in anaphoral chants. These passages consist primarily of particular vocables, which form "nothing but a musical calque of invocation, supplication, and veneration" (Mzhavanadze and Chamgeliani 2016, p. 78). This phenomenon is of great theological importance for the nature of sung prayer, especially in cases where liturgical text is not a factor. Svan paraliturgical prayer and Western chant school ornamentation are similar musical and theological expressions. ${ }^{43}$

39 http://www.alazani.ge/base/Riho/Riho_-_Jgragish.mp3.

40 https://www.youtube.com/watch?v=AO2YAfB4Lr0.

41 http://www.alazani.ge/base/Svaneti/Svaneti_-_Sadami.mp3.

42 http://www.alazani.ge/base/Svaneti/Svaneti_-_Zari.mp3.

43 It is noteworthy that the zari genre was more widespread in Western Georgia, though it is used in practice today only in Svaneti. There are examples from Guria and Samegrelo, including a variant from the same chanter whose paschal troparion we briefly discussed above; it can be heard at http://www.alazani.ge/base/AnchiskhatiP/Anchiskhati_-_Zari.mp3. 


\section{Jgragish}
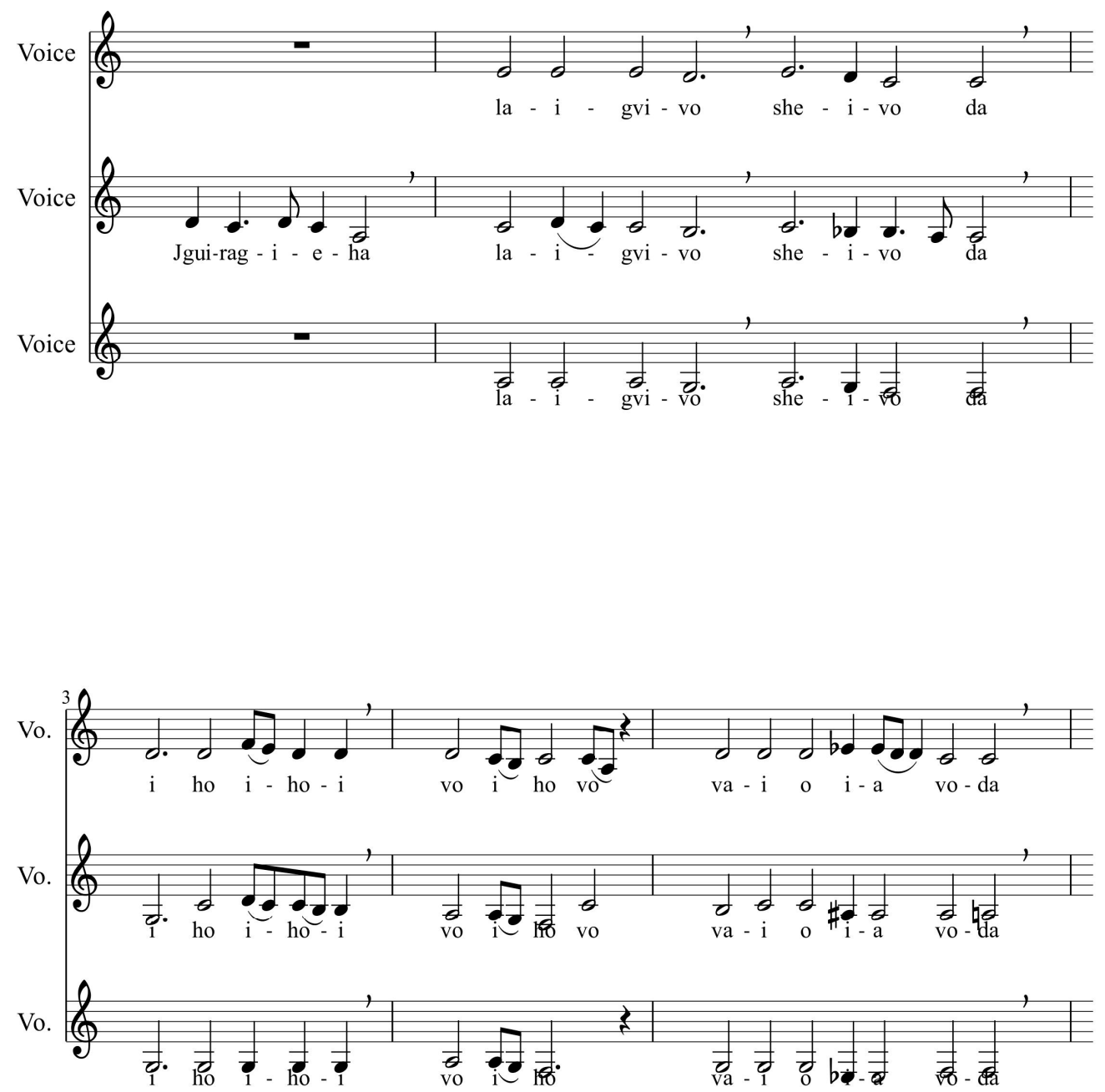

Figure 21. Cont. 

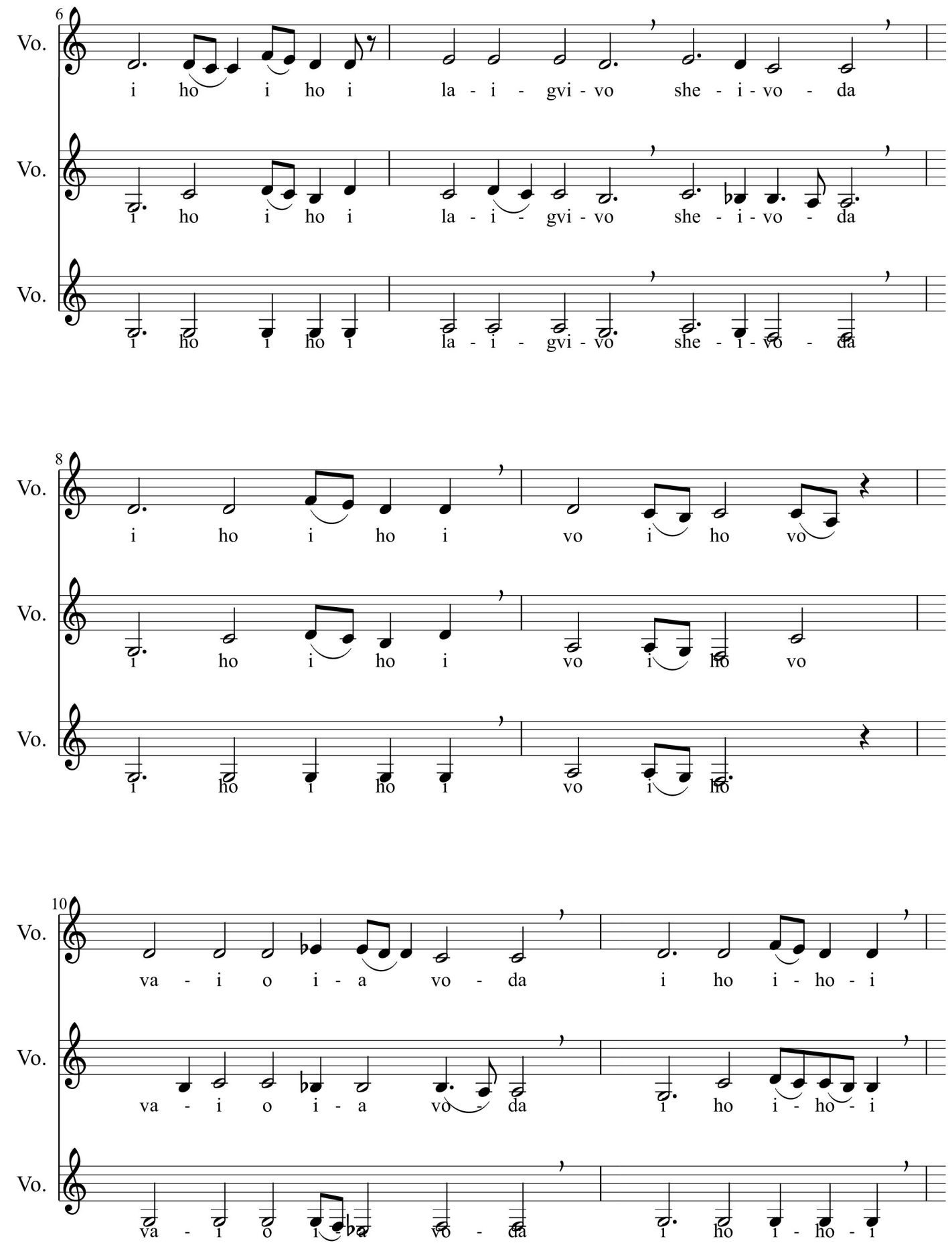

2

Figure 21. Cont. 


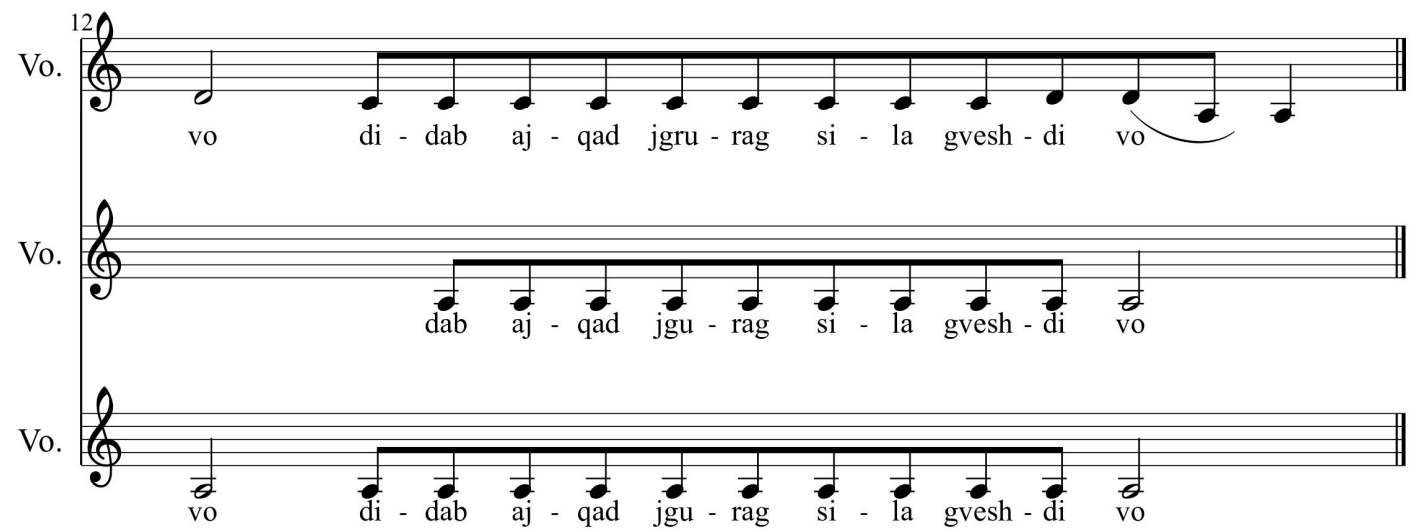

Figure 21. Jgragish; Svan hymn to St. George, Lakhushdi variant.

Let us consider the hymn "Lile" (Figure 22) along with the related round-dances.

The musical material of the hymn, while expressing the general features of the genre, can be understood as an expansion of the round-dance melody, or, vice-versa, as the root of the compacted round-dance. While the first process is like that which takes place throughout the styles of chant, the other may be more likely. Many round-dances are composed of sections that successively become more compact, refracting the opening segment. These sections are not simply rhythmically accelerated; they follow the same structures and key pitches but with shortened and altered phrases, and they generally share texts. Some, such as Lazhghvash, referred to above, include rendering the same musical material at double speed, but most form new compacted phrases of the material (e.g., "Voi Da Didabi" $\left.{ }^{\prime 4}\right)$. Round-dances and work songs from other regions, such as Rach'a, ${ }^{45} \mathrm{Guria}^{46}{ }^{4 m e r e t i},{ }^{47}$ and Samegrelo, ${ }^{48}$ share this feature. While one example, "Shisha da Gergil", ${ }^{49}$ is often sung with a compact section followed by an unfolded one, its variant "Geregil" 50 begins with a hymn like section, followed by the later section of "Shisha da Gergil;" The first case demonstrates the expansion process found in ecclesiastical chant, and the latter arrangement is most common in Svan song. The feature of a hymn-like introduction is significant and especially present in sacred examples. The round-dance "Didebata" (Figure 23) also has a hymn-like introduction, followed by the square, compact round-dance, and the aforementioned "Lile" is sometimes sung in two sections, the hymn followed by the round-dance.

44 http://www.alazani.ge/base/Meshveliani/Meshveliani___Voi_Da_Didabi.mp3.

45 This round-dance has text that may be related to the legendary figure Amirani, who has been compared to Prometheus. https://www.youtube.com/watch?v=rNWLU49FFpk.

46 A work song can be heard at http://www.alazani.ge/base/AnchiskhatiS/Anchiskhati___Elesa.mp3.

47 This example is a paraliturgical paschal round-dance, which also includes "kyrie eleison" vocables: http://www.alazani.ge/ base/AnchiskhatiS/Anchiskhati_-_Krialeso.mp3.

48 This example is a harvesting song: http://www.alazani.ge/base/Polikarpe/Polikarpe_-_Ocheshkhvei.mp3.

49 http://www.alazani.ge/base/Riho/Riho_-_Gergili.mp3.

50 An important historical recording by the Lat'ali Village choir is available at http://www.georgian-music.com/folk-songs/folksong-and-dance-ensemble-of-latali-village. Note that the tracks are mislabeled. "Geregil" is the track with the label "Name of an Old Man." 


\section{Lile}

Traditional
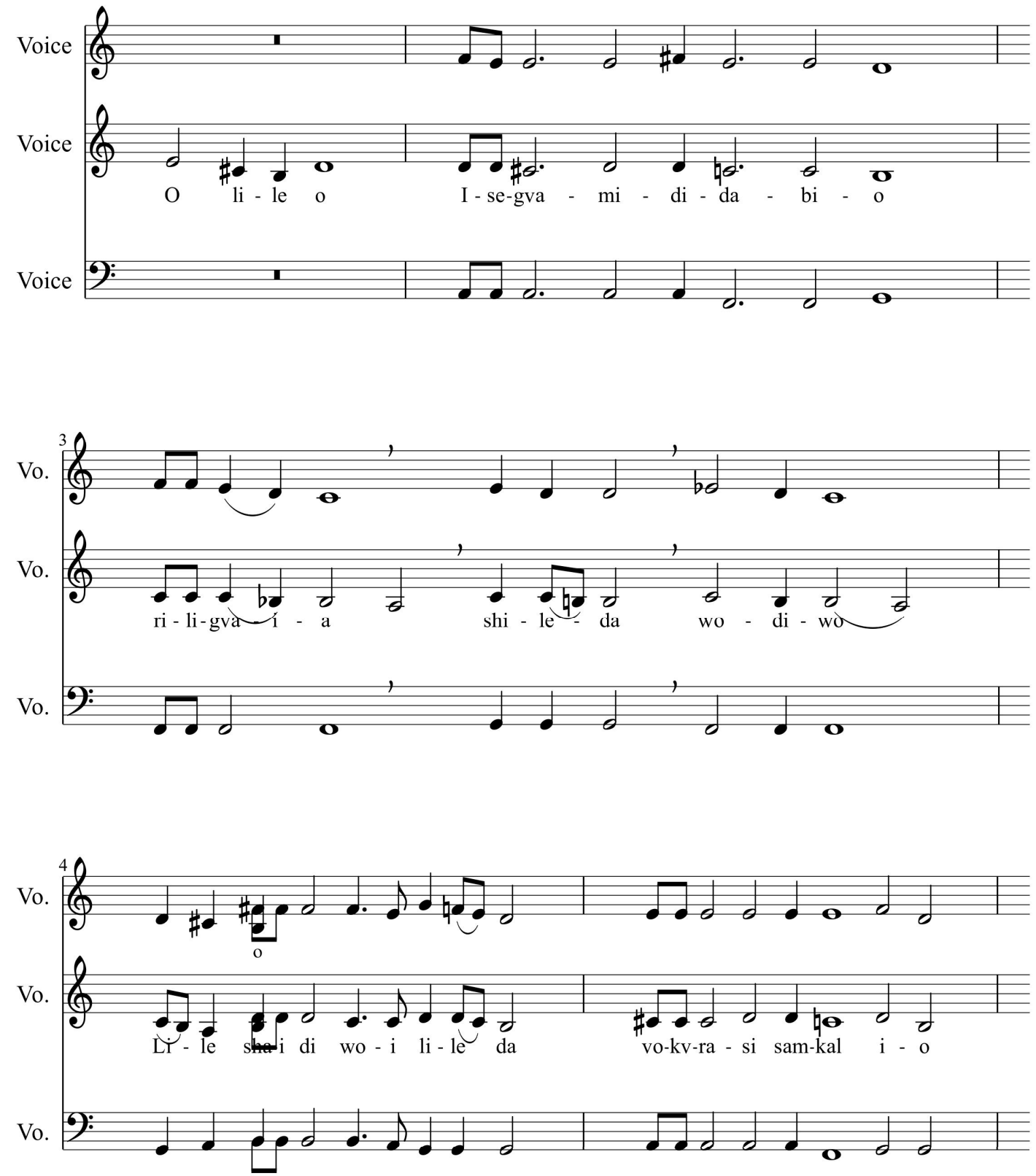

Figure 22. Cont. 

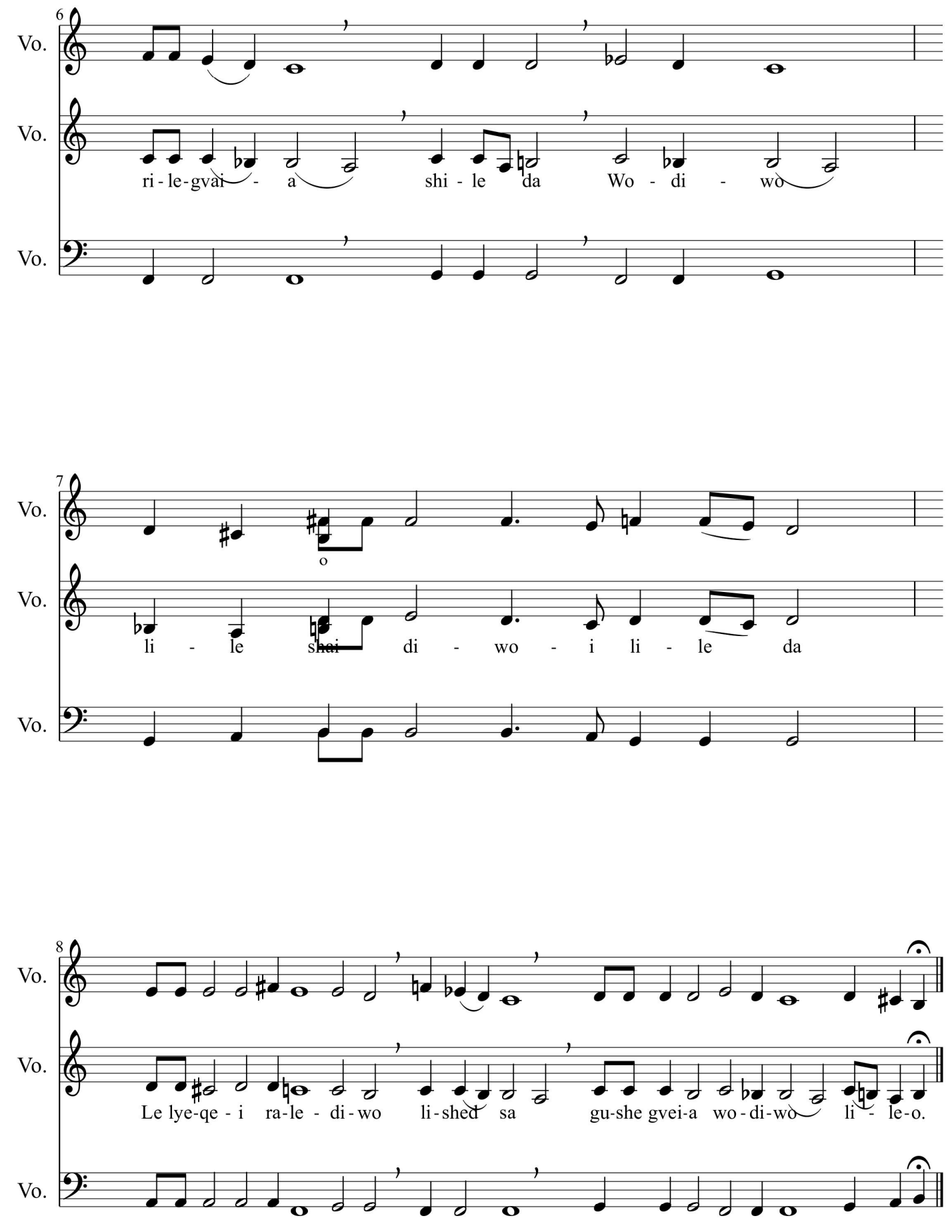

2

Figure 22. Lile; Svan hymn, Lakhushdi variant. 

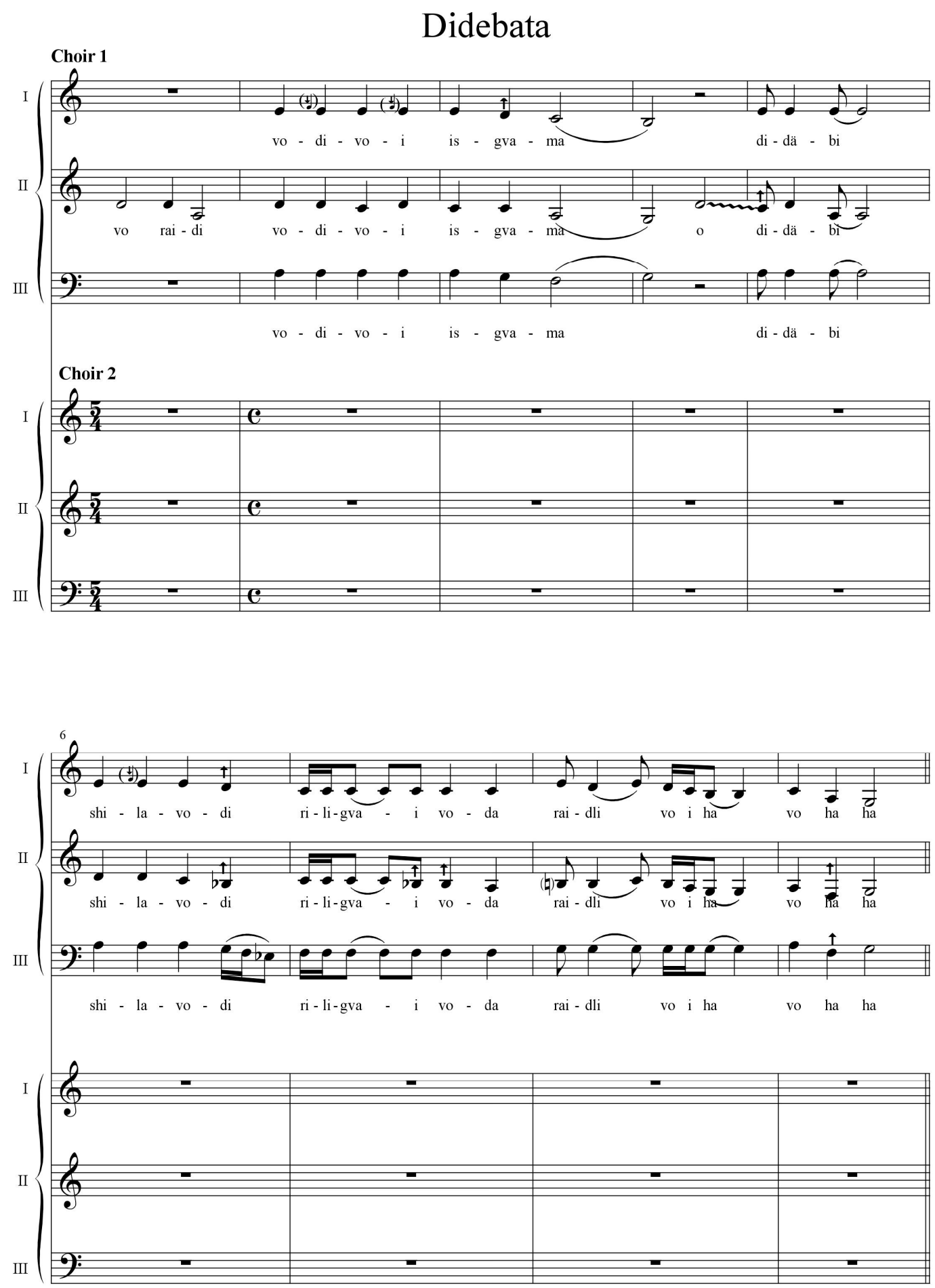

Figure 23. Cont. 


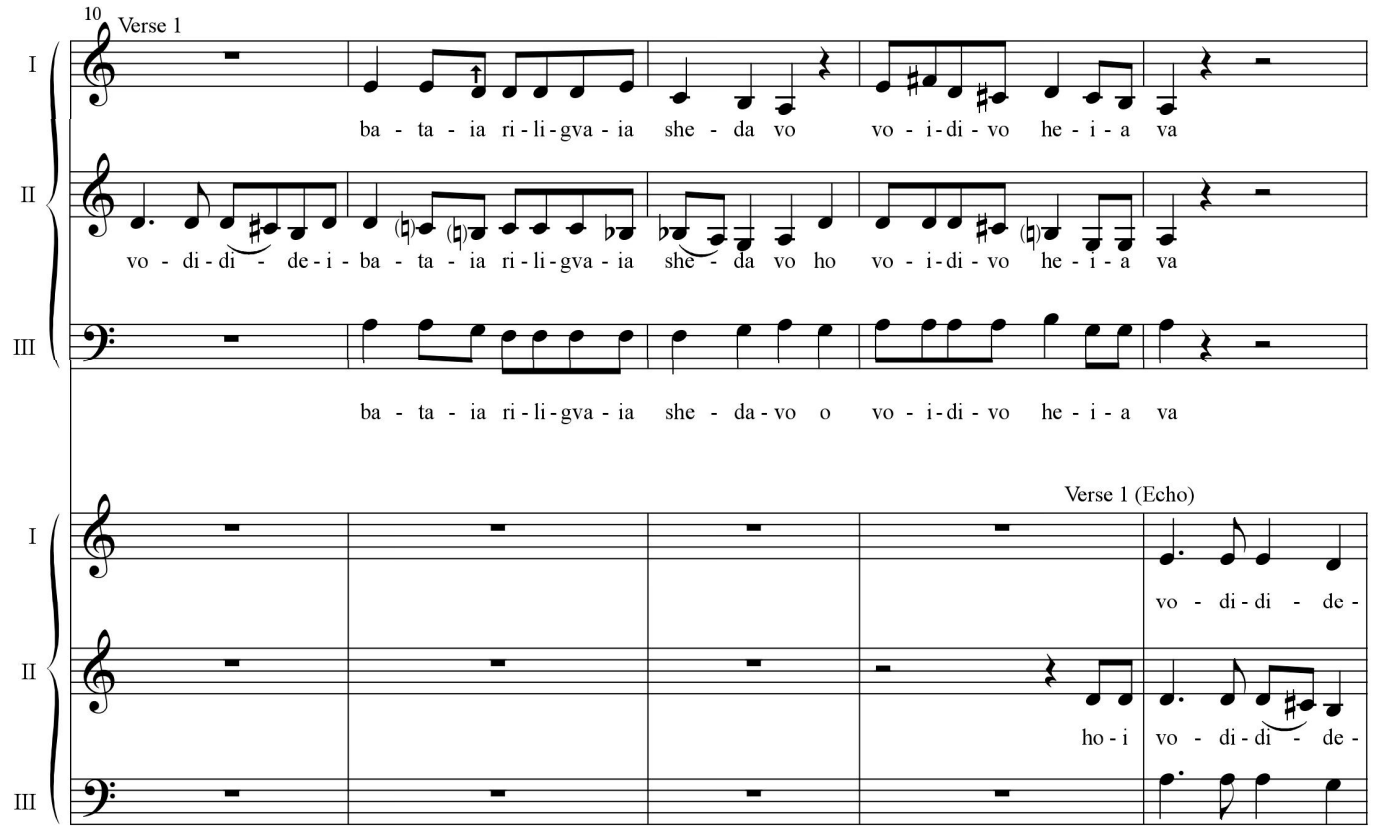

vo - di - di - de -

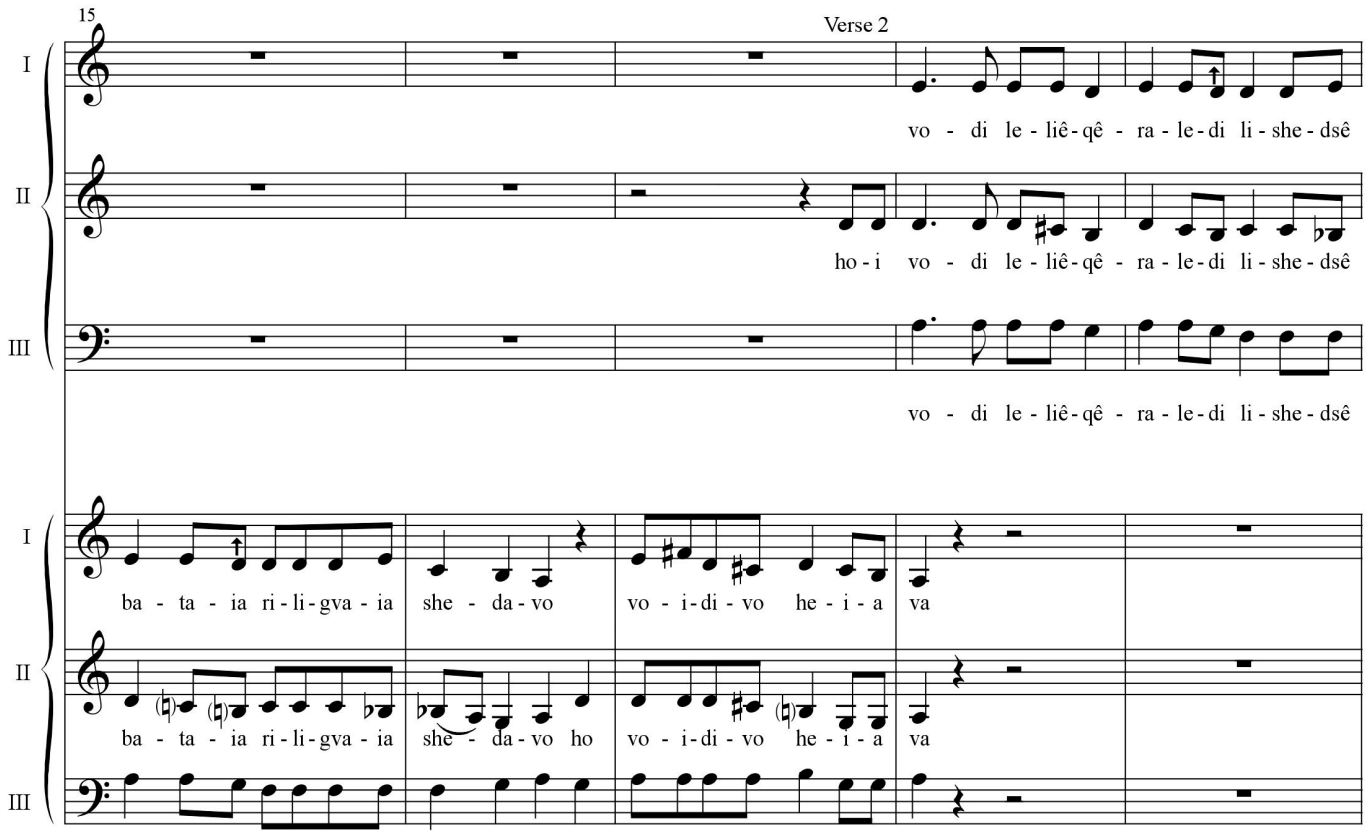

ba - ta - ia ri-li-gva - ia she - da - vo o vo - i-di - vo he - i - a va

$-2-$

Figure 23. Cont. 

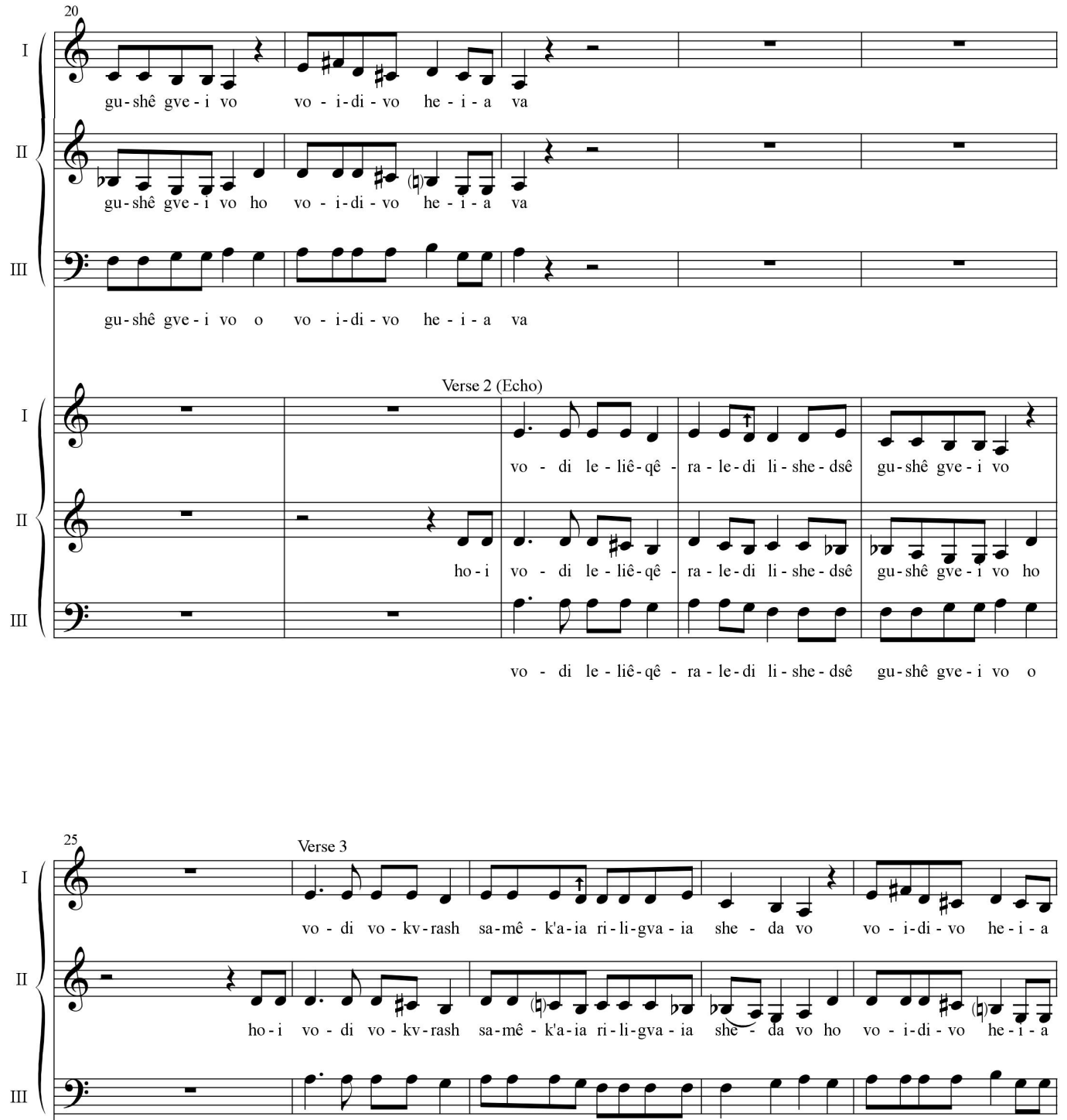

vo - di vo - kv-rash sa-mê - k'a-ia ri-li-gva - ia she - da vo o vo - i-di - vo he - i - a

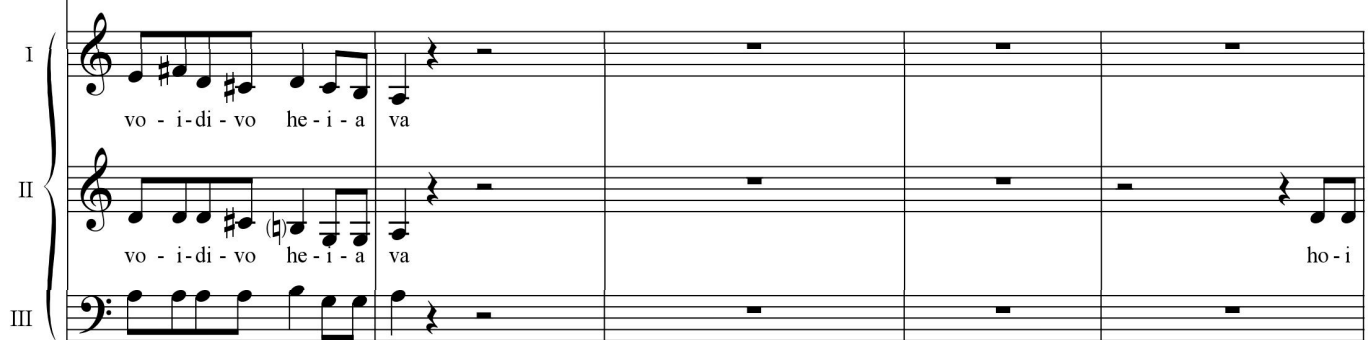

vo - i-di - vo he - i - a va

$-3-$

Figure 23. Cont. 


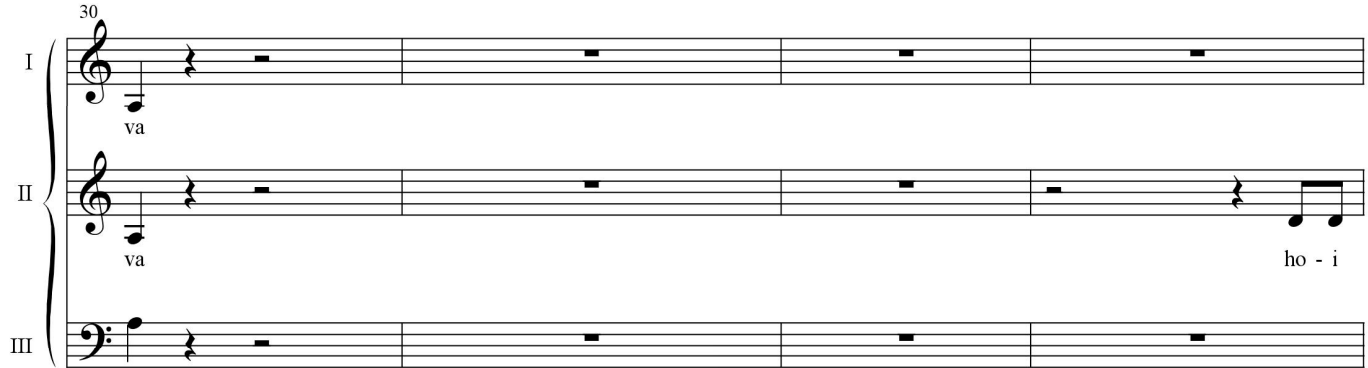

va

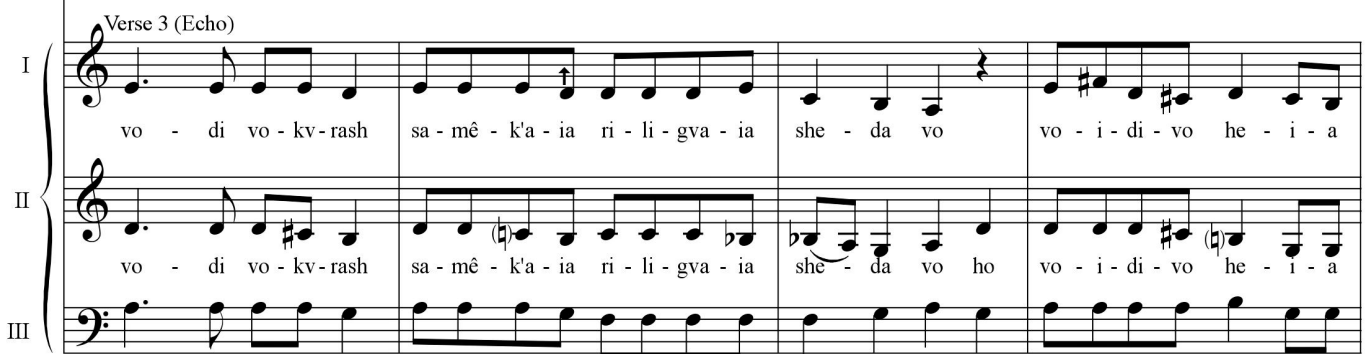

vo - di vo - kv-rash sa - mê - k'a - ia ri - li - gva - ia she - da vo o vo - i - di - vo he - i - a

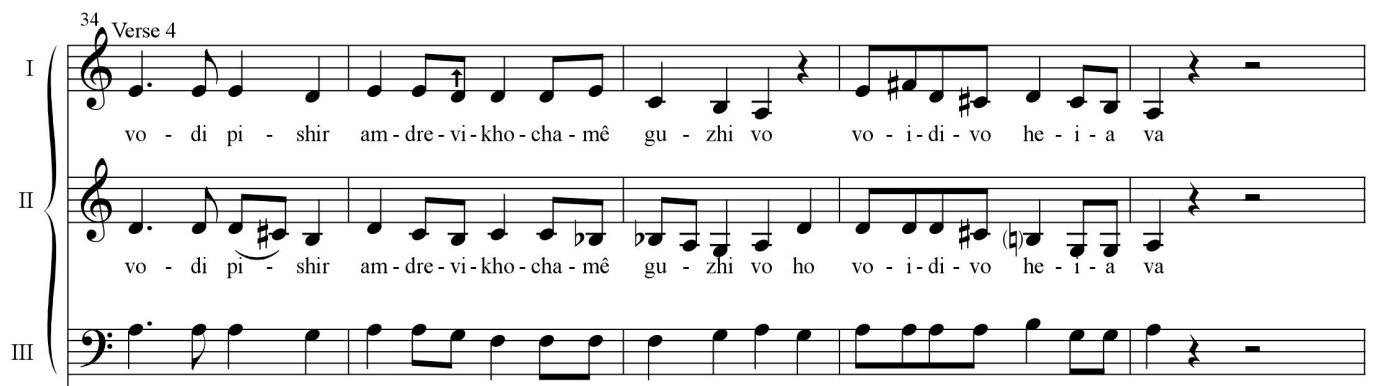

vo - di pi - shir am-dre-vi-kho-cha-mê gu - zhi vo o vo - i-di - vo he - i - a va

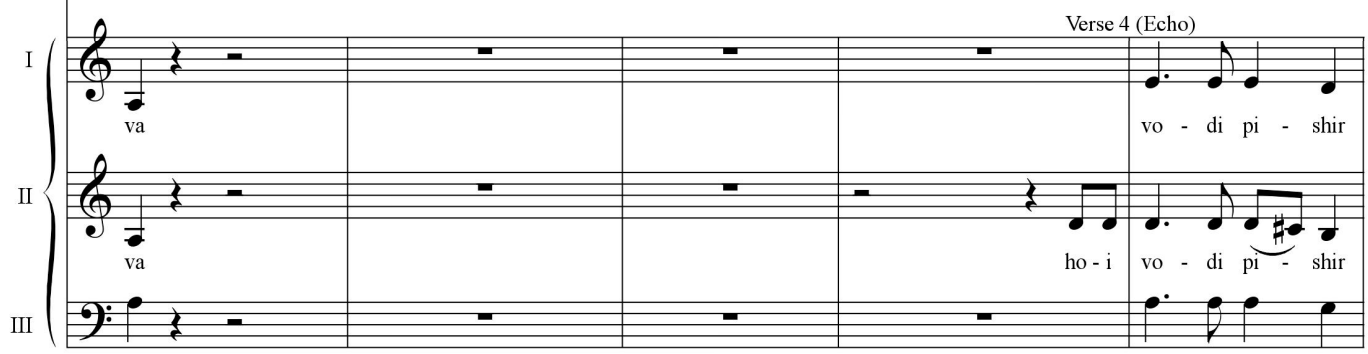

Figure 23. Cont. 


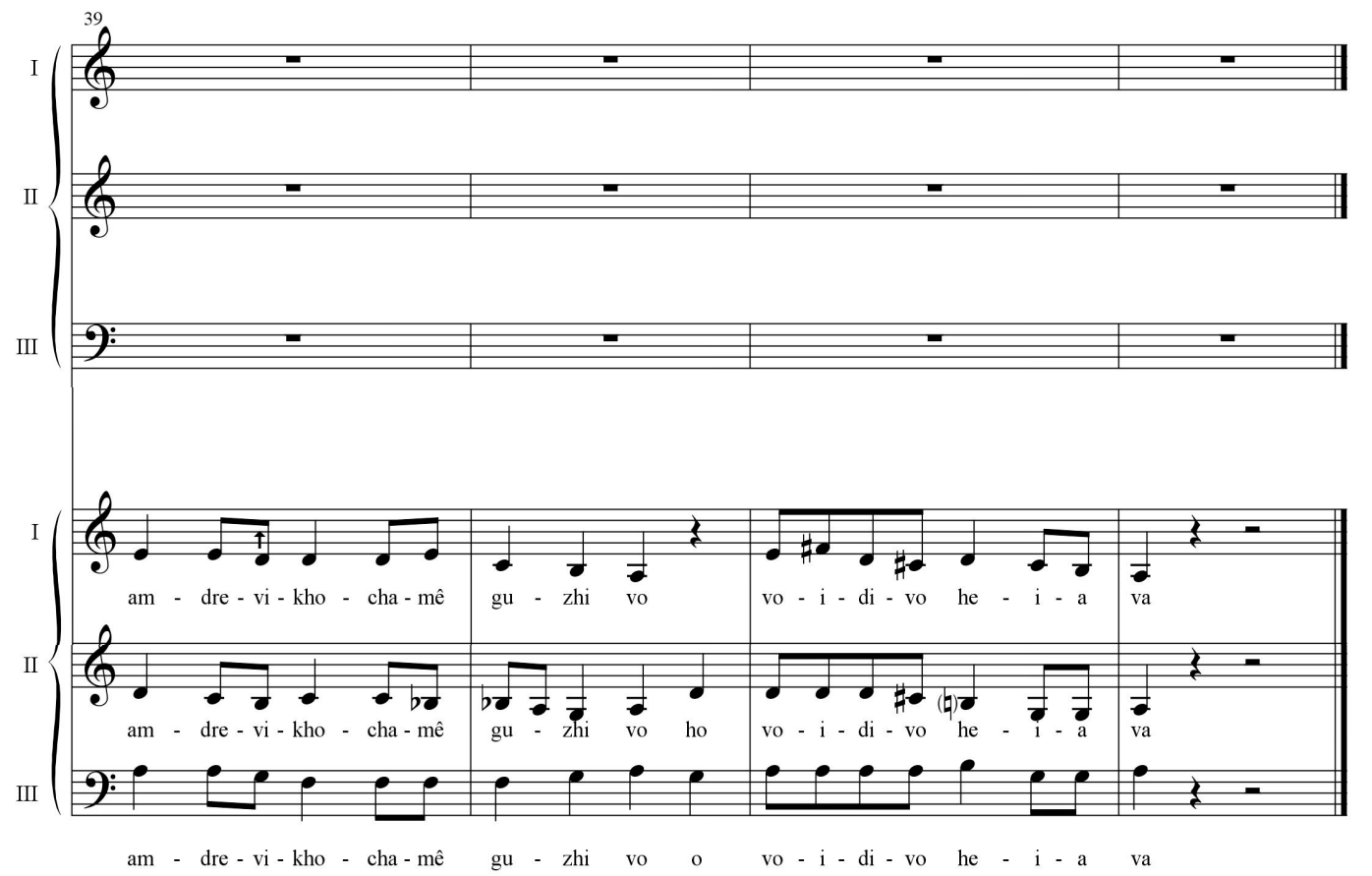

Figure 23. Didebata; Svan round-dance to the Archangels, Lakhushdi variant.

This segmented structure is fractal-like and hierarchical. Yet, the seemingly expanded, sometimes hymn-like, section gives rise to those that follow. Some hymns, such as "Barbal Dolash" (Figure 24)", ${ }^{1}$ have more square, round-dance-like rhythm, rendering yet again three modes of sacred paraliturgical song along a continuum.

The expansive style has its particular character, exhibiting slow, homorhythmic movement, sparse ornamentation, and direction, such as in call gestures, and action delineated by the middle voice. The round-dance contains similar counterpoint but has well-defined, square rhythm, and the songs and sections that fit between these two styles are more regular or metrical in their rhythm and structure. I suggest that these styles have generally co-existed and that it may not be possible to determine if, for instance, expansive hymns developed first in a strictly historical sense. However, they take temporal precedence in the rendering of multi-section compositions.

The interesting process of compacting musical material is a direct reflection of that seen in the three styles of ecclesiastical chant. Yet, the underlying principle of the prototypical hymn molding what follows is held in common. In ecclesiastical chant, this foundation is the text and model melody; in Svan song, it is the hymn or most expansive section, sometimes joined to a text. The example of "Geregil" shows that the path may go in both directions (i.e., that a round-dance section can be expanded), but that hymns are the wide basis from which all following sections are folded. While I suggested earlier that the Svan funeral Trisagion may have developed from the so-called "plain mode" ordinary variant, the trajectory of Svan folk song indicates that the simpler version may have developed from the ornamented one. Perhaps the latter is not ornamented at all, its vocables and other features acting like features of handwriting rather than additional illuminations. Likewise, singers, such as those who adorn the Patriarch's compositions, may not view their renderings as ornamented but simply as the shape of the song as they form it.

51 For comparison with the transcribed variant, another can be heard at http://www.alazani.ge/base/Svaneti/Svaneti_-_Barbal_ Dolash.mp3. 


\section{Barball Dolash}

Traditional

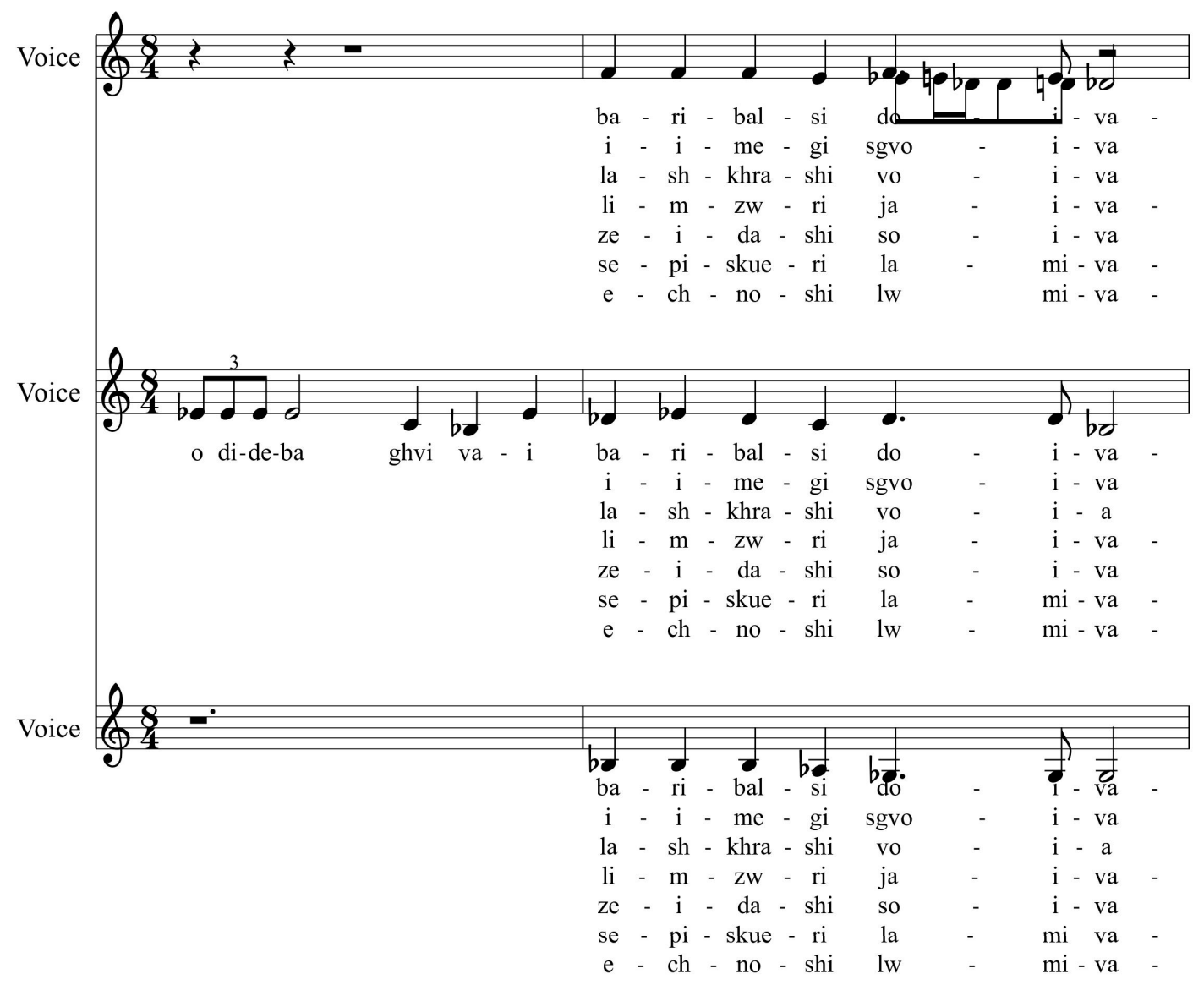

Figure 24. Cont. 


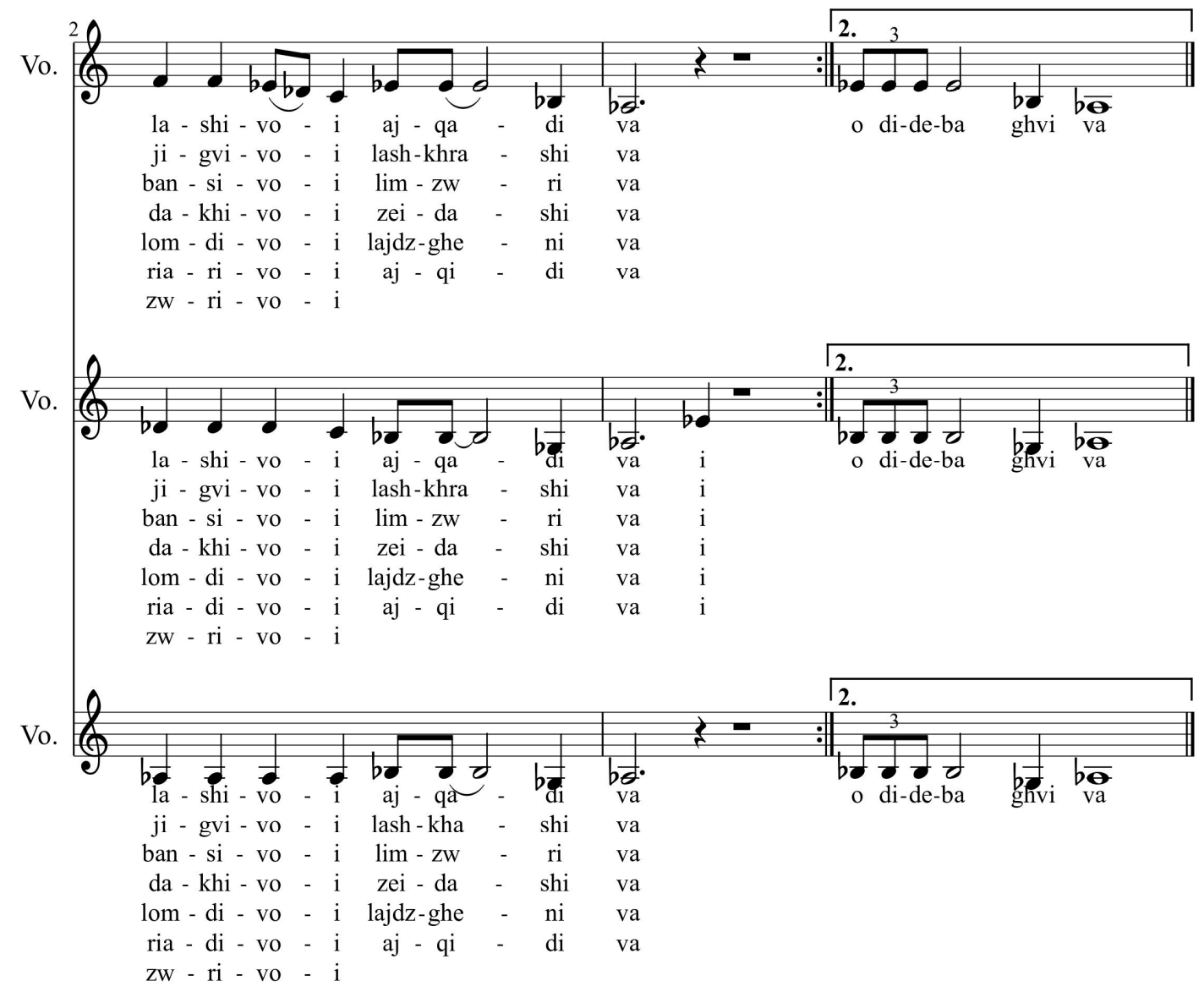

Figure 24. Barbal Dolash; Svan hymn to St. Barbara, Lakhushdi variant.

Our exploration of decoration and expansion in Kartvelian sacred song has brought to light two primary, rhythmically-opposite processes that are nevertheless embodied within congruous sacred repertoires. The nature of prototypes and their diverse copies renders a situation in which any given example can be either unfolded or folded. It can be enlarged and further diversified with ornaments, or it can become more narrow, direct, and smaller in scale, as a molded object is smaller than its mold, such that it can fit inside it. The assimilated patterns and destination remain the same.

\section{Conclusions: Threading Sound, Text, and Theology in Prayer}

We will end with some brief theological reflections. We have summarized a great deal of theological and historical material, examined the concepts and processes as they occur and are applied in examples, and discussed how theology continues to give birth to sacred song. We have observed great intricacy and variegation within individual chants, and this poikilia also exists across variants, both diachronically and synchronically. We have described the voices as warp and weft and as forming complementary figures that create complex surfaces, and unfolded chants have a more expansive, densely-patterned face while folded variants hold potential and patterns beneath a smaller, simpler, outward side. Even this side can be embellished, especially by the middle voice. Among all this musical material, however, hymn texts, vowels and vocables, and the prayerful purpose of the sound have their essential place, which can be described with further textile metaphor. These give shape to pitch and rhythm, as alignment, twist, thickness, number of plies, and other aspects form threads from fibers. In a homily on the Song of Songs, St. Gregory of Nyssa states that the "scarlet thread" of the lips of the Church is the confession of faith, the "agreement in mind", plied together as "one cord" from the "different strands" of its members (Norris 2013, p. 239); "scarlet thread means "Faith working by love.' By 'faith,' scarlet is explained, while 'love' interprets thread" (Norris 2013, p. 241). Faith and love 
are active forces in the composition and performance of chant. St. Polievktos Karbelashvili's threading of text and model melody is like the making of a warp, and subsequent harmonization by the other two voices, decoration, and expansion provide the weft and thread density. Alternatively, it can be said that the thread of each voice is laid out and stitched onto a pre-existing cloth. Above, historical change was referred to in this way as a shifting underlay for model melodies, but the threading of all chant would stand as cobwebs without the foundation of theology, that is, revelation and experience of God (Archimandrite Aimilianos of Simonopetra 2009, pp. 266-93). No being or hierarchy would exist without its source in, and movement towards, God, and every element of liturgy, including chant, is a "God-bearing reality", a "sign that points to God", a "vehicle of His presence and grace", as the contemporary Greek Elder Aimilianos describes (Archimandrite Aimilianos of Simonopetra 2009 , p. 331). Since God became incarnate, He adds a unique thread, being "woven into the fabric of human nature" (Archimandrite Aimilianos of Simonopetra 2009, p. 168), and He takes up the others, making human beings to "become His garments" (Archimandrite Aimilianos of Simonopetra 2009, p. 348). There are further foundational threads from God, which clothe humans in robes "spun from the grace of the Holy Spirit", as the nineteenth-century Russian St. Seraphim of Sarov says (Mileant 2001, pp. 13-14). Thus, God in turn provides new garments for the faithful. The weaving of these garments is a synergistic process, and St. Hippolytos of Rome includes the Father, Christ, the Holy Spirit, the Theotokos, Prophets, and Patriarchs; weaving takes place through the Incarnation and Passion, and the cross is the warp beam. Christ is described in all aspects, His grace providing thread, which binds human and divine natures by His love, and He Himself is a shuttle (On Christ and Antichrist, 4). We previously associated chant with the preaching of the Gospel, and; thus, it relates to the work of apostles and the Word and has an important place in building up the body of the Church.

St. Synklektike refers to chant as "incorruptible food" (Isaiah 2001, p. 30), and its threads, though imperfect in their Earthly form, and not always easy to relate in every way to their angelic prototypes, are affected by the Incarnation, like the visible threads of the sash of the Mother of God, which has been made incorruptible. As it says about the Theotokos herself in the hymn that we studied, she is "more honorable than the cherubim and beyond compare more glorious than the seraphim", and the same applies to all subsequently deified members of the Church. At the Resurrection, when human bodies will be changed in a manner beyond comprehension, with their "threads worked up into something more subtle and ethereal", as St. Makrina says (St. Gregory of Nyssa, On the Soul and the Resurrection), then will our chant also be made truly incorruptible. Yet, even now, through its many symbolic aspects, the liturgical context, and grace, it already participates in the Kingdom in an indescribable way. God is interwoven with everything, even our cries (Archimandrite Aimilianos of Simonopetra 2009, pp. 176-77). These metaphors and theological reflections can be unfolded further, but chant and silence may express their content better than further discourse, especially that silence which is, as St. Maximos the Confessor says, "rich in tone" (Berthold 1985, p. 190).

Funding: This research received no external funding.

Conflicts of Interest: The author declares no conflict of interest.

\section{References}

Allen, Pauline, and Bronwen Neil, eds. 2003. Maximus the Confessor and His Companions: Documents from Exile. Oxford: Oxford University Press.

Archimandrite Aimilianos of Simonopetra. 2009. The Way of the Spirit: Reflections on Life in God. Athens: Indiktos. Berthold, George C. 1985. Maximus the Confessor: Selected Writings. New York: Paulist Press.

Bogdanović, Jelena. 2011. Rethinking the Dionysian Legacy in Medieval Architecture: East and West. In Dionysius the Areopagite: Between Orthodoxy and Heresy. Edited by Filip Ivanovic. Cambridge: Cambridge Scholars Publishing, pp. 109-34.

Cameron, Averil. 2015. The Mediterranean World in Late Antiquity: AD. New York: Routledge, pp. 395-700. 
Chichinadze, Nino. 2008. Precious metal revetments on Georgian medieval painted icons: Some observations on a devotional practice. Caucasus Journal of Social Sciences 1: 259-79.

Chichinadze, Nino. 2014. Fresco-Icons on Façades of Churches in Upper Svaneti (Georgia). Kadmos 6: 50-94.

Chkhikvishvilli, Marta, and Nino Razmadze, eds. 2010. Traditional Georgian Church Hymns. Tbilisi: Centre for Chant Studies of the Georgian Patriarchate.

Doborjginidze, Nino. 2014. Religious Inculturation and Problems of Social History of the Georgian Language. In Georgian Christian Thought and Its Cultural Context. Leiden: Brill Academic Publishers, pp. 327-43.

Dubowchik, Rosemary T. 1996. A Jerusalem Chant for the Holy Cross in the Latin and Eastern Rites. Plainsong and Medieval Music 5: 113-29. [CrossRef]

Eastmond, Antony, ed. 2015. Viewing Inscriptions in the Late Antique and Medieval World. Cambridge: Cambridge University Press.

Erkvanidze, Malkhaz, ed. 2004. Georgian Chant. Vespers. Matins. Liturgy. According to Father Superior Ekvtime Kereselidze's and Deacon Razhden Khundadze's Manuscripts. Tbilisi: Chant Center of the Georgian Patriarchate. (In Georgian and English)

Freedman, Novice Nicoletta. 2017. 'Everything is to Glorify Christ': Liturgical Creation in Svan Religious Folk Song and Practice. In Proceedings of the Sixth Conference of the International Society for Orthodox Church Music. Joensuu: Joensuu Theological Centre, pp. 369-89.

Freedman, Nun Sidonia. 2019. Trochees, Textiles, and Triptychs: Theology, Patterns, and Synergy of Objects and Music in Liturgy. Paper presented at Seventh Conference of the International Society for Orthodox Church Music, Joensuu, Finland, June 10-16.

Frøyshov, Stig Simeon. 2008. The Georgian Witness to the Jerusalem Liturgy: New Sources and Studies. In Inquiries into Eastern Christian Worship. Selected Papers of the Second International Congress of the Society of Oriental Liturgies, Rome, Italy, 17-21 September 2008. Paris: Peeters Publishers, pp. 227-67.

Gagoshidze, Giorgi. 2014. Jerusalem in Medieval Georgian Art. In Visual Constructs of Jerusalem. Edited by Bianca Kühnel, Galit Noga-Banai and Hanna Vorholt. Turnhout: Brepols Publishers.

Gagoshidze, Giorgi. 2015. Katskhi Pillar. Collectanea Christiana Orientalia 12: 287-306.

Ghambashidze, Nino. 2006. The Tradition of Chona (Easter Ritual) and Some Issues of Its Genesis. In The Second International Symposium on Traditional Polyphony. Edited by Rusudan Tsurtsumia and Joseph Jordania. Tbilisi: International Research Centre for Traditional Polyphony of Tbilisi State Conservatoire, pp. 248-53. (In Georgian and English)

Gigineishvili, Levan. 2007. The Platonic Theology of Ioane Petritsi. Piscataway: Gorgias Press.

Gigineishvili, Levan. 2014. Ioane Petritsi's Preface to His Annotated Translation of the Book of Psalms. In Georgian Christian Thought and Its Cultural Context. Leiden: Brill Academic Publishers, pp. 194-235.

Giorgadze, Marine, and Nino Inaishvili. 2016. The Colchis Black Sea Littoral in the Archaic and Classical Periods. HISTORIKA Studi di Storia Greca e Romana 5: 151-65.

Gippert, Jost. 2013. The Gospel Manuscript of Kurashi. Le Muséon 126: 83-160.

Graham, John A. 2007. Maxime Sharadze: Transcriptions and Publication in the Nineteenth and Twentieth Century Preservation Movement. In Sacred Music Series: Issues in Musicology. Tbilisi: International Research Centre for Traditional Polyphony of Tbilisi State Conservatoire, pp. 98-106. (In Georgian and English)

Graham, John A. 2008. The Role of Memory in the Transmission of Georgian Chant. In The Fourth International Symposium on Traditional Polyphony. Edited by Rusudan Tsurtsumia and Joseph Jordania. Tbilisi: International Research Centre for Traditional Polyphony of Tbilisi State Conservatoire, pp. 1-18. (In Georgian and English)

Graham, John A. 2012. Ivliane Nikoladze: The Alternate Redacteur of the Georgian Heirmoi. In Proceedings of the Fifth International Symposium on Traditional Polyphony. Tbilisi: V. Sarajishvili State Conservatory Press, pp. 425-46. (In Georgian and English)

Graham, John A. 2013. Without Parallel: Voice-Crossing and Textual Rhythm in West-Georgian Chant. In Proceedings of the Second International Conference on Orthodox Church Music. Joensuu: Joensuu Theological Centre, pp. 164-77.

Graham, John A. 2015. The Transcription and Transmission of Georgian Liturgical Chant. Ph.D. dissertation, Princetoon University, Princeton.

Graham, John A. 2016. Lecture. Field Notes. Yale University, March 4.

Harries, Jeanette. 1973. Pattern and choice in Berber weaving and poetry. Research in African Literatures 4: 141-53.

Hildebrand, Stephen M. 1980. St Basil the Great: On the Holy Spirit. Crestwod: St Vladimir's Seminary Press. 
Isaiah, Abba. 2001. Matericon: Instructions from Abba Isaiah to the Honourable Nun Theodora. Safford: St Paisius Serbian Orthodox Monastery.

Ivanovic, Filip. 2011. Dionysius the Areopagite: Between Orthodoxy and Heresy. Cambridge: Cambridge Scholars Publishing.

Jangulashvili, Svimon, ed. 2013. Ilia II Catholicos-Patriarch of All Georgia: Hymns. Tbilisi: PMG Ltd.

Jeffery, Peter. 1992. The Lost Chant Tradition of Early Christian Jerusalem: Some Possible Melodic Survivals in the Byzantine and Latin Chant Repertories. Early Music History 11: 151-90. [CrossRef]

Jordania, Joseph. 2006. Who Asked the First Question? The Origins of Human Choral Singing, Inteligence, Language, and Speech. Tbilisi: International Research Centre for Traditional Polyphony of Tbilisi State Conservatoire.

Jordania, Joseph. 2011. Why Do People Sing?: Music in Human Evolution. Melbourne: Logos.

Kalandadze-Makharadze, Nino. 2014. Polyphonic Thinking: Uninterrupted Georgian Tradition (On the Example of Chants Recorded from Polikarpe Khubulava). In The Seventh International Symposium on Traditional Polyphony. Edited by Rusudan Tsurtsumia and Joseph Jordania. Tbilisi: International Research Centre for Traditional Polyphony of Tbilisi State Conservatoire, pp. 233-42.

Kenna, Margaret E. 1985. Icons in theory and practice: An Orthodox Christian example. History of Religions 24: 345-68. [CrossRef]

Khalil, Alexander Konrad. 2009. Echoes of Constantinople: Oral and Written Tradition of the Psaltes of the Ecumenical Patriarchate of Constantinople. Ph.D. thesis, University of California, Oakland, CA, USA.

Khardziani, Maka. 2010. On the Change of Three-Part Songs into One-Part Songs in Georgian Traditional Polyphony (Racha and Svaneti). In The Fifth Symposium on Traditional Polyphony. Edited by Rusudan Tsurtsumia and Joseph Jordania. Tbilisi: International Research Center for Traditional Polyphony of Tbilisi State Conservatoire, pp. 168-74.

Khrushkova, Liudmila. 2007. The Spread of Christianity in the Eastern Black Sea Littoral (Written and Archaeological Sources). Ancient West \& East 6: 177-219.

Lang, David Marshall. 1995. Lives and Legends of the Georgian Saints. Crestwood: St Vladimir's Seminary Press.

LeVen, Pauline A. 2013. The Colors of Sound: Poikilia and Its Aesthetic Contexts. Greek and Roman Musical Studies 1: 229-42. [CrossRef]

Licheli, Vakhtang. 1998. St. Andrew in Samtskhe-Archaeological Proof? In Ancient Christianity in the Caucasus. Edited by Tamila Mgaloblishvili. Surrey: Curzon Press, pp. 25-38.

Lidov, Alexei. 2010. Spatial Icons: A Hierotopic Approach to Byzantine Art History. In Towards Rewriting?: New Approaches to Byzantine Archaeology and Art. Edited by Piotr L. Grotowski. Cracow: Polish Society of Oriental Art, pp. 85-101.

Lingas, Alexander Leonidas. 2004. Preliminary Reflections on Studying the Liturgical Place of Byzantine and Slavonic Melismatic Chant. Paris and Dudley: Peeters, pp. 147-55.

Lossky, Vladimir. 1997. The Mystical Theology of the Eastern Church. Crestwood: St Vladimir's Seminary Press.

Loudovikos, Nikolaos. 2010. A Eucharistic Ontology: Maximus the Confessor's Eschatological Ontology of Being as Dialogical Reciprocity. Brookline: Holy Cross Orthodox Press.

Lourié, Basil. 2010. Peter the Iberian and Dionysius the Areopagite: Honigmann—Van Esbroeck's Thesis Revisited. Scrinium 6: 143-212. [CrossRef]

Louth, Andrew. 2007. Trans. St John of Damascus: Three Treatises on the Divine Images. Crestwood: St Vladimir's Seminary Press.

Luibheid, Colm, Paul Rorem, and Rene Roques. 1987. Pseudo-Dionysius: The Complete Works. New York: Paulist Press.

Makharadze, Nino, and Nino Ghambashidze. 2014. CHVENIEROBA Festival and Traditional Music Related to It. In The Seventh International Symposium on Georgian Polyphony. Edited by Rusudan Tsurtsumia and Joseph Jordania. Tbilisi: International Research Centre for Traditional Polyphony of Tbilisi State Conservatoire, pp. 252-60. (In Georgian and English)

Managadze, Khatuna. 2006. Heirmoi of St Andrew of Crete's 'Canon of Repentance'. In The Second International Symposium on Traditional Polyphony. Edited by Rusudan Tsurtsumia and Joseph Jordania. Tbilisi: International Research Centre for Traditional Polyphony of Tbilisi State Conservatoire, pp. 409-14. (In Georgian and English)

McVey, Kathleen E. 1989. Ephrem the Syrian: Hymns. New York: Paulist Press.

Mgaloblishvili, Tamila, ed. 1998. Ancient Christianity in the Caucasus. Surrey: Curzon Press. 
Mgaloblishvili, Tamila. 2014. How Mtskheta Turned into the Georgians' New Jerusalem. In Visual Constructs of Jerusalem. Edited by Bianca Kühnel, Galit Noga-Banai and Hanna Vorholt. Turnhout: Brepols Publishers.

Mgaloblishvili, Tamila, and Lela Khoperia, eds. 2009. St Maximus the Confessor and Georgia. London: Bennett and Bloom.

Mileant, Bishop Alexander, ed. 2001. On the Acquisition of the Holy Spirit. La Canada: Holy Trinity Orthodox Mission.

Moody, Ivan. 2015. The Seraphim above: Some Perspectives on the Theology of Orthodox Church Music. Religions 6: 350-64. [CrossRef]

Moody, Ivan. 2016. Music, Beauty, and Prayer (Keynote Address). Journal of the International Society for Orthodox Church Music 2: 51-56.

Mora, Manolete. 2012. Tune and Textile: Interrelatedness in the Music and Weaving Arts of the T'boli, Philippines. Humanities Diliman: A Philippine Journal of Humanities 9: 1-31.

Moran, Neil. 2010. A second medial mode Palestinian chant in Old Roman, Beneventan and Frankish sources. Plainsong E Medieval Music 19: 1-19.

Mzhavanadze, Nana, and Madona Chamgeliani. 2016. Regarding the Problem of Asemantic Texts in Svan Songs. Anthropological Linguistics 58: 49-84.

Naroditskaya, Inna. 2005. Azerbaijani mugham and carpet: Cross-domain mapping. Ethnomusicology Forum 14: 25-55. [CrossRef]

Norris, Richard A. 2013. Gregory of Nyssa: Homilies on the Song of Songs. Atlanta: Society of Biblical Literature.

Oniani, Ekaterine. 2013. Georgian Neumatic System in the Context of Orthodox Chant Tradition. Musicology Today 20. Available online: http://www.musicologytoday.ro/BackIssues/Nr.20/studies4.php (accessed on 16 May 2019).

Pataridze, Tamar. 2013. Christian Literature Translated from Arabic into Georgian. Annual of Medieval Studies at CEU 19: 47-65.

Pentcheva, Bissera V. 2010. The Sensual Icon: Space, Ritual, and the Senses in Bazantium. University Park: Pennsylvania State University Press.

Pirtskhelava, Nino. 2014. Interpretation of Proclus Diadochos' and Plato's Philosophy from the Viewpoint of Research into the History of Georgian Polyphony. In The Seventh International Symposium on Georgian Polyphony. Edited by Rusudan Tsurtsumia and Joseph Jordania. Tbilisi: International Research Centre for Traditional Polyphony of Tbilisi State Conservatoire, pp. 481-87. (In Georgian and English)

Purpura, Ashley M. 2017. God, Hierarchy, and Power: Orthodox Theologies of Authority from Byzantium. New York: Fordham University Press.

Rorem, Paul, and John C. Lamoreaux. 1998. John of Scythopolis and the Dionysian Corpus: Annotating the Areopagite. Oxford: Oxford University Press.

Russell, Norman. 2004. The Doctrine of Deification in the Greek Patristic Tradition. Oxford: Oxford University Press. Samsonadze, Victoria. 2012. Genre Peculiarities of the Meskhetian Musical Dialect. In The Sixth International Symposium on Traditional Polyphony. Edited by Rusudan Tsurtsumia and Joseph Jordania. Tbilisi: International Research Centre for Traditional Polyphony of Tbilisi State Conservatoire, pp. 360-67. (In Georgian and English)

Schrade, Brigitta. 2001. Byzantium and Its Eastern Barbarians: The Cult of Saints in Svaneti. In Eastern Approaches to Byzantium: Papers from the 33rd Spring Symposium of Byzantine Studies, University of Warwick, Coventry, March 1999. Edited by Antony Eastmond. Aldershot: Ashgate Publishing, pp. 169-99.

Shelemay, Kay Kaufman, Peter Jeffery, and Ingrid Monson. 1993. Oral and written transmission in Ethiopian Christian chant. Early Music History 12: 55-117. [CrossRef]

Shneurson, Erga. 2012. Sacred Space: Parochet and Hierotopy on Georgian church façades. Paper presented at the International Conference, Haifa, Israel, May 16-17.

Shugliashvili, Davit. 2010. 'Wordless' Polyphony in Traditional Georgian Music. In The Fifth Symposium on Traditional Polyphony. Edited by Rusudan Tsurtsumia and Joseph Jordania. Tbilisi: International Research Center for Traditional Polyphony of Tbilisi State Conservatoire, pp. 227-35. (In Georgian and English)

Shugliashvili, Davit. 2013. Concerning Polyphony in Georgian Chanting. Musicology Today. 20. Available online: http://www.musicologytoday.ro/BackIssues/Nr.20/studies.php (accessed on 3 December 2015).

Shugliashvili, David, and Zaal Tsereteli, eds. 2012. Georgian Chant: Svetitskhoveli School. Tbilisi: Folklore State Centre of Georgia. (In Georgian and English) 
Shugliashvili, David, Giorgi Bagrationi, and John A. Graham, eds. 2014. Georgian Church Hymns (Shemokmedi School): Transcriptions of Artem Erkomaishvili Recordings. Tbilisi: Georgian Chanting Foundation. (In Georgian and English)

Simmons, Harry L. 1984. Treatise on Prayer by Symeon of Thessalonike. Brookline: Holy Cross Orthodox Press.

Sukhiashvili, Magda. 2014a. On Some Aspects of the Manifestation of the Science of Hymns in Georgian Chants. In The Second International Symposium on Traditional Polyphony. Edited by Rusudan Tsurtsumia and Joseph Jordania. Tbilisi: International Research Centre for Traditional Polyphony of Tbilisi State Conservatoire, pp. 421-29. (In Georgian and English)

Sukhiashvili, Magda. 2014b. On the Oral Tradition of Georgian Sacred Chant. In The Seventh International Symposium on Traditional Polyphony. Edited by Rusudan Tsurtsumia and Joseph Jordania. Tbilisi: International Research Centre for Traditional Polyphony of Tbilisi State Conservatoire, pp. 435-48. (In Georgian and English)

Sukhiashvili, Magda. 2015. One old Georgian musical term. Facta Universitatis, Series Visual Arts and Music 1: 41-45.

Tarchnischvili, Mikaeli. 1959. Le Grande Lectionnaire de l'Eglise de Jerusalem. Louvain: Peeters Publishers.

Tchekhanovets, Yana. 2011. Early Georgian Pilgrimage to the Holy Land. Liber Annuus 61: 453-71. [CrossRef]

Touliatos, Diane. 1989. Nonsense Syllables in the Music of the Ancient Greek and Byzantine Traditions. The Journal of Musicology 7: 231-43. [CrossRef]

Tsereteli, Zaal. 2012. Deciphering the Old Georgian Neumatic System and Reintroducing It into Practice. In The Sixth International Symposium on Traditional Polyphony. Edited by Rusudan Tsurtsumia and Joseph Jordania. Tbilisi: International Research Centre for Traditional Polyphony of Tbilisi State Conservatoire. (In Georgian and English)

Tsetskhladze, Gocha R. 1992. Greek Colonization of the Eastern Black Sea Littoral (Colchis). Dialogues D'histoire Ancienne 18: 223-58. [CrossRef]

Tsitsishvili, Nino. 2010. National Unity and Gender Difference: Ideologies and Practices in Georgian Traditional Music. Saarbrücken: Lambert Academic Publishing.

Tuite, Kevin. 1996. Highland Georgian paganism-archaism or innovation. Annual of the Society for the Study of Caucasia 7: 79-91.

Tymoczko, Dmitri. 2006. The geometry of musical chords. Science 313: 72-74. [CrossRef]

Tymoczko, Dmitri. 2010. A geometry of Music: Harmony and Counterpoint in the Extended Common Practice. Oxford: Oxford University Press.

Vinogradov, Andrey. 2017. History of Christianity in Alania Before 932. Higher School of Economics Working Paper. Available online: https://wp.hse.ru/en/prepfr_Humanities/ (accessed on 16 May 2019).

Williams, Georgia J. 2010. An Exploration of Hierarchy as Fractal in the Theology of Dionysios the Areopagite. In Power and Authority in the Eastern Christian Experience: Papers of the Sophia Institute Academic Conference. New York: Theotokos Press, pp. 103-18.

Woodfin, Warren T. 2010. Celestial hierarchies and earthly hierarchies in the art of the Byzantine church. In The Byzantine World. New York: Routledge, pp. 303-19.

(C) 2019 by the author. Licensee MDPI, Basel, Switzerland. This article is an open access article distributed under the terms and conditions of the Creative Commons Attribution (CC BY) license (http://creativecommons.org/licenses/by/4.0/). 